\title{
Velocity structure of the Whataroa Valley using Ambient Noise Tomography
}

By

Andrew T. McNab

A thesis

submitted to Victoria University of Wellington in fulfilment of the requirements for the degree of Master of Science in Geophysics.

Victoria University Wellington

2017 


\section{Abstract}

This thesis applies ambient noise tomography to investigate the shallow structure of the Whataroa Valley. Ambient noise techniques are applied to continuous seismic recordings acquired on 158 geophones deployed during the Whataroa Active Source Seismic Experiment. Despite only having four days of data, a robust shearwave velocity model is calculated using a phase-weighted stacking approach to improve the cross-correlation functions' signal-to-noise ratios, allowing for robust velocity measurements to be obtained between periods of 0.3 and $1.8 \mathrm{~s}$. This yields a database of 12,500 vertical component cross correlation functions and the corresponding Rayleigh wave phase and group velocity dispersion curves. Linearised straight-ray tomography is applied to phase and group velocity dispersion measurements at periods ranging from periods of 0.3 to $1.8 \mathrm{~s}$. The tomography reveals a velocity that decreases from the vicinity of the DFDP-2B borehole to the centre of the valley. This is interpreted to be the geologic basement deepening towards the centre of the valley. A Monte-Carlo inversion technique is used to jointly invert Rayleigh-wave phase and group velocity dispersion curves constructed from phase and group velocity tomography maps of successively higher periods. Linear interpolation of the resulting 1D shear-wave velocity profiles produces a pseudo-3D velocity model of the uppermost 1,000 $\mathrm{m}$ of the Whataroa Valley. Using sharp increases in velocity to represent lithological change, we interpret two velocity contours at 1,150 and $1,250 \mathrm{~m} / \mathrm{s}$ as potential sediment-basement contacts. Depth isocontours of these velocities reveal that the basement deepens towards the centre of the valley, reaching a maximum depth of 400 or $600 \mathrm{~m}$ for the 1,150 and 1,250 m/s velocity contours respectively. These depths indicate strong glacial over-deepening and have implications for future drilling projects in the Whataroa Valley. A sharp velocity increase 
of $200 \mathrm{~m} / \mathrm{s}$ also occurs at $100 \mathrm{~m}$ depth at the DFDP-2B borehole. We interpret this to be a change in sedimentary rock lithology from fluvial gravels to lacustrine silty sands, related to a change in sedimentary depositional environment. 


\section{Acknowledgements}

I would sincerely like to thank my supervisors, John Townend and Martha Savage for always having their door open to me and providing me with the opportunity to perform this research. The dedication Martha shows to her students is impressive, even from the other-side of the world! John and Martha have provided me with many opportunities for which I am grateful, including deploying seismometers after the Kaikoura Earthquake and attending two conferences; Geoscience NZ and the American Geophysical Union Fall Meeting. I was fortunate to have the help of FanChi Lin from the University of Utah, who's assistance in understanding some of the phenomena in the data is greatly appreciated. I also thank Calum Chamberlain for encouraging me to learn Python and for answering my many questions.

I am very grateful to have received a Marsden Grant Scholarship, provided by the Royal Society of New Zealand. This allowed me to complete my thesis without worrying about financial aspects.

Thank you to Jennifer Eccles, Richard Kellett, Stefan Buske, Alexis Constantinou, Douglas Schmitt, Malcolm Bertram, Kevin Hall, Andrew Gorman, Randy Kofman, Vera Lay, and the rest of Whataroa Active Source Seismic Experiment field team.

Thank you to everyone in the geophysics group at Victoria, especially Rachel Heckels, Katrina Jacobs and Francesco Civilini for answering all the questions I had about ambient noise analysis, Adrian Benson and Aleksandr Beliaev for helping me with computing matters, and Chet Hopp and Dominic Evanzia for providing great lunch time chat. I also thank my office mates Hamish Hirschburg, Sam Taylor-Offord, 
Rachel Barrett, Nicolas Oestreicher, Seb Thornton and Stefan Mroczek.

My parents David and Lesley, and sister Claire are thanked for all their support and encouragement in finishing this thesis and over the course of my university studies. Thank you to my Grandma Jean for encouraging me to attend university and her support throughout my studies. Finally, thank you to Dani Lindsay for all her support, particularly the last few months of writing this thesis. 


\section{Contents}

Abstract iii

Acknowledgements $\quad$ v

Contents vii

List of Figures $\quad$ x

List of Tables $\quad$ xi

1 Introduction 1

1.1 Motivation and Thesis Aims . . . . . . . . . . . . . . . 1

1.2 Geologic Setting . . . . . . . . . . . . . . . . . . 2

1.2 .1 Alpine Fault . . . . . . . . . . . . . . . . . . . 4

1.2 .2 Whataroa ..................... 5

1.3 Previous Studies . . . . . . . . . . . . . . 6

1.4 Dataset . . . . . . . . . . . . . . . . . 9

1.5 Ambient Noise in Seismology . . . . . . . . . . . . . . . . . . . . 12

1.5.1 Surface-wave Propagation and Nature of the Ambient Noise

Wave-field . . . . . . . . . . . . . . . . . 12

1.5.2 Reconstructing the Green's Function . . . . . . . . . . . . 13

1.6 Thesis Structure . . . . . . . . . . . . . . . . 16

2 Methods 19

2.1 Measuring Surface Wave Dispersion from Ambient Noise . . . . . . . 19

2.1.1 Single Station Data Preparation . . . . . . . . . . . . . . . 20

2.1.2 Calculating Cross-Correlations . . . . . . . . . . . . . . 22

2.1.3 Calculating Surface Wave Dispersion Curves . . . . . . . . . . 27

2.1.4 Quality Control . . . . . . . . . . . . . . . . 30

2.2 Locating Persistent Localised Sources . . . . . . . . . . . . . . . . . 31

2.3 Inversion for Velocity Structure . . . . . . . . . . . . . . . . . . . 32

2.3.1 Surface Wave Tomography . . . . . . . . . . . . . . . . . 33

2.3.2 Inversion for Shear-Wave Velocity . . . . . . . . . . . . . . . 35

2.3.3 1D and pseudo-3D Shear-Wave Velocity Modelling . . . . . . . 36

2.3.4 Error Analysis . . . . . . . . . . . . . . . . . . . . . 37

$\begin{array}{lll}3 & \text { Results } & 39\end{array}$

3.1 Cross-Correlation Functions . . . . . . . . . . . . . . . . . . 39

3.1.1 Back-projection of Cross-Correlation Functions . . . . . . . 46

3.2 Rayleigh Wave Dispersion Curves . . . . . . . . . . . . . . . . . . . 47

3.3 Rayleigh Wave Velocity Maps . . . . . . . . . . . . . . . . . . . 55 
3.3.1 Resolution ................... . 56 56

3.3.2 Velocity Maps . . . . . . . . . . . . . . . . . 61

3.4 Shear-Wave Velocity Inversions . . . . . . . . . . . . . . . . . . . 68

3.4.1 1D Shear-Wave Velocity Profiles . . . . . . . . . . . . . 68

3.4.2 Pseudo-3D Shear-Wave Velocity Profiles . . . . . . . . . . . . 73

4 Discussion $\quad \mathbf{7 5}$

4.1 Data Analysis and Considerations . . . . . . . . . . . . . . 75

4.1.1 Cross-correlation Functions . . . . . . . . . . . . . . . 75

4.1 .2 Dispersion Curves . . . . . . . . . . . . . . . . . . . 82

4.1 .3 Tomography . . . . . . . . . . . . . . . . 83

4.1.4 Shear-wave Velocity Inversions . . . . . . . . . . . . . . . 85

4.2 Interpretation of Velocity Models . . . . . . . . . . . . . . . . . 90

4.3 Comparison to Previous Studies . . . . . . . . . . . . . . . . 96

5 Conclusions 101

5.1 Future Work . . . . . . . . . . . . . . . . . . . . 102

$\begin{array}{ll}\text { Bibliography } & 105\end{array}$ 


\section{List of Figures}

1.1 Map of New Zealand . . . . . . . . . . . . . . . . . . . . . . . 3

1.2 Geology map of Whataroa Valley and surrounding area . . . . . . . . 6

1.3 Map of the Whataroa Valley and instruments used in this thesis . . . 10

1.4 Schematic showing stationary phase zone . . . . . . . . . . . . 15

1.5 Noise source distributions and the sum of all cross-correlations . . . . 17

2.1 Simplified processing flow for measuring surface wave dispersion after Bensen et al. (2007). . . . . . . . . . . . . . . . . . . . 21

2.2 Signal processing routines applied to ambient noise waveforms to prepare the traces for cross-correlation . . . . . . . . . . . . 23

2.3 Comparison of traces stacked using a linear and phase-weighted stack method . . . . . . . . . . . . . . . . . . 27

$2.4 V_{p} / V_{s}$ model and the synthetic phase velocity dispersion curve used in AFTAN . . . . . . . . . . . . . . . . . . . . . . . . . . . 29

2.5 CCF and its back-projection for potential stationary source location . 33

3.1 Moveout plot of all raw Cross-Correlation Functions (CCF) stacked into $25 \mathrm{~m}$ distance bins. . . . . . . . . . . . . . . . . . . . . . . 40

3.2 Moveout plot of all CCFs stacked into $25 \mathrm{~m}$ distance bins and highpass filtered at $1 \mathrm{~Hz} . \ldots \ldots$. . . . . . . . . . . . . 41

3.3 Moveout plots of specified stations as a virtual source vs all other stations . . . . . . . . . . . . . . . . . 44

3.4 Maps of signal-to-noise ratio of stations used in Figure 3.3 as a virtual

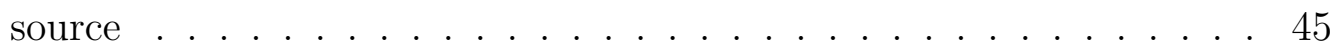

3.5 Back-projection of all contaminated cross-correlation functions . . . . 47

3.6 Rayleigh wave group and phase velocity synthetic dispersion curves of the fundamental and first order higher mode . . . . . . . . . . . . 49

3.7 Rayleigh wave group and phase velocity dispersion curves from individual station pairs . . . . . . . . . . . . . . . . . 5 51

3.8 Map of station paths used in Figure 3.7 and stations used in the sub-array ......................... 53

3.9 Rayleigh wave group and phase velocity dispersion curves . . . . . . . 54

3.10 Travel-time vs. interstation distance plot of all period measurments at $0.6 \mathrm{~s}$ period . . . . . . . . . . . . . . . . . 55

3.11 Rayleigh wave phase velocity checkerboard tests . . . . . . . . . 58

3.12 Rayleigh wave group velocity checkerboard tests . . . . . . . . . . . 59

3.13 Rayleigh wave phase and group velocity tomography path density . . 60

3.14 Rayleigh wave phase and group velocity tomography azimuth coverage 61

3.15 Rayleigh wave phase velocity maps . . . . . . . . . . . . . . . . 64

3.16 Rayleigh wave group velocity maps for periods below 1.0 s period . . 65

3.17 Rayleigh wave group velocity maps for periods above $1.0 \mathrm{~s}$ period . . 66 
3.18 Travel-time misfit and smoothing factor applied to Rayleigh wave phase and group velocity maps . . . . . . . . . . . . . . . . . 67

3.19 Regularization smoothing factor applied Rayleigh wave phase and group velocity maps . . . . . . . . . . . . . . . . . . 68

3.20 Shear wave inversion results from selected geographic locations using phase velocity dispersion curves . . . . . . . . . . . . . . . 70

3.21 Shear wave inversion results from selected geographic locations using phase and group velocity dispersion curves . . . . . . . . . . . . . 72

3.22 Fence plot of shear-wave velocity depth profiles of the Whataroa Valley using joint shear-wave inversions of phase and group velocity dispersion curves . . . . . . . . . . . . . . . . . . 74

4.1 Signal-to-noise ratio difference between linear and phase-weighted stacked CCF . . . . . . . . . . . . . . . . . . 77

4.2 Comparison of sample CCFs at different inter-station distances calculated using conventional cross-correlation and phase cross-correlation methods . . . . . . . . . . . . . . . . 79

4.3 Comparison of CCFs back-projection for virtual source move-out plots in Figure 3.3b and c . . . . . . . . . . . . . . . . 81

4.4 Daily dispersion curves of phase and group velocity . . . . . . . . . 83

4.5 Comparison of misfit for the best model of phase (a) and joint (b) inversion . . . . . . . . . . . . . . . . . 88

4.6 Standard deviation of depth from the pseudo-3D shear-wave velocity

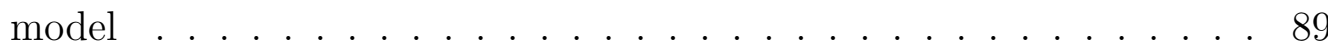

4.7 Standard deviation of shear-wave velocity from the pseudo-3D shearwave velocity model . . . . . . . . . . . . . . . . . . 90 90

4.8 Velocity tracks at discrete periods from phase and group velocity maps 91

4.9 Smoothed velocity contours of the $720 \mathrm{~m} / \mathrm{s}$ isosurface . . . . . . . . . 92

4.10 Smoothed velocity contours of the 1100 and $1250 \mathrm{~m} / \mathrm{s}$ isosurface . . . 93

4.11 Schematic geology interpretation of the pseudo-3D shear-wave velocity model in Figure 3.22 . . . . . . . . . . . . . . . . . . . . . . . 95

4.12 Comparison of the shear-wave velocity model to the DFDP-2B core log 97

4.13 Figures from previous studies by Lepine (2016)(a), Jenkins (2017)(b) and Lay et al. (2016)(c) . . . . . . . . . . . . . . . . . . . 99 


\section{List of Tables}

2.1 Parameters used in Alternate Frequency-Time Analysis (AFTAN) to calculate dispersion measurements for group and phase velocity. . . . 29

4.1 Parametrisation of phase velocity inversion . . . . . . . . . . . . 86

4.2 Parametrisation of joint inversion . . . . . . . . . . . . 87 


\section{Introduction}

\subsection{Motivation and Thesis Aims}

The Alpine Fault is a major continental transform fault that runs the length of the South Island, New Zealand. Large earthquakes $\left(M_{w}\right.$ 7.6-8.2) occur along the fault approximately every 329 \pm 68 years (Berryman et al., 2012) with the last event occurring in 1717 (Sutherland et al., 2006). The fault is late in its seismogenic cycle, with a $27 \%$ probability of a large earthquake occurring over the next 50 years (Biasi et al., 2015). A unique opportunity exists to study the processes of a fault capable of producing a large earthquake before it ruptures (Townend et al., 2009).

Located on the central Alpine Fault, the Whataroa valley is an ideal location to study fault zone structure and processes as it provides access to the hanging wall at a range of distances from the fault. The site has hosted multiple scientific studies aimed at further understanding the seismogenic processes of the Alpine Fault and its fault mechanics (Townend et al., 2009). In January 2016, as part of the Deep Fault Drilling Project (DFDP), the Whataroa Active Source Seismic Experiment deployed a suite of downhole and surface instruments to image the Alpine Fault in the Whataroa Valley. During the deployment, 158 3-component geophones were continuously recording from the 17th to 21st of January.

Previous seismic studies aimed at characterising the Alpine Fault in the vicinity of the Whataroa Valley have mostly used reflection and refraction methods and have encountered a strong scattering of seismic waves and out-of-plane reflectors (Davey, 2010). The use of passive and tomographic methods to construct a velocity model 
has shown promise in areas where it is difficult to use traditional methods (Brenguier et al., 2007). Lay et al. (2016) successfully used first arrival compressional-wave travel-time tomography to characterise the Alpine Fault in the Whataroa Valley. In this thesis we extend velocity characterisation of the Whataroa Valley using surface wave tomography, performed using continuous recordings of seismic ambient noise.

This thesis aims to answer the following questions:

1. Can we make robust velocity models be made from from four days of continuous seismic ambient noise recordings using ambient noise tomography?

2. What is the Shear-wave velocity structure of the Whataroa Valley?

3. How deep is the geologic basement in the Whataroa Valley?

\subsection{Geologic Setting}

New Zealand sits astride the boundary of the Pacific and Australian tectonic plates. Interaction between these two plates has created a geologically diverse landscape of natural processes such as volcanism, earthquakes and mountain building. The plate boundary within New Zealand can be split into three main sections, the Hikurangi Margin, Alpine Fault and Puysegur Trough [Figure 1.1]. The Hikurangi Margin is the southern continuation of the Tonga-Kermadec subduction zone and is formed by the Pacific Plate subducting westward beneath the Australian Plate. Inter-plate motion transitions through the northern South Island Marlborough Fault System and into the Alpine Fault, an oblique dextral transform fault along the South Island's western coast (Sutherland et al., 2006). Near the bottom of the South Island, the plate boundary motion has the opposite polarity to the Hikurangi Margin, creating the Puysegur Trough off the coast of the South Island (Berryman et al., 1992). 


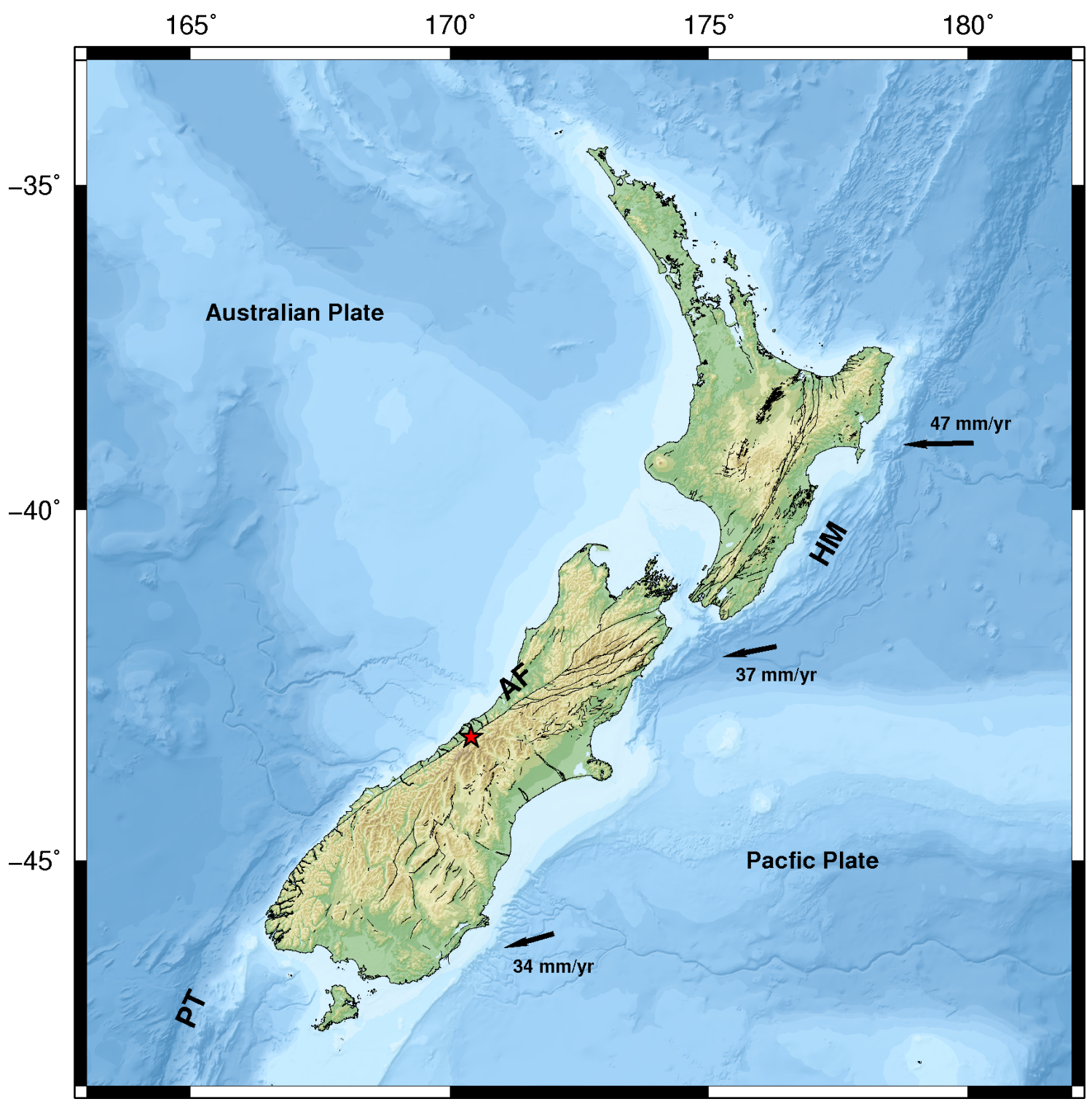

Figure 1.1: Map of New Zealand showing the approximate plate boundary between the Pacific and Australian Plates. Relative motion between the two plates is represented by the black vectors. HT refers to the Hikurangi Margin, AF refers to the Alpine Fault and PT refers to the Puysegur Trough, all referenced in the text. Whataroa Valley, the study area, is marked by the red star. The arrows represent relative plate motion between the Pacific and Australian Plate (Altamimi et al., 2012). The black lines are surface fault traces from the New Zealand active fault database (Langridge et al., 2016). 


\subsubsection{Alpine Fault}

The Alpine Fault was first identified from its topographic expression (Wellman and Willett, 1942); as a linear feature extending along the Western edge of the Southern Alps. Presently, the fault has an average strike of $055^{\circ}$ (DeMets et al., 1994), and accommodates $75 \%$ of intra-plate motion and $100 \%$ compression in the central part of the fault (Norris and Cooper, 2001). Over the last $23 \mathrm{Ma}$ a total of $460 \mathrm{~km}$ of dextral offset has occurred, recorded by offset of the Dun Mountain Ophiolite Belt (Sutherland et al., 2000). Reconstructions of plate motion show a total offset of $850 \mathrm{~km}$ between the western North Island and eastern South Island (Molnar et al., 1999). The $390 \mathrm{~km}$ difference in offset may be taken up by shear on other structures (Norris and Cooper, 2001). Vertical motion of the Alpine Fault was first recognised in regional offset of terrace surfaces and the long-term formation of the Southern Alps (Wellman, 1953, Wellman et al., 1952). Total uplift of the Southern Alps is estimated to be between 9 and $22 \mathrm{~km}$ (Cooper, 1980).

The dip character of the Alpine Fault changes down its length. The northern section dips steeply to the east (Cox and Sutherland, 2007), the central section dips $45-60^{\circ}$ to the east (Stern et al., 2007) and the southern section is nearly vertical (Sutherland et al., 2007). While fault motion is oblique for most of its length, some sections are considered dextral strike-slip and reverse slip-dip (Norris and Cooper, 2001, Sibson et al., 1979). Average horizontal motion of the fault is estimated to be 21-27 mm per year, with the southern most section having an estimated $31 \mathrm{~mm}$ per year (Sutherland et al., 2006).

New Zealand's basement geology is made up of a series of terranes and igneous suites (Cox and Sutherland, 2007). The basement terranes are grouped into Eastern and Western Provinces (Mortimer, 2004). The Western Province forms the foot-wall of the present day Alpine Fault and contacts the Eastern Province at the Alpine Fault (Mortimer, 2004). The Western Province is comprised of quartzose 
sediments that have undergone metamorphism from plutonic intrusions (Cox and Sutherland, 2007). Along the West Coast of the South Island, the Western Province is overlain by 2000-4000 $\mathrm{m}$ of Cenozoic sediments (Nathan et al., 1986). Rocks of the Eastern Province are dominantly lithic and feldspathic greywackes, at differing levels of metamorphism (Cox and Sutherland, 2007). Immediately adjacent to the Alpine Fault is the Alpine Schist which formed during collision and metamorphism of the Caples and Rakaia Terranes (Mortimer, 2004). The Alpine Schist grades into proto-mylonite, mylonite, ultramylonite and finally cataclasite at the Alpine Fault Damage zone (Norris and Cooper, 2007).

\subsubsection{Whataroa}

Geologic mapping has revealed that the Alpine Fault changes geometry in the vicinity of the Whataroa Valley (Norris and Cooper, 2007). To the south of Whataroa, the fault is broken up into north-striking thrust zones and easterly striking, subvertical strike-slip zones (Norris and Cooper, 1995). North of Whataroa, the Alpine Fault is mostly a straight trace, with an oblique-dextral reverse slip sense of motion (Norris and Cooper, 2007). In the Whataroa Valley region, vertical displacement rates of $8-12 \mathrm{~mm} / \mathrm{yr}$ are estimated and while horizontal displacement rates are estimated to be 22-27 mm/yr, (Herman and Braun, 2006) suggest in 100-200 m of uplift since the last glaciation (14 ka) (Herman and Braun, 2006). West of the Alpine Fault in the Whataroa region, basement rocks are overlain by a $2.5-3 \mathrm{~km}$ thick sedimentary sequence (Davey, 2010).

The Whataroa Valley is a glacial carved U-shaped valley characterised by river flats and terraces that record past earthquakes of the Alpine Fault (Herman and Braun, 2006). A mix of fluvioglacial and alluvial deposits characterise the surface geology of the valley floor [Figure 1.2]. The valley walls show a typical Alpine Fault hanging wall rock sequence where schist grades into mylonite towards the Alpine Fault [Figure 1.2]. The DFDP-2B borehole encountered a $240 \mathrm{~m}$ sedimentary sequence of 
glaciolacustrine deposits overlain by deltaic sands and post-glacial alluvium (Sutherland et al., 2015). The thicker than expected sedimentary sequence suggests glacial over-deepening of the valley and rapid sedimentation since the last glacial cycle (Sutherland et al., 2015).

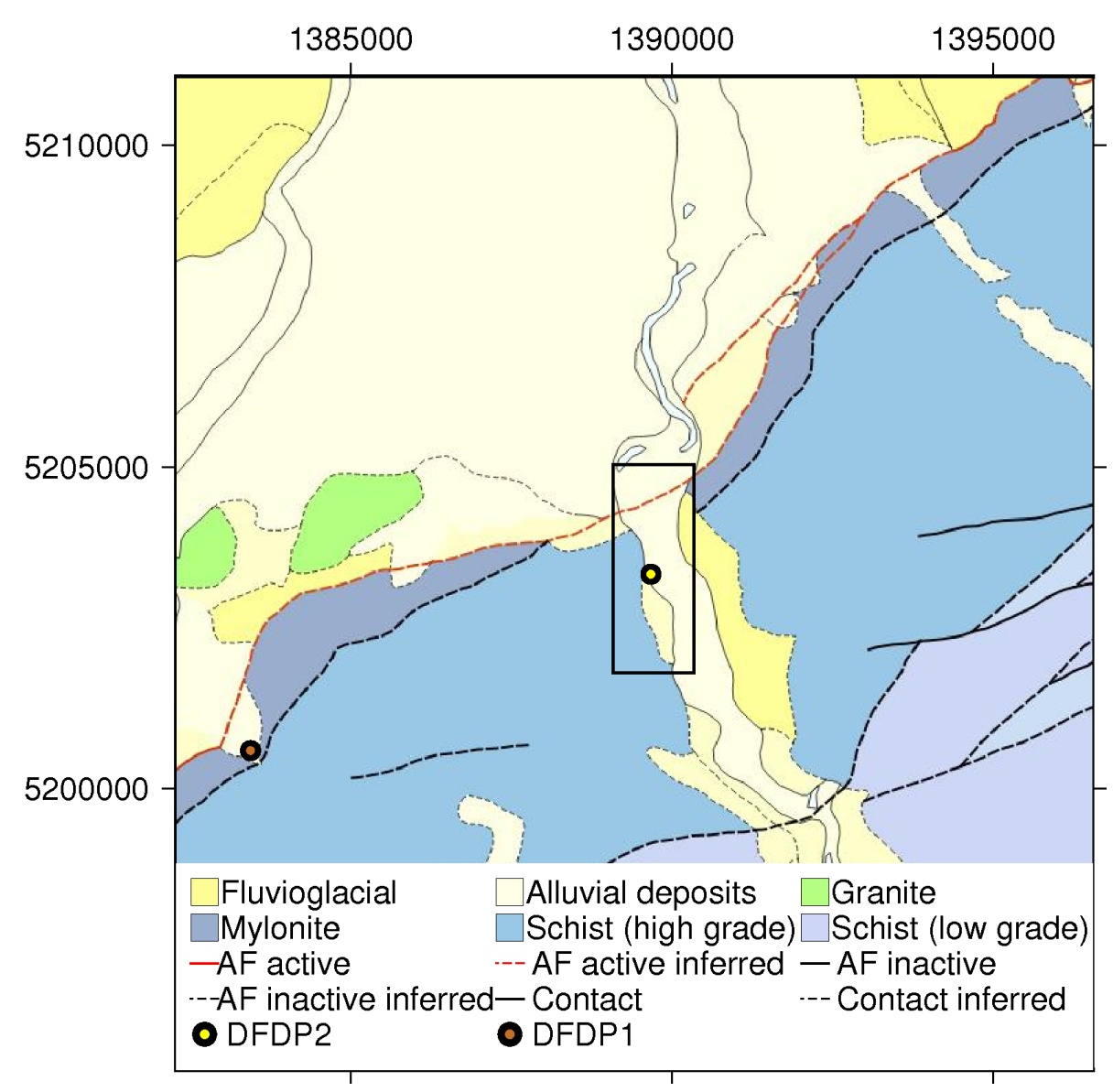

Figure 1.2: Geology map of Whataroa Valley and surrounding area. The study area is marked by the black box [Projection: NZTM].

\subsection{Previous Studies}

The Alpine Fault has been the subject of a broad range of research due to its importance as a seismic hazard and international relevance as a large fault exposed on-land. This section will only outline studies relevant to this thesis. 


\section{Deep Fault Drilling Project}

The Deep Fault Drilling Project (DFDP) is a multicomponent project investigating the Alpine Fault late in its seismic cycle. The main objective of the project has been a series of boreholes aimed at drilling through the Alpine Fault to make observations in the hanging wall, principle slip zone and foot wall (Townend et al., 2009). Two boreholes were drilled at Gaunt Creek, $8 \mathrm{~km}$ southwest of the Whataroa Valley [Figure 1.2], reaching a vertical depth of $101 \mathrm{~m}$ and $151 \mathrm{~m}$ (DFDP-1A and DFDP-1B respectively). The principle slip zone of the Alpine Fault was recovered at $128 \mathrm{~m}$ in DFDP-1B (Townend et al., 2009). In mid 2014, a second phase of drilling began that aimed to intersect the principle slip zone of the Alpine Fault at appropriately $1100 \mathrm{~m}$ depth. DFDP-2 drilled two boreholes to a vertical depth of $211 \mathrm{~m}$ and $813 \mathrm{~m}$ (DFDP-2A and DFDP-2B respectively). Strongly foliated schist resulted in DFDP2B deviating North, giving a total drilled depth of $893 \mathrm{~m}$ (Sutherland et al., 2015). Hostile drilling conditions including a hydrothermal gradient of $125 \pm 55^{\circ} \mathrm{C} / \mathrm{km}$ (Sutherland et al., 2017), a deeper than expected sedimentary sequence and highly foliated schist culminated in broken casing, leading to the well being abandoned before it reached its principle target (Sutherland et al., 2015). Despite not reaching its target, valuable geologic and geophysical observations were made, including higher than expected temperatures. Wireline logging was undertaken including the installation of a optical fibre cable outside the borehole casing to $893 \mathrm{~m}$ (Sutherland et al., 2015).

\section{Active Source Seismic}

Multiple active source seismic studies have been conducted in and around Whataroa Valley. The 1996 South Island Geophysical Transect (SIGHT) was a large 2D seismic line across the South Island that went through the Whataroa Valley. Offshore and onshore seismic lines were deployed with the aim of investigating the styles of lithospheric deformation associated with continent-continent collision at a major plate 
boundary (Davey et al., 1998, Van Avendonk et al., 2004). In 1998, Whataroa98 was completed as an extension of the 1996 SIGHT survey, with the aim of imaging the Alpine Fault and crustal structures along the Whataroa Valley and across the coastal plain (Davey, 2010). Using reflection and refraction data, 300-500 m thick sedimentary sequences overlying basement were imaged in the Whataroa Valley and across the Alpine Fault, before deepening sharply $6 \mathrm{~km}$ North-west of the fault (Davey, 2010). The basement and sedimentary sequence contact was tied to the Harihari-1 and Waiho-1 exploration wells, dating it at Early Miocene (Davey, 2010).

In preparation for the Deep Fault Drilling Project, the WhataDUSIE survey acquired a $5 \mathrm{~km} 2 \mathrm{D}$ seismic line down the Whataroa Valley and a small 3D survey at the valley mouth with the aim of imaging the upper few kilometres with borehole site characterisation in mind. Lay et al. (2016) used the 2D line from WhataDUSIE and Whataroa98 to produce reflection and velocity models of the upper $5 \mathrm{~km}$. They observe a strong reflector at depths of 1.5 to $2.2 \mathrm{~km}$ with an apparent dip of $48^{\circ}$ interpreted as the Alpine Fault. Parallel reflectors above the main reflector are interpreted as a $600 \mathrm{~m}$ wide damage zone. Velocity modelling shows sediments overlying the basement to be $300-600 \mathrm{~m}$ thick with highly variable $\mathrm{P}$-wave velocity of $600-2300 \mathrm{~m} / \mathrm{s}$. Basement P-wave velocity ranges from 4500 to $5500 \mathrm{~m} / \mathrm{s}$ with a low velocity zone extending from 800 to $2000 \mathrm{~m}$ within the basement (Lay et al., 2016).

Lepine (2016), a Master of Science student from the University of Otago, conducted a hammer drop and weight drop experiment, producing several 2D reflection profiles that image the sediment overlying the basement in the Whataroa Valley. Weak reflectors are observed at $250 \mathrm{~m}$ near DFDP-2B and are interpreted to be basement (Lepine, 2016). 


\section{Gravity}

Several regional gravity studies have been conducted in the Whataroa area, mostly with the aim of characterising the Alpine Fault footwall. Brikke (2007) combined gravity and seismic measurements to model basement depth of the Whataroa Plains. An average depth to basement in the Whataroa Valley was constrained to appropriately $300 \mathrm{~m}$ (Brikke, 2007). Davy et al. (2013) added a further 361 stations to the area surveyed by Brikke (2007) and identified large glacial channels previously identified by Brikke (2007) as a large negative gravity anomaly. Jenkins (2017) added a further 446 high precision gravity measurements in Whataroa Valley and the floodplain. A steep residual Bouguer gravity gradient near the DFDP-2B borehole is suggested to be a moderately dipping reverse fault or sub-vertical erosional wall. A negative Bouguer gravity anomaly south-east of DFDP-2B was interpreted as glacial lake deposits (Jenkins, 2017).

\subsection{Dataset}

Data used in this project are from the three-component geophone array deployed during the 2016 Whataroa Active Source Seismic Experiment [Figure 1.3]. This section introduces the dataset and outlines the Whataroa Active Source Seismic Experiment.

In Janurary 2016, the Whataroa Active Source Seismic Experiment was conducted in the Whataroa Valley, Westland with the aim of imaging the hanging wall of the Alpine Fault. The experiment was the latest phase of the Deep Fault Drilling Project and utilised the optical fibre installed down to $893 \mathrm{~m}$ and open casing to $400 \mathrm{~m}$. The experiment aimed to:

1. Directly image the Alpine Fault in order to determine its geometry and seismic characteristics and thus inform the targeting and technical design of future 


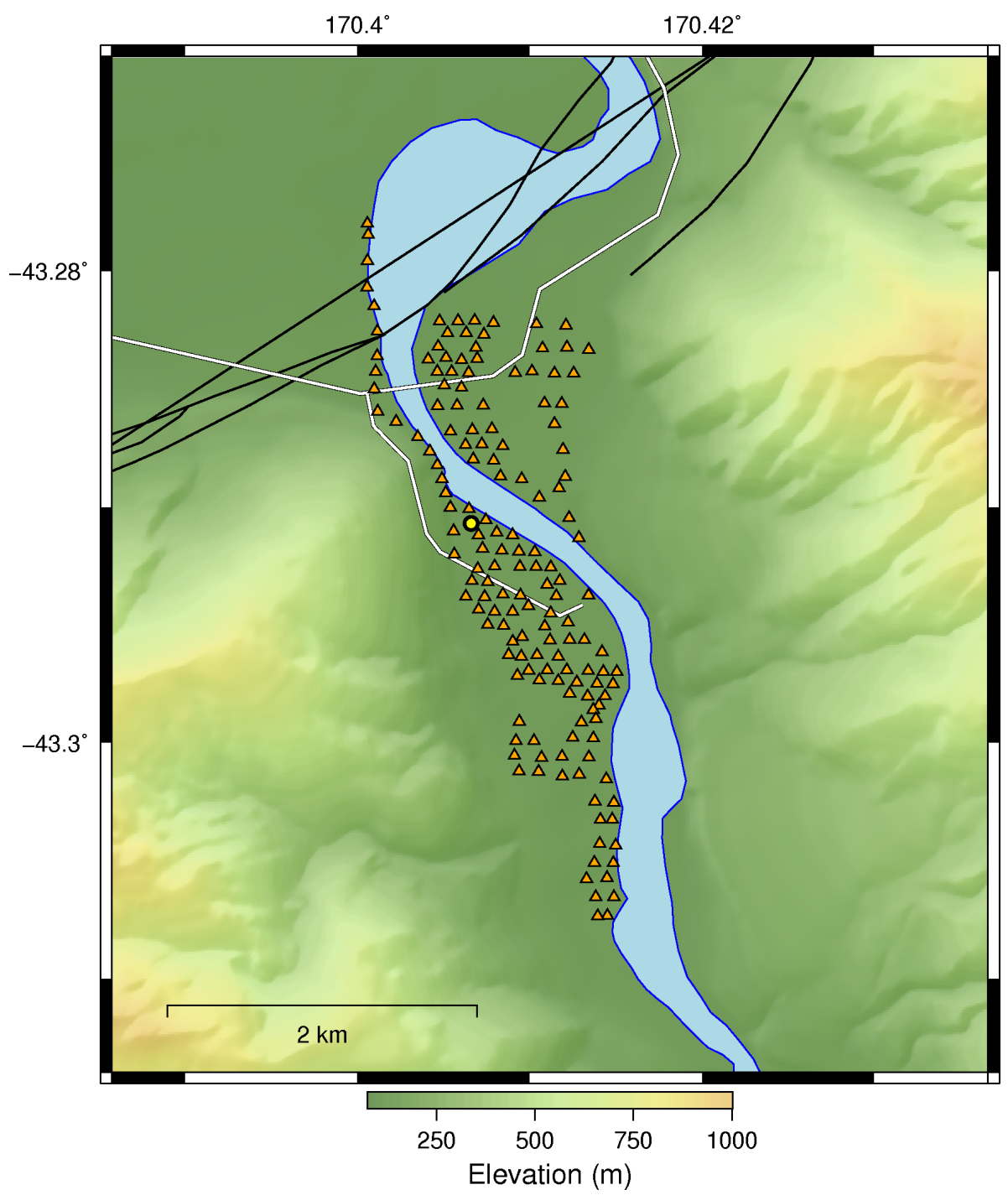

Figure 1.3: Map of the Whataroa Valley and instruments used in this thesis. The orange triangles mark the geophone locations. The yellow circle marks the DFDP$2 \mathrm{~B}$ borehole and location of the recorder and base operations of the active source survey. The Whataroa River is marked in blue, roads are marked as white lines and the Alpine Fault surface trace is marked as black lines. 
Deep Fault Drilling Project drilling activities,

2. Test new optical fibre Distributed Acoustic Sensing methods in the borehole and compare results to those obtained using traditional down-hole geophones and seismometers, for both active source and earthquake seismology,

3. Determine the acoustic and elastic properties of the hanging-wall rocks in the vicinity of the Alpine Fault for comparison with geophysical logs collected in the well

An extensive pool of geophysical equipment was used in the experiment, which can be split into three categories:

1. Surface instruments - The main surface instruments were 158 3-component geophones with a GFZ DSS cube3 $4.5 \mathrm{~Hz}$ recorder and a ARIES Multichannel Reflection System of 1-component geophones. An array of Reftek 3-component seismometers was also deployed.

2. Borehole instruments - Heterodyne Distributed Vibration Sensing (hDVS) system was deployed to $893 \mathrm{~m}$ and a SERCEL downhole Vertical Seismic Profiling (VSP) system was deployed to $400 \mathrm{~m}$.

3. Sources - The primary energy source was a IVI EnviroVibe Minivibe supplied by the University of Calgary that provided $16 \mathrm{~s}$ sweeps from 10 to $200 \mathrm{~Hz}$. A trailer mounted $250 \mathrm{~kg}$ weight drop was used to orientate the VSP.

The sparse geophone array was active from 16th to 21st January, 2016, and is used in this thesis. Due to field logistics, geophones were not correctly orientated to North, so this project only uses vertical component data as calculating orientations is beyond the scope of the project. The raw data were extracted from the cubes by staff from the University of Freiburg in a binary format, with each file containing p0, p1, and p2 channels, corresponding to EHZ, EHN and EHE. Gipptools, a program provided by the geophone supplier, was used to convert the files into miniSEED format. Obspy Python libraries were then used to archive each file into day long continuous 
waveforms with the Buffer of Uniform Data (BUD) structure (Beyreuther et al., 2010).

\subsection{Ambient Noise in Seismology}

The benefits of using surface waves to study the Earth have long been recognised (e.g. Stein and Wysession, 2009). However, until recently, using surface waves extracted from the ambient noise field was an under utilised method (e.g. Stein and Wysession, 2009). Inspired by the work of Aki (1957) and cross-correlation of random wavefields in acoustics (Lobkis and Weaver, 2001, Weaver and Lobkis, 2004), Shapiro and Campillo (2004) showed ambient noise can be cross-correlated to extract the Green's Function, and thus calculate surface wave dispersion. The use of ambient noise as a source overcomes a major spatial limitation of using earthquakes, which as a general rule mostly occur near plate boundaries and rifts. Increasingly, ambient noise is also used as non-intrusive complementary method to active source studies at local scales (e.g. De Ridder and Biondi, 2013, Hannemann et al., 2014, Lin et al., 2013). Previous studies using ambient noise tomography on a similar target frequency range have used longer recordings of ambient noise. Lin et al. (2013) used three weeks of recordings to make measurements between 0.5 and $4 \mathrm{~Hz}$, and Hannemann et al. (2014) used two weeks and frequency range of 1.6 to $9 \mathrm{~Hz}$.

\subsubsection{Surface-wave Propagation and Nature of the Ambient Noise Wave-field}

Seismic surface waves propagate along earth's surface, decaying over a two-dimensional surface, while body waves decay over a three-dimensional space, making surface waves the dominant phase in most earthquake seismographs (Stein and Wysession, 2009). Rayleigh and Love waves are the two main types of surface waves. Rayleigh waves have similar particle motion to compressional-waves (P-waves) and vertically 
polarised shear-waves (SV-waves), with motion on the vertical and radial components of a seismograph (Stein and Wysession, 2009). Love waves have similar particle motion to horizontally polarised shear-waves (SH-waves), with particle motion on the transverse component of a seismograph (Stein and Wysession, 2009). Surface waves are also dispersive, meaning different frequencies travel at different velocities. Surface waves also travel at two speeds due to their dispersive nature; the single wave velocity is called phase velocity and the wave envelope velocity is called the group velocity which is the derivative of the phase velocity (Stein and Wysession, 2009).

The dispersive nature of surface waves and their sensitivity to different depth underpins their usefulness. Different periods sample the extent of different depths, allowing a dispersion curve to be constructed that can then be inverted into a profile of shear-wave velocity with depth (Stein and Wysession, 2009).

Rayleigh and Love waves are commonly split into three different period bands; $>1$, 1-0.2 and $<0.2 \mathrm{~s}$ (Bonnefoy Claudet et al., 2006). The period band above $1 \mathrm{~s}$ is produced by natural sources such as changes in air pressure or by ocean waves impinging on coast lines. Between 0.2 and 1 s, noise can be either natural or cultural from sources such a rivers, while below $0.2 \mathrm{~s}$ it is usually cultural noise such as road traffic, human footsteps or machinery (Bonnefoy Claudet et al., 2006).

\subsubsection{Reconstructing the Green's Function}

The extraction of surface wave information from the ambient noise wavefield was first demonstrated by Aki (1957), who showed the theoretical relationship between diffuse surface waves and ambient noise cross-spectra. Using ultrasonic acoustics, Lobkis and Weaver (2001) showed that cross-correlating diffuse wave-fields recorded at different stations can reconstruct the Green's Function, the response at each station to an impulse at the other. They then expanded the theory to open systems 
such as the Earth (Weaver and Lobkis, 2004).

The work by Lobkis and Weaver (2001) set the framework for a resurgence in interest in the use of surface waves as a tool for imaging the earth. Campillo and Paul (2003) used earthquake coda wave cross-correlations to extract the surface wave component of the approximated Green's Function between two stations. They showed that all nine components of the Green's tensor were estimated by comparing synthetic tensors to real data. Shapiro and Campillo (2004) were the first to crosscorrelate seismic ambient noise waveforms to retrieve the approximated Green's function. They then showed fundamental mode Rayleigh wave group velocity dispersion curves can be calculated from Cross-Correlation Functions (CCF). Using the same method, Shapiro et al. (2005) used Rayleigh wave group velocity dispersion curves to construct velocity maps of California at 7.5 and $15 \mathrm{~s}$ period. In doing this, they revealed the potential of using ambient noise to image the subsurface by correlating their surface wave velocity maps with well known geological features.

The CCFs from a noise source distribution, representing the ambient noise field, can be approximated using the equation derived by Yao and Van Der Hilst (2009). The cross-correlation $C_{x y}$ of the wave-field recorded at station x and y, from sources emitting harmonic wave pulses of amplitude $\rho$ and angular frequency $\omega$, is

$$
C_{x y}(\Delta t, \omega, W)=\int W\left(\Delta t_{d}\right) \rho\left(\Delta t_{d}, \omega\right) \cos \left[\omega\left(\Delta t-\Delta t_{d}\right)\right] d \Delta t_{d}
$$

where $\Delta t$ is the lag-time, $\Delta t_{d}$ is the travel-time difference of wave phases travelling to stations $\mathrm{x}$ and $\mathrm{y}$, and $W$ is a windowing function describing the shape of the phases (Yao and Van Der Hilst, 2009). Figure 1.5 show examples of equation 1.1 using different source distributions with each source emitting a Gaussian-shaped phase of amplitude 1 , period of $5 \mathrm{~s}$ and a travel-time of $10 \mathrm{~s}$. The two stations are located $300 \mathrm{~km}$ apart. For a single source, the CCF signal corresponds to a correlation gather of source-position angle [see Snieder and Wapenaar (2010); Figure 1.5a]. 
Integrating over sources from all directions obtains two symmetric signals, representing a wave travelling from station $\mathrm{x}$ to $\mathrm{y}$ (virtual source to virtual receiver) at positive lag-time and $\mathrm{y}$ to $\mathrm{x}$ at negative lag-time at $3000 \mathrm{~m} / \mathrm{s}$ [Figure $1.5 \mathrm{c}$ ]. This illustrates the stationary phase argument of Snieder (2004) where signals originating from outside of the stationary phase zone destructively interfere while signals from a source within the stationary phase zone will constructively interfere [Figure 1.4].

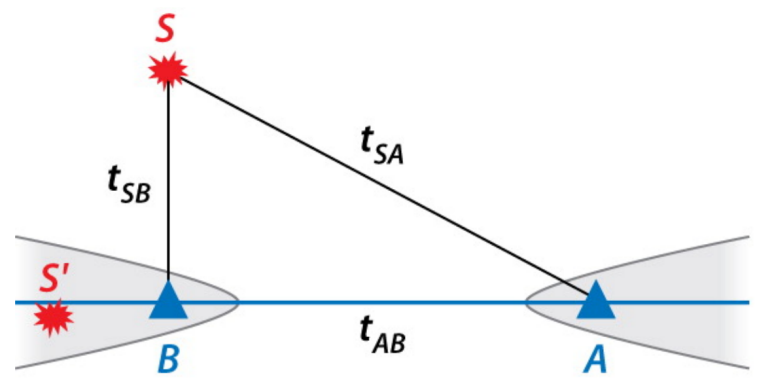

Figure 1.4: Schematic showing stationary phase zone for stations A and B where signal from $S^{\prime}$ will constructively interfere and signal from $S$ will destructively interfere. The grey area marks the stationary phase zone. Figure taken from Snieder and Larose (2013).

Asymmetric CCF are a common occurrence when cross-correlating seismic ambient noise, where sources have an uneven distribution, such as near the ocean (e.g. Lin et al., 2013). Wapenaar (2006) showed that it is possible to retrieve the approximated Green's Function from a one-sided distribution of noise sources. In the case of a one-sided source distribution, the approximated Green's Function is only retrieved from one side of the CCF [Figure 1.5b]. Ambient noise cross-correlations can also have symmetric signal in terms of lag-time, but with differing amplitude (e.g. Lin et al., 2013). This is shown in Figure 1.5d, where the number of sources for an acausal signal is five times the number of sources for the causal signal. The strength of signal in this situation will also control asymmetry of the CCF amplitude. 


\subsection{Thesis Structure}

This section outlines the thesis structure by briefly describing the contents of each chapter. This thesis is written in the context of 'we' rather than 'I', reflecting the amount of time my supervisors and others have contributed to this thesis.

This thesis is structured as follows:

- Chapter 1: An introduction to the motivation and objectives of this study. The geologic setting of New Zealand and Alpine Fault is introduced before we describe the geology of the Whataroa Valley that is relevant to this study. The dataset used in this thesis was acquired during the Whataroa Active Source Seismic Experiment so we introduce the experiment and the dataset together. The underlying theory of turning noise into signal is described, along with examples of ideal and non-ideal noise source distributions and resulting CCF.

- Chapter 2: We outline methods used to turn ambient noise recordings into a CCF representing an approximated Green's Function and subsequent dispersion measurements that can be calculated from CCF. Inversion techniques used to obtain surface-wave and shear-wave velocity models are introduced. We also introduce techniques used for error analysis.

- Chapter 3: Results calculated using the methods outlined in Chapter 2 are presented in this chapter. We present our observations from each result, including CCFs, back-projection for persistent localised source location, dispersion curves, surface-wave velocity maps and shear-wave velocity models.

- Chapter 4: We assess our results by first discussing the errors and considerations of each key finding. Our velocity models are then interpreted to answer the aims of this thesis stated at the start of this chapter.

- Chapter 5: Concluding remarks are stated in this chapter, including key findings and recommendations for future work. 
a
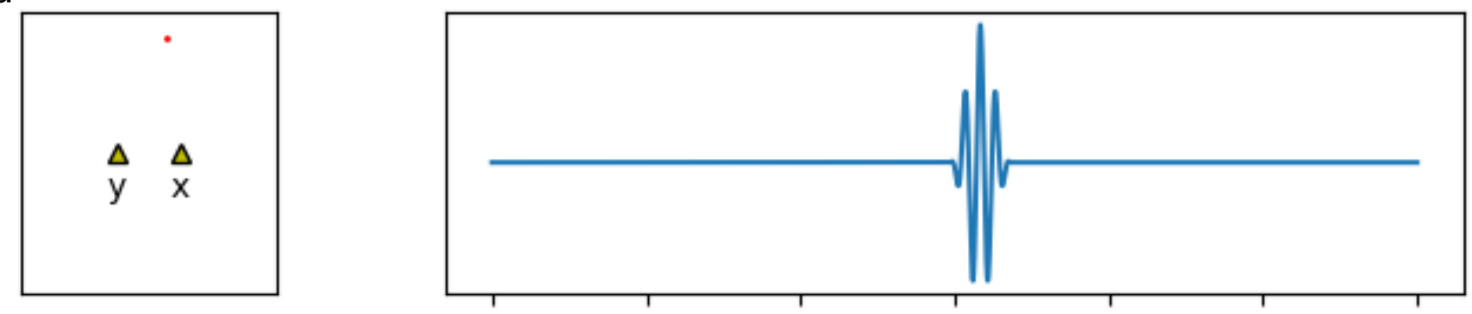

b
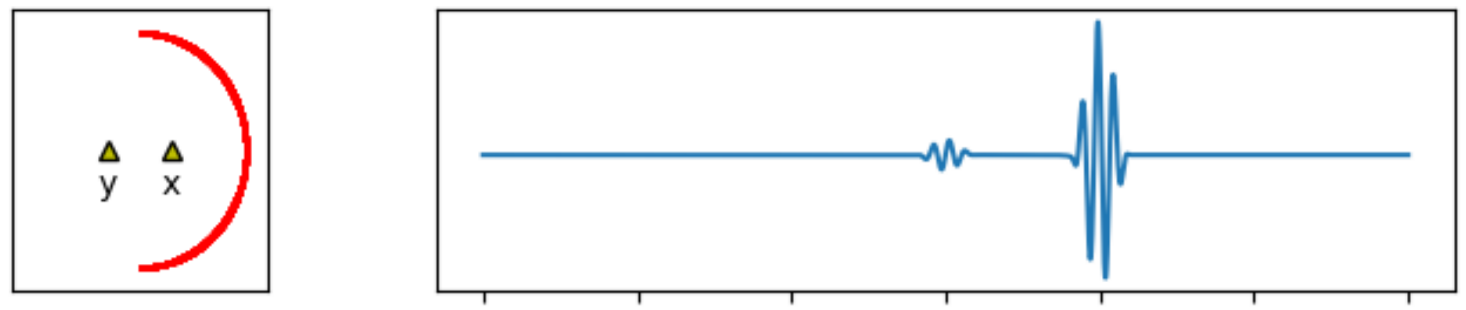

C
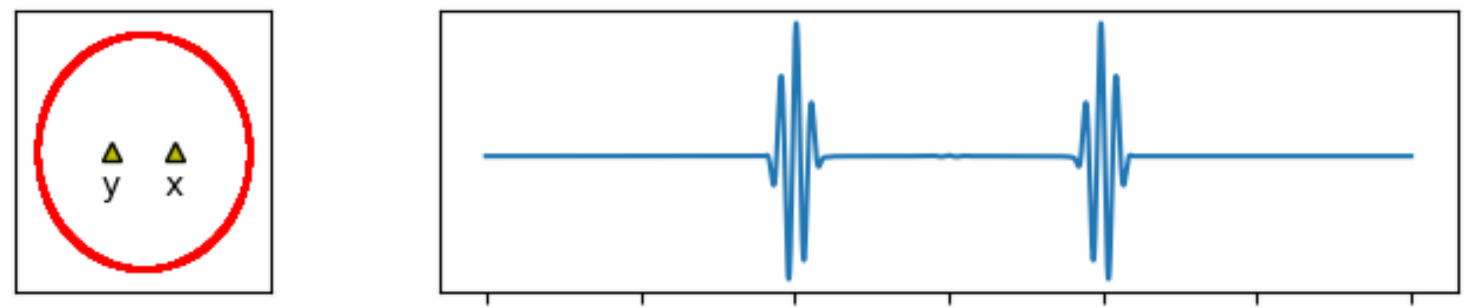

d
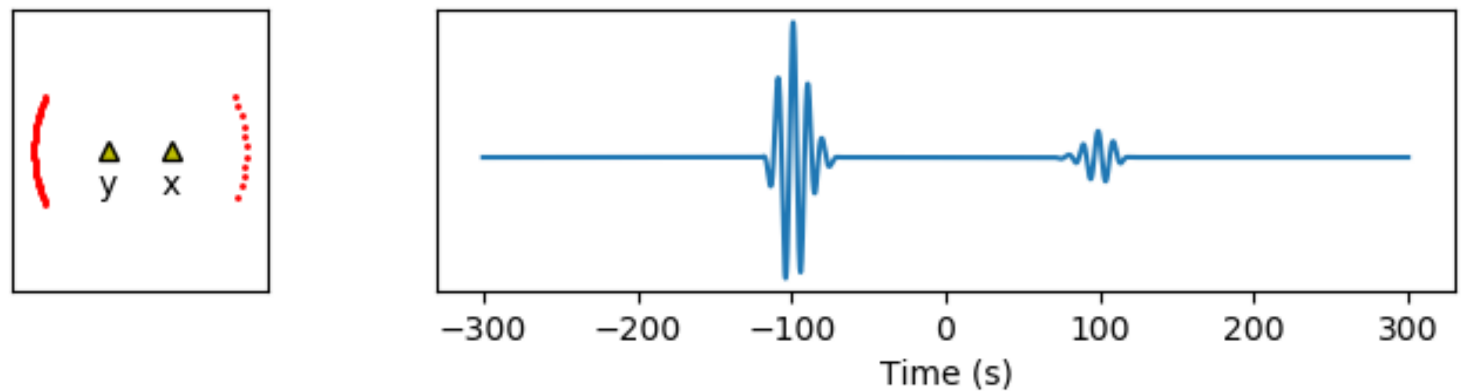

Figure 1.5: Noise source distributions and the summed Cross-Correlation Function. The left panels show the locations of noise source (red circles) signal recorded at stations $\mathrm{x}$ and $\mathrm{y}$ (yellow triangles) and then cross-correlated. The right panels show the sum of all cross-correlation functions from the corresponding source configuration on the left (after Behr, 2011). 


\section{Methods}

The methods used to calculate the velocity structure of the Whataroa Valley are introduced in this chapter. We first discuss processing techniques used to obtain surface wave dispersion curves from cross-correlation of seismic ambient noise recordings, followed by inversion procedures to obtain surface-wave velocity maps and shear-wave depth profiles.

\subsection{Measuring Surface Wave Dispersion from Am- bient Noise}

To calculate reliable surface wave velocities from ambient noise recordings, several processing steps must be undertaken: waveform preparation, cross-correlation, measuring surface wave dispersion curves and quality control [Figure 2.1]. Before waveforms are cross-correlated, they must be processed using signal processing routines with the aim of obtaining a set of ambient noise waveforms that best represent a stable noise-field in both space and time (Roux, 2009). Due to the short recording time of the dataset, we test techniques that differ from conventional processing of ambient noise recordings, namely phase cross-correlation and Phase-Weighted Stack (PWS).

We use a Python package, Monitoring Seismic Noise (MSNoise) (Lecocq et al., 2014), to process raw data into cross-correlations before using the dispersion curve package Alternate Frequency-Time Analysis (AFTAN) (http://ciei.colorado.edu/Products/, last accessed May 2017). The advantage of MSNoise is its modular design, allow- 
ing for easy modification of codes and the ability to extract data part way through processing. It also has multi-thread processing allowing for more efficient computation, especially when performing cross-correlation, which can be a computationally expensive task.

\subsubsection{Single Station Data Preparation}

Waveforms are merged into day-long records and then demeaned, detapered and resampled to $20 \mathrm{~Hz}$ to reduce the file size. A bandpass filter with 0.01 and $8 \mathrm{~Hz}$ corners is applied before the day-long records are cut into shorter records and then a cosine taper is applied to both ends of the waveform to allow for smooth transition between the time and frequency domain [Figure 2.2]. We do not remove the instrument response because the geophones are all identical (Bensen et al., 2007). Standard procedure is to reject day data with less than $80 \%$ of the day filled, however we have a limited recording time so this procedure is rejected during processing of CCF, but it is assessed during quality control (Bensen et al., 2007) [see Section 2.1.4].

We then apply time-domain normalisation to reduce bias in the cross-correlation from earthquakes, stationary noise sources and instrument spikes (Yao and Van Der Hilst, 2009). Bensen et al. (2007) outlined five methods for time-domain normalisation; one-bit normalisation (e.g. Larose et al., 2004, Yao et al., 2006); Root-MeanSquare (RMS) clipping (Sabra et al., 2005); automated event detection; absolute mean normalisation; and water-level normalisation. The methods are data dependant and should be tested to obtain the best result (Bensen et al., 2007). Absolute mean normalisation and water-level normalisation are the preferred methods of Bensen et al. (2007), however they are computationally expensive and give similar results to the simpler one-bit normalisation. A disadvantage of one-bit normalisation is dominant frequency bands such as a high frequency localised source may over-print non-dominant frequency bands. This study uses noise from both cultural and natural sources making one-bit normalisation problematic as the presence of 

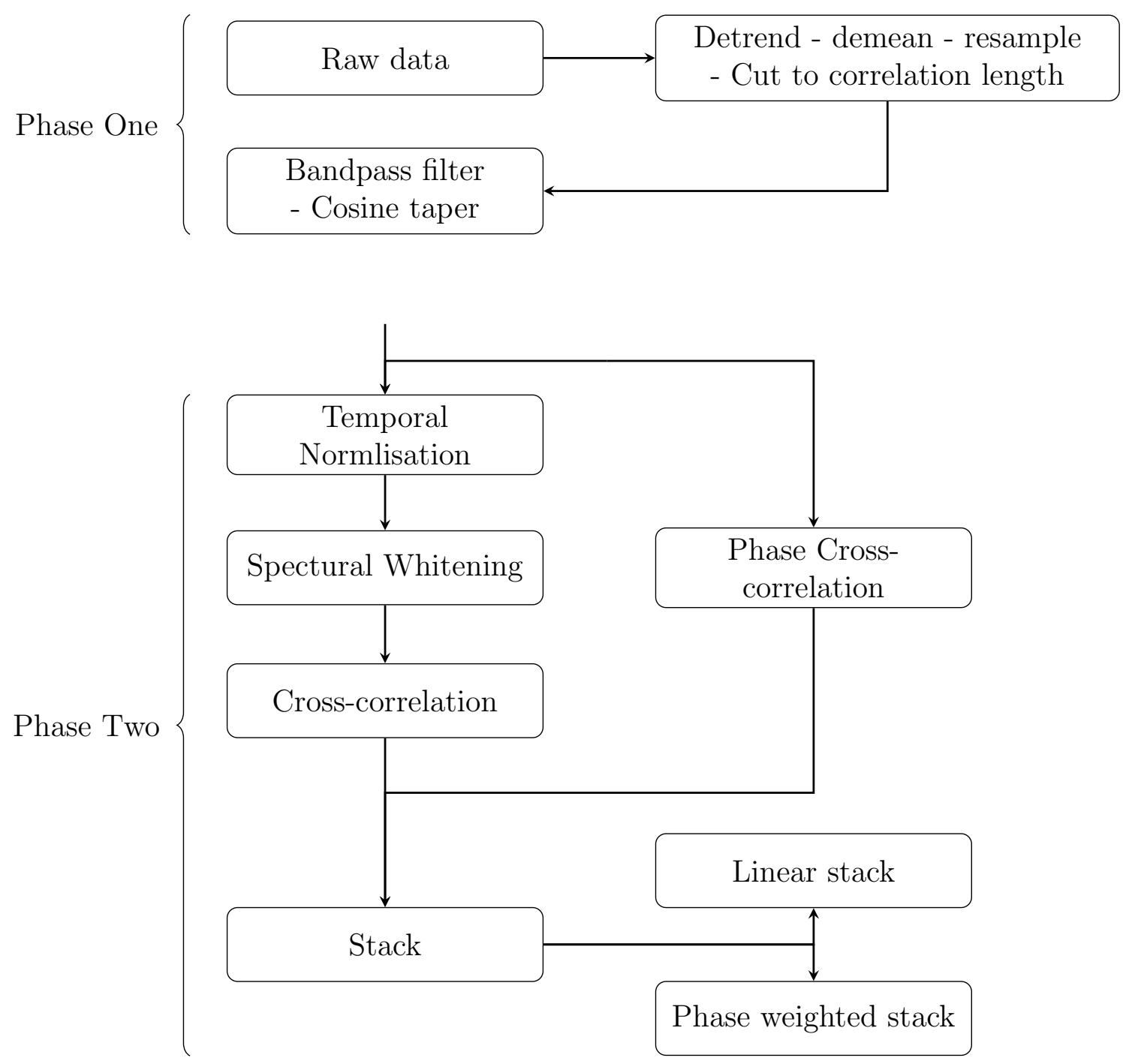

Phase Three $\left\{\begin{array}{c}\text { Phase and Group } \\ \text { velocity dis- } \\ \text { persion curves }\end{array}\right.$

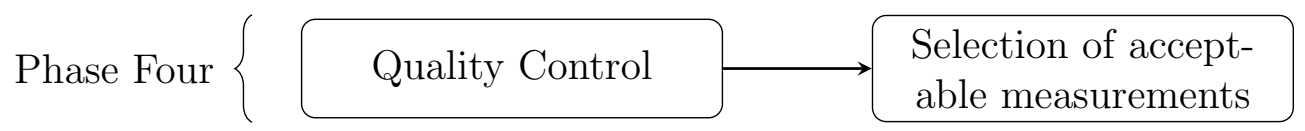

Figure 2.1: Simplified processing flow for measuring surface wave dispersion after Bensen et al. (2007). 
high frequency noise from local sources may over print useful signal in the $1 \mathrm{~Hz}$ range. Instead we clip the amplitudes by three times the Root Mean Square (RMS) of the amplitude and find satisfactory results [Figure 2.2].

The Ambient noise wave-field contains an uneven distribution of spectral energy (Bensen et al., 2007). Over a broadband scale, three distinctive peaks occur; the first at $7.5 \mathrm{~s}$, the second at $15 \mathrm{~s}$, and a third peak at $50 \mathrm{~s}$ referred to as the Earth hum (Rhie and Romanowicz, 2004). In this project we are concerned with periods below $2 \mathrm{~s}$, so any peaks in spectral energy are likely from localised cultural and natural sources. Spectral whitening equalises energy across a specified frequency band, ensuring the same spectral energy between the whitened frequency bounds (Stehly et al., 2009). To whiten, the RMS clipped waveform is transformed into the frequency domain where its spectral energy is whitened between 0.1 and $5 \mathrm{~Hz}(10$ and $0.2 \mathrm{~s}$ period) [Figure 2.2]. We limit the upper corner of the frequency band-width during whitening to $5 \mathrm{~Hz}$ to remove signal from the Vibroseis. The lower corner frequency of $0.1 \mathrm{~Hz}$ is intentionally left smaller than reasonable when considering rational wavelengths so we can explore the lower frequency signals that may be present in $\mathrm{CCF}$ of longer inter-station distances.

\subsubsection{Calculating Cross-Correlations}

Efforts to produce the best representation of the Green's Function usually focus on waveform preparation (Bensen et al., 2007). But due to the short recording time of the geophone dataset, we also test alternate cross-correlation and stacking methods to try to improve our Cross-Correlation Functions (CCF).

\section{Cross-Correlation}

We compute cross-correlations using two methods: standard cross-correlation and phase cross-correlation (Schimmel, 1999). Standard cross-correlation measures the coherence between the amplitude of the phase using the equation, 

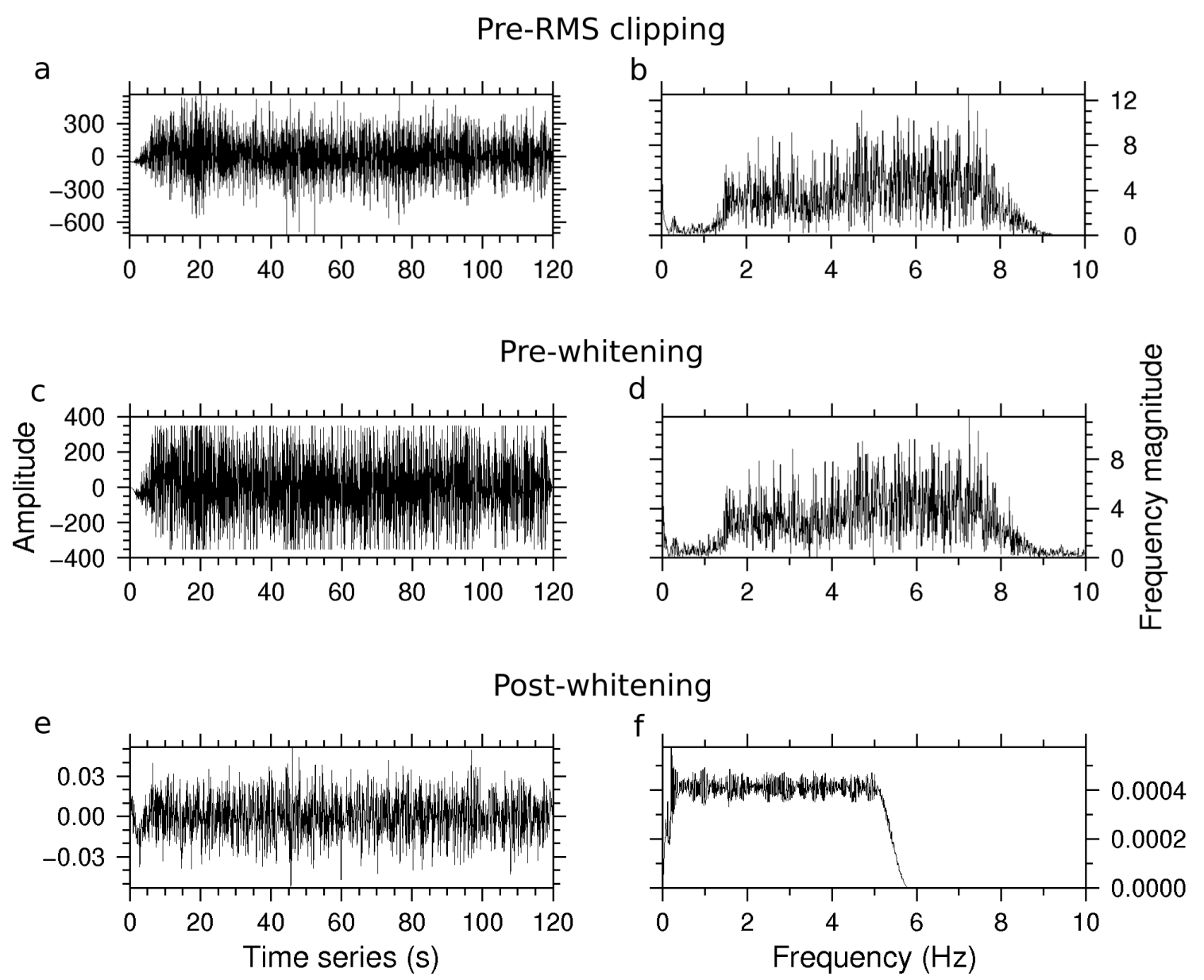

Figure 2.2: Signal processing routines applied to ambient noise waveforms prepare the traces for cross-correlation. Left panel shows $120 \mathrm{~s}$ long waveforms in the time domain at a) pre RMS clipping, b) pre-whitening and c) post whitening. Right panel shows the waveforms in the frequency domain at a) pre RMS clipping, b) pre-whitening and c) post whitening. Pre-whitening spectral energy is mostly above $2 \mathrm{~Hz}$; however once whitened there is an even energy distribution between the whitened bounds of 0.1 and $5 \mathrm{~Hz}$. 


$$
c_{c c f}(t)=\sum_{\tau=\tau_{0}}^{\tau_{0}+T} u_{1}(t+\tau) u_{2}(\tau)
$$

where $u_{1}$ and $u_{2}$ are the waveforms, $T$ is time series length and $t$ is the lag time. This type of cross-correlation is amplitude biased which is why so much processing is required to prepare the waveforms prior to cross-correlation (Bensen et al., 2007). To calculate cross-correlations using equation 2.1 , we use $T=120$ second and a lagtime of $40 \mathrm{~s}$.

An alternative cross-correlation method is called the phase cross-correlation and it is un-biased by amplitude (Schimmel, 1999, Schimmel et al., 2011). It measures the coherence between the instantaneous phase of the waveforms, meaning no time domain normalisation or spectral whitening needs to be performed (Schimmel et al., 2011). Instead we apply a bandpass filter with 0.1 and $5 \mathrm{~Hz}$ corners to keep the frequency spectrum of both cross-correlations consistent. Phase cross-correlation uses analytic signal theory where the analytic signal $s(t)$ of a real time series $u(t)$ is defined as $s(t)=u(t)+i H[u(t)]$, where $H[u(t)]$ is the Hilbert transform and $s(t)$ the imaginary component in the complex domain. In exponential form $s(t)=a(t) \exp (i \phi(t))$, the envelope function $a(t)$ and instantaneous phase $\phi(t)$ contain neighbouring waveform information and a coherence measure respectively. The phase cross-correlation $\left(c_{p c c}\right)$ is defined as

$$
c_{p c c}(t)=\frac{1}{2 T} \sum_{\tau=\tau_{0}}^{\tau_{0}+T}\left\{\left|e^{i \phi(t+\tau)}+e^{i \psi(\tau)}\right|^{v}-\left|e^{i \phi(t+\tau)}-e^{i \psi(\tau)}\right|^{v}\right\}
$$

where $\phi(\tau)$ and $\psi(\tau)$ are the instantaneous phases of time series $u_{1}$ and $u_{2}$, as a function of lag-time $t$. The factor of $1 / 2 T$ normalises the phase cross-correlation, where $c_{p c c}=1$ is a perfect correlation and -1 an anti-correlation. To control the sensitivity, the power $v$ is changed and generally leads to improved signal-to-noise ratio but decreased absolute correlation values (Schimmel et al., 2011).

We tested several $v$ values and find that the default value of 1 is sufficient as the 
use of phase-weighted stack gives us sufficient signal-to-noise ratio [see Stacking for explanation of phase-weighted stack]. Several time series lengths are tested using the phase correlation method and we found the phase CCF is almost identical when using time series lengths of 120-960 s. To increase computational efficiency, we opt to use $960 \mathrm{~s}$ time-series as calculating phase cross-correlations is computationally expense $(\sim 300$ s per job for $\sim 53000$ total jobs using 120 s time lengths versus $\sim 80 \mathrm{~s}$ for $960 \mathrm{~s}$ time lengths).

We decide to use the standard cross-correlation method defined in equation 2.1 as the phase cross-correlation limits the range of inter-station distances that can be used for reliable dispersion measurements; see Section 4.1 for a discussion on the two techniques.

\section{Stacking}

Individual cross-correlations are then stacked into the Cross-Correlation Functions (CCF) representing each Julian day of data to improve signal-to-noise ratio (Bensen et al., 2007). Stacking improves the signal-to-noise ratio by calculating the mean of each point in the CCFs trace, with coherent signal that is similar through time 'adding', while non-coherent signal will cancel out [Figure 2.3]. The standard method for stacking is the linear stack where the amplitude of the wavelet is used and there is no weighting to any individual trace (Bensen et al., 2007). The linear stack $\left(\right.$ stack $\left._{\text {lin }}\right)$ is defined as

$$
\operatorname{stack}_{\text {lin }}(t)=\frac{1}{N} \sum_{j=1}^{N} s_{j}(t)
$$

where $N$ is the number of signals $s_{j}$ to be averaged. Recent studies have shown the phase-weighted stack gives a higher signal-to-noise ratio than the traditional linear stack (Schimmel and Paulssen, 1997, Thurber et al., 2014). The principle of the phase-weighted stack is to down-weight components of signals that do not share the 
same instantaneous phase while up-weighting signals that do (Thurber et al., 2014).

Phase-weighted stacking first calculates the mean coherence between the instantaneous phase in all CCFs. The coherence is then used as a weighting factor to calculate the mean of each point on the trace. Phase-weighted stacking uses analytical signal theory in a similar fashion to the phase cross-correlation, where a CCF trace $s_{j}(t)$ and its Hilbert transform $H\left[s_{j}(t)\right]$ are combined to form the complex trace $S_{j}(t)$, defined as $S_{j}(t)=s_{j}(t)+i H\left[s_{j}(t)\right] . S_{j}(t)$ is expressed in exponential form as $S j(t)=A_{j}(t) \exp \left(i \phi_{j}(t)\right)$ where $A_{j}(t)$ is the amplitude and $i \phi_{j}(t)$ the instantaneous phase of the signal. Since no amplitudes are explicitly involved, for every $t$, the phase stack (weight $\left.t_{\text {phase }}\right)$ is defined as

$$
\text { weight }_{\text {phase }}(t)=\frac{1}{N} \sum_{j=1}^{N} e^{i \phi_{j}(t)}
$$

where $N$ is the number of traces. weight phase $(t)$ is normalised to have an amplitude range between 0 and 1, with 1 meaning the signal is coherent and 0 is non-coherent. The phase stack is then used as a lag-time-dependant weighting factor for the linear stacking method $\left(\right.$ stack $\left._{\text {lin }}\right)$ (Schimmel and Paulssen, 1997). This is performed by multiplying equations 2.3 and 2.4 , so that together the phase-weighted stack $\left(\right.$ stack $\left._{p w s}\right)$ is defined as

$$
\operatorname{stack}_{p w s}(t)=\frac{1}{N} \sum_{j=1}^{N} s_{j}(t)\left|\frac{1}{N} \sum_{j=1}^{N} e^{i \phi_{j}(t)}\right|^{u}
$$

The power $u$ controls the weight of weight $t_{\text {phase }}$. We find a $u$ value of 2.0 gives the best result as using a higher value results in unrealistic signal. The phase-weighted stack method is used as our stacking method in this thesis; see section 4.1 for discussion of the two methods.

Each daily CCF is then stacked into one stack using the phase-weighted stack method. We chose to remove Julian day 16 from our final stack as it only contains 4 hrs of data. Julian day 20 CCFs only contain $\sim 60-80 \%$ of daily recording 


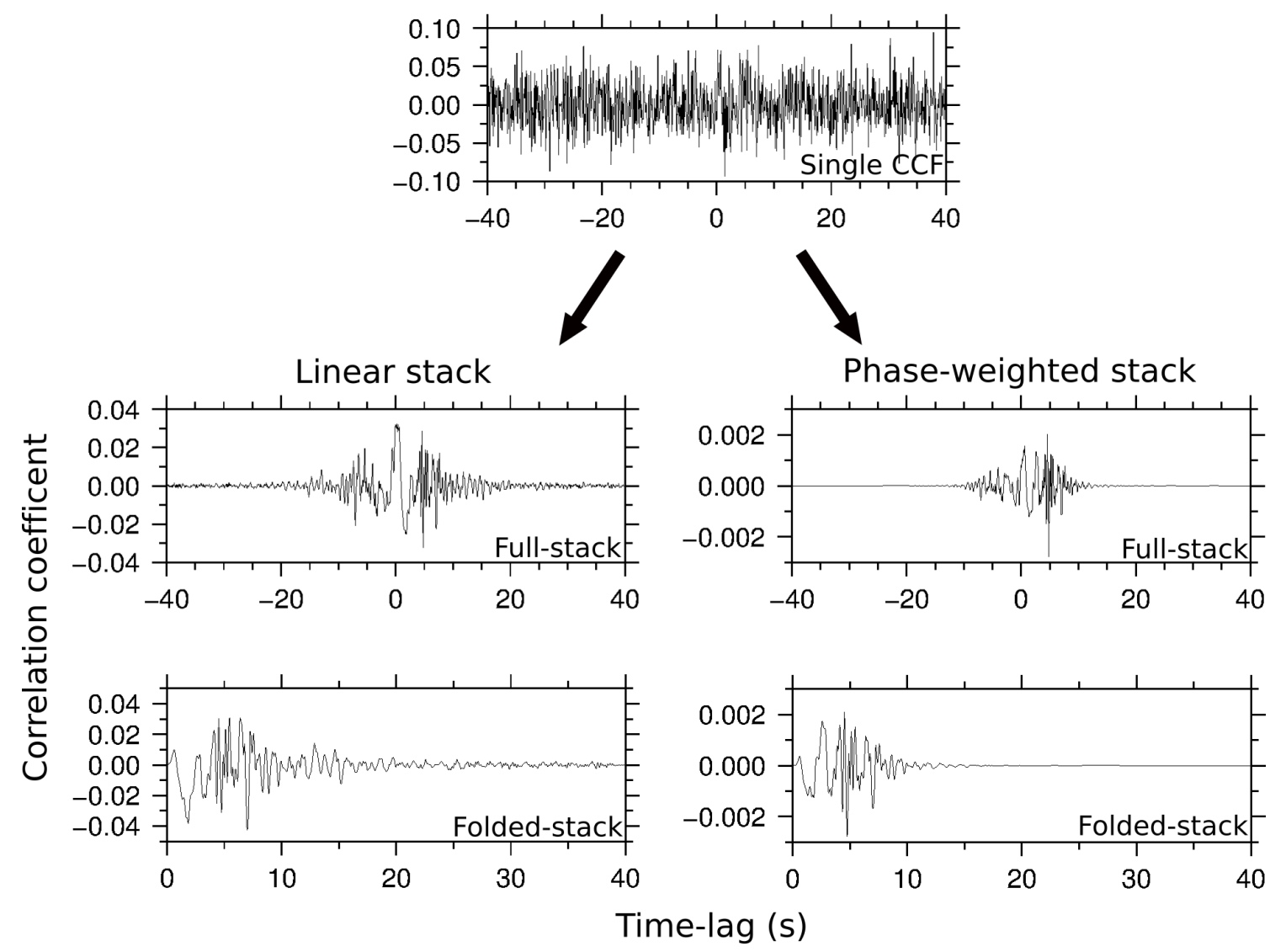

Figure 2.3: Comparison of traces stacked using a linear and phase-weighted stack method. The plot marked single CFF is produced using equation 2.1. The left and right panels show the stacked CCF using the linear and phase-weighted stack methods. The plots marked full-stack show the final CCF using equation 2.3 and 2.5 respectively. The causal and acausal components are then averaged to produce a symmetric CCF resulting from linear and phase-weighted stack methods (marked as folded-stack in the plots).

time so we choose to also reject these daily CCFs from our final stack in accordance with the guidelines of Bensen et al. (2007). Using the principle of reciprocity, we then average causal and acausal components of final CCFs to reduce the effect of a heterogeneous noise-field (Shapiro and Campillo, 2004). The resulting CCFs are referred to as symmetric CCFs and are considered to be the final cross-correlation.

\subsubsection{Calculating Surface Wave Dispersion Curves}

We measure Rayleigh wave group and phase velocity by applying frequency-time analysis to all symmetric cross-correlations (Bensen et al., 2007, Levshin et al., 1972, 1992). The frequency-time analysis we use is called AFTAN (http://ciei.colorado.edu/Products last accessed May 2017). Frequency-time analysis is an efficient method for mea- 
suring dispersion from a high number of CFF due to its automatic nature (Bensen et al., 2007). To measure group velocity, the CCF is transformed into the frequency domain and then filtered with narrow-band Gaussian filters. For each filter, the function is transformed back into the time domain, resulting in a smooth envelope function and phase function. The group velocity travel-time for each filter is defined as the peak of the envelope function. Phase velocity is then measured using the method outlined by Lin et al. (2008), who showed that phase velocity (c) at period $t_{\text {max }}$ can be calculated with the equation

$$
c=\frac{\omega}{\kappa}=\frac{r \omega}{\phi\left(t_{\max }\right)+\omega\left(t_{\max }\right)-\frac{\pi}{4}-2 \pi N}
$$

where $\omega$ is the angular frequency, $\kappa$ the wave number, $r$ the inter-station distance of the station pair, $\phi$ the phase of the filtered cross-correlation function and $N$ the number of wave cycles at $\omega$ between the station pair. To calculate $\mathrm{N}$, a previous dispersion curve is required to act as a reference curve (Lin et al., 2008). As we are only measuring vertical-vertical components we can keep the $-\frac{\pi}{4}$ phase ambiguity constant as shown by (Lin et al., 2008). The phase velocity reference curve used to calculate $\mathrm{N}$ is created using the software package Gpdc (http://geopsy.org/wiki/index.php/Gpdc, last accessed May 2017). Input into Gpdc requires layer thickness, shear and compressional-wave velocity, attenuation factor of compression and shear-wave velocity, and density (Figure 2.4). The parameters used in AFTAN are explained in Table 2.1. 
Table 2.1: Parameters used in AFTAN to calculate dispersion measurements for group and phase velocity. The Gaussian filters centre on a range of periods between $T_{\min }$ and $T_{\max }$. The window of the symmetric CCF is defined by velocity bounds $V_{\min }$ and $V_{\max }$. We choose a SNR value of 2 to allow a full range of measurements, we then apply stricter criteria at the next stage of processing.

\begin{tabular}{|l|l|}
\hline Parameters & Value \\
\hline Factor to multipy phase ambiguity $\left(\frac{\pi}{4}\right)$ & -1 \\
\hline Velocity $\min \left(V_{\min }-\mathrm{km} / \mathrm{s}\right)$ & 0.4 \\
\hline Velocity $\max \left(V_{\max }-\mathrm{km} / \mathrm{s}\right)$ & 2.0 \\
\hline Period $\min \left(T_{\min }-\mathrm{sec}\right)$ & 0.2 \\
\hline Period max $\left(T_{\max }-\mathrm{sec}\right)$ & 2.0 \\
\hline Second derivative threshold for group velocity jump $($ tresh $)$ & 20.0 \\
\hline Factor of Gaussian filter width $($ f fact $)$ & 0.1 \\
\hline Factor of left end taper $($ taperl $)$ & 1.0 \\
\hline SNR cut-off $(S N R)$ & 2 \\
\hline Factor to compress signal width $($ fmatch $)$ & 1.0 \\
\hline
\end{tabular}

a

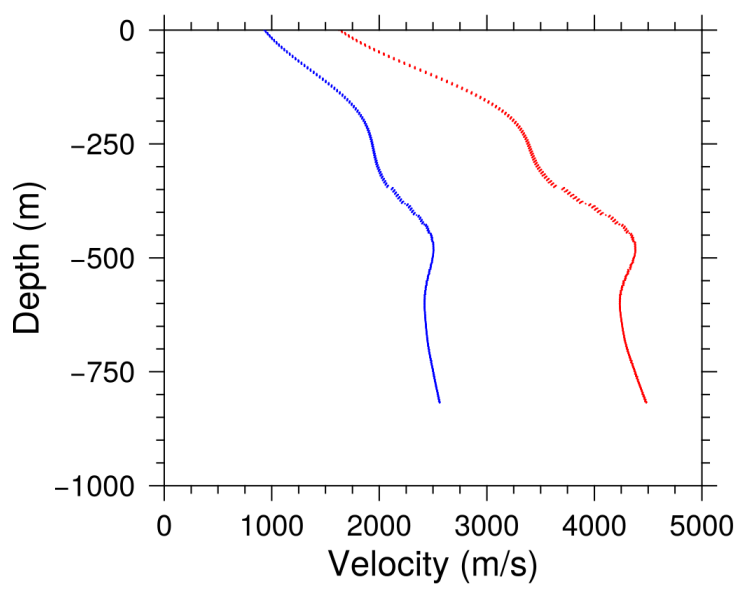

b

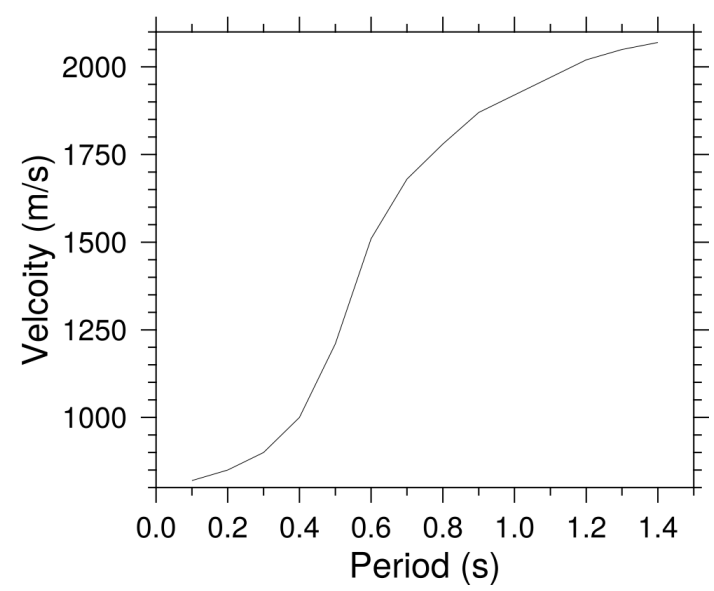

Figure 2.4: a) Compressional/shear-wave velocity model, and b) synthetic phase velocity dispersion curve used in AFTAN. The reference $V_{p} / V_{s}$ model is calculated using the $V_{p}$ model at the DFDP-2B borehole of Lay et al. (2016). To calculate $V_{s}$ we use a ratio of 1.75. Density is calculated using Gardners relation $1.74 \times V_{p}^{0.25}$ (Gardner et al., 1974) and we assume a constant attenuation factor of 100 for both $Q_{p}$ and $Q_{s}$.

We chose to omit phase-matched filtering from dispersion curve measurements because of the narrow frequency range measured. As mentioned in Bensen et al. (2007), short period signals are contaminated by prominent side-lobes when the Gaussian filtered signal is collapsed, contaminating the signal. For this reason Bensen et al. (2007) only advocate the use of phase match filters for broadband signals. 


\subsubsection{Quality Control}

Error is not directly measured when calculating surface wave dispersion curves with AFTAN so selection criteria are applied to identify acceptable measurements. Bensen et al. (2007) advocate the use of signal-to-noise ratio, a minimum wavelength criteria and dispersion curve measurements of sub-stacks of the full stack.

Dispersion measurements with a signal to noise ratio below 15 are discarded, defined as the maximum amplitude of the signal divided by the RMS value of the noise (Bensen et al., 2007). The signal to noise ratio of 15 was as chosen as the value that gave the best quality dispersion measurements whilst maintaining an acceptable number of measurements for further analysis e.g. path coverage for tomography. The lag-time window of each CCF, specified as $t_{\min }$ and $t_{\text {max }}$, is defined using the inter-station distance of each $\mathrm{CCF}$, and velocities $V_{\min }$ and $V_{\max }$ specified in Table 2.1. The velocities are chosen as minimum and maximum values that provide a window that best represents the velocity range that signal may travel at between stations. All signal outside of the window defined above is considered noise.

The minimum wavelength criterion varies between papers; Bensen et al. (2007) proposes a minimum inter-station distance of three wavelengths, Shapiro et al. (2005) use two and Brenguier et al. (2007) use one. Studies using broadband signals tend to require a higher number wavelengths while studies using higher frequency bandwidths use less (Brenguier et al., 2007). We require one wavelength because our dispersion measurements appear to remain stable, allowing us to have a higher number of measurements at longer periods.

Phase velocity dispersion measurements at discrete periods are plotted as a function of travel-time and distance to look for outliers and cycle skipping of phase velocity measurements (Lin et al., 2008). This occurs when the number of wave cycles calculated using the reference dispersion differs from the real value ( $N$ in equation 2.6). 
To test the reliability of our dispersion curve measurements we adapt the method of Bensen et al. (2007) and measure dispersion curves from CCFs made of sub-stacks representing one day of data. Following Behr et al. (2011), we measure a lower and upper dispersion curve for every dispersion curve measurement by taking the lower and upper envelope of the daily dispersion curves. This allows us to capture the variability of our dispersion measurements. While it is not a direct measure of error, it provides an estimate of dispersion curve error.

\section{$2.2 \quad$ Locating Persistent Localised Sources}

Inspection of CCF virtual source moveout plots show a linear feature of a similar frequency and slope to the direct wave signal [see Figure 3.3b for example]. Zheng et al. (2011) found that stationary sources, termed persistent localised sources, located within an array can generate a signal similar to what is observed in our CCFs. The presence of this signal in CCFs when measuring surface wave velocity using AFTAN will bias the group velocity measurement. If the stationary source signal is at a different frequency to the ambient noise wave-field frequencies then frequency filtering can remove the signal. But signal at a similar frequency can only be removed by discarding affected CCF traces. To identify these traces the persistent localised sources must be located.

To locate the sources, we follow Zheng et al. (2011) who used a back-projection method similar to Ishii et al. (2005), but adapted to CCF. First, all points from a $10 \mathrm{~m}$ spaced grid are considered as potential source locations where the lag-time of the CCFs is the difference in distance from potential source to virtual source and receiver, divided by apparent velocity. A constant apparent velocity is assumed, which is calculated from the slope of the persistent localised source phase on virtual source moveout plots. To counter the effects of positive and negative amplitudes 
cancelling, the positive envelope function is taken for each CCF [Figure 2.5b]. The amplitude of each lag-time for every potential source is then mapped through space to give a grid of hyperbolas that map the possible source location for every $\mathrm{CCF}$ lag-time [Figure 2.5c]. We repeat this for every CCF with a stationary source phase present and then stack the amplitude grids to give a final location [see Figure 3.8 for affected stations].

The persistent localised source signal is in a similar spectral range $(0.4$ to $0.8 \mathrm{~s}$ period) to our CCFs, making it difficult to remove via frequency filtering. To ensure unbiased dispersion curve measurements, acausal or causal time lags are removed from a CCF if it is contaminated by a persistent localised source phase. Using the back-projection location, the distance from the persistent localised source to both virtual source and receiver is calculated and if it is located within a great circle connecting both station and receiver, then the CCF is considered contaminated. The persistent localised source is located on the positive lag if it is closer to the virtual source and on the negative lag if it is closer to the virtual receiver. For CCFs where both stations are identified as contaminated, the function is discarded if the persistent localised source is located within the great circle connecting both virtual source and receiver. For stations not identified as contaminated, the causal and acausal functions are stacked into a symmetric CCF.

\subsection{Inversion for Velocity Structure}

Surface wave dispersion curves can be inverted for tomographic maps of surface velocity at discrete periods and for shear wave velocity with depth. Inverting a surface wave dispersion curve calculated from a CCF for shear-wave velocity will give the average 1D velocity structure between two stations (e.g. Behr et al., 2010). To better model the velocity structure, surface-wave tomography maps of discrete periods can be used to create interpolated dispersion curves from each grid point 

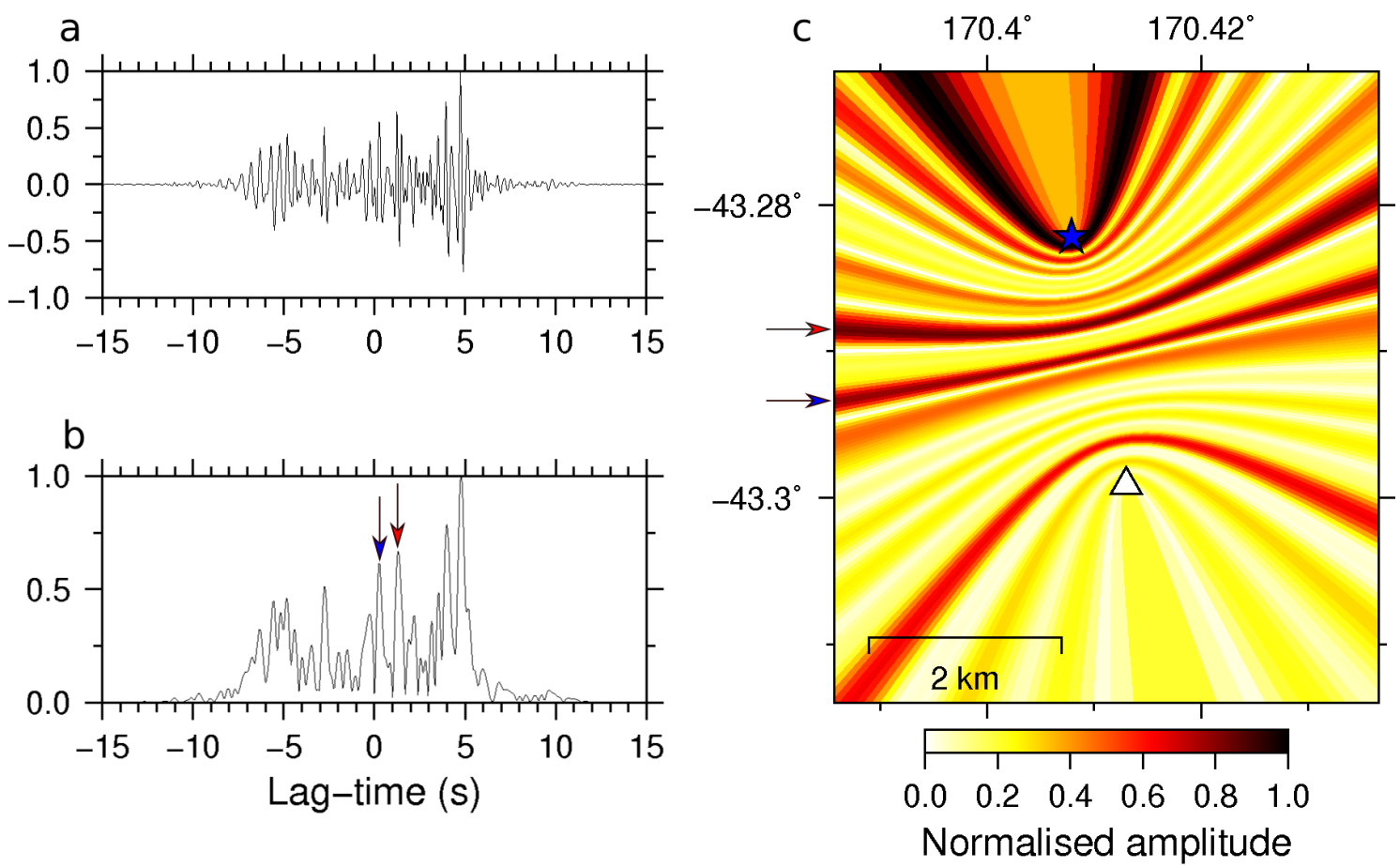

Figure 2.5: a) CCF, b) positive envelope function of CCF, c) back-projection of positive envelope function. The CCF is first bandpass filtered between 1 and $5 \mathrm{~Hz}$ and then a postive envelope function is calculated. A backprojection (c) is then applied to the envelope function (b). The red and blue arrows show the location of the stationary phase signal on the envelope function (b) and each locations potential source location is mapped (c). Real amplitudes are used for the stacked backprojections despite being normalised in this example. The blue star is the virtual source and white triangle is the vertical receiver

within the tomographic model (e.g. Behr et al., 2011, Lin et al., 2013). The interpolated dispersion can then be inverted for shear-wave velocity, giving the $1 \mathrm{D}$ velocity structure for a grid point. Using 1D inversions from each grid point, a pseudo-3D shear-wave velocity model is constructed by interpolating the $1 \mathrm{D}$ profiles into $3 \mathrm{D}$ space.

\subsubsection{Surface Wave Tomography}

The calculation of dispersion curves from CCFs make these measurements suitable to tomography methods as both the source and receiver locations are known. A popular method was proposed by Barmin et al. (2001) which minimises a penalty function, assuming no ray-bending. More recently, eikonal tomography has become a common method which solves the eikonal equation for apparent phase velocity 
by tracking a wave-front propagating across an array from a virtual source and calculating the travel-time gradient and its direction at each grid point (Lin et al., 2009). We choose to not use the Barmin et al. (2001) method because no codes were available that would suit this dataset and writing new ones is beyond the scope of this thesis. Eikonal tomography uses bent-ray theory so we decide to use a simpler method considering the array geometry.

To calculate the spatial variation of phase and group velocities within the study area, we use a linear straight ray travel-time tomography method (Uieda et al., 2013). The problem is in the linear form of

$$
d=G(m)
$$

where $d$ is the data, $m$ is the model and $G$ is a linear function linking $d$ and $m$. The problem minimises the objective function $\phi$ of travel-time misfit between the observed and modelled travel-time by finding the parameter vector $\bar{p}$ that solves the linear system

$$
\overline{\bar{H}} \bar{p}=-\bar{g}
$$

where $\overline{\bar{H}}$ is the Hessian matrix of $\phi$ and $\bar{g}$ is the gradient vector of $\phi$. Minimising the objective function $\phi$ through a straight-forward linearisation is very sensitive to outliers, resulting in a unstable and unrealistic solution (Uieda et al., 2013). To overcome this we apply a regularizing function that uses a 1st order Tikhonov regularization that requires adjacent parameters have similar values. The strength of smoothing is controlled by a scaler value chosen by finding the value where misfit is stabilised.

\section{Checker-board Tests}

To test for lateral resolution of velocity maps we employ checker-board tests (e.g. Rawlinson et al., 2014). The checker-board test models how well a synthetic model made up of blocks with varying velocity can be reconstructed using the ray-paths 
of the observed dataset. Travel times are first calculated for each ray-path using the synthetic velocity model, where the ray-paths are same used for each velocity map calculation. Tomography is then performed on the travel-times as outlined in section 2.3.1. The level of similarity between the input synthetic model and reconstructed synthetic model gives an estimate of resolution. Typical features observed are smearing of checkers and the damping of velocity (Rawlinson et al., 2014).

\subsubsection{Inversion for Shear-Wave Velocity}

Inversion of surface wave dispersion curves is a non-linear optimization problem that gives non-unique solutions (Dunkin, 1965). Popular techniques include linearised methods and direct search techniques (Wathelet et al., 2004). Direct search methods are well suited to problems with a limited number of unknowns (Wathelet, 2008).

We use the Neighbourhood Algorithm (NA), a stochastic direct search method that is steered towards a best fitting solution (Sambridge, 1999a,b). The software package Dinver is used which implements a modified version of the NA where a parameter space with irregular boundaries can be defined (Wathelet, 2008,

http://www.geopsy.org/wiki/index.php/Dinver, last accessed May 2017). We start by defining a parameter space of shear velocity, thickness, compressional velocity (linked to shear-velocity by Poissons Ratio) and density that is divided up into a number of Voronoi cells $\left(n_{s 0}\right)$ by a pseudo-random generator. For each Voronoi cell sample, a forward model dispersion curve fitting the sample parameters is computed using the method of Dunkin (1965). A misfit value between the forward modelled dispersion curve and the input data (in our case a dispersion curve(s)) is calculated using the equation

$$
\text { misfit }=\sqrt{\sum_{i=0}^{n_{F}} \frac{\left(x_{d i}-x_{c i}\right)^{2}}{\sigma_{i}^{2} n_{F}}}
$$


where $x_{d i}$ is the velocity of the observed curve at frequency $f_{i}, x_{c i}$ is the velocity of the theoretical curve at $f_{i}, \sigma_{i}$ is the uncertainty of frequency samples and $n_{F}$ is the number of frequency samples considered (Wathelet, 2008). We do not give uncertainty for observed dispersion curves so replace $\sigma_{i}$ with $x_{d i}$ (following Wathelet et al., 2004). A new random generation of samples is guided by the misfit value from previous samples. For all Voronoi cells, $n_{r}$ number of cells with the lowest misfit are chosen and $n_{s}$ number of new samples are randomly generated to better sample promising area of low misfit. The inversion is then repeated for the new and old cells, and for each new point a misfit value is calculated. The process continues for $i t_{\text {max }}$ number of iterations (Wathelet, 2008). For a discussion of the parametrisation used in this thesis, see Section 4.1.4.

\subsubsection{D and pseudo-3D Shear-Wave Velocity Modelling}

The benefit of using the Neighbourhood Algorithm for our shear-wave velocity inversions is the ability to model the results based on misfit values. Instead of accepting the model with the lowest misfit, we consider all models below a misfit value and calculate the mean at $10 \mathrm{~m}$ depth increments using misfit values as a weighting scheme [see Section 2.3.4 for how the misfit value is chosen]. This method serves to smooth the shear-wave velocity profile. We can also test if the inversion solution has converged on a model by plotting a mesh of cells that shows the number of accepted models going through each cell. If a sufficient number of models is contained in a narrow zone of cells then the inversion has converged.

In ambient noise tomography, a common method for modelling 3D variations of shear-wave velocity is to project $1 \mathrm{D}$ shear-wave velocity profiles into $3 \mathrm{D}$ space using linear interpolation (e.g. Behr et al., 2011, Hannemann et al., 2014, Lin et al., 2013). This type of model is referred to as a pseudo-3D velocity model as it is not a 3D inversion (Behr et al., 2011). To calculate a velocity model using a 3D inversion, the 3D wave equation must be solved (Tape et al., 2010) or 3D sensitivity kernels 
can be used (Fichtner, 2010, Zhou et al., 2006). Previous studies have shown that the linear interpolation method is a reasonable approximation of $3 \mathrm{D}$ structure at a local scale so we decide to use this as it is a simpler method (Brenguier et al., 2007, Hannemann et al., 2014). The limitation of this method is that it involves two inversions, the first being surface wave tomography maps and the second the shear-wave velocity inversion; hence we interpret our results carefully (Behr, 2011).

\subsubsection{Error Analysis}

To calculate error in our surface-wave tomography and shear-wave inversions we follow Behr et al. (2011). Surface-wave tomography error for phase and group velocity is estimated by taking the low and high bound of a set of daily dispersion measurements described in Section 2.1.4 and performing tomography on both sets, giving three surface wave maps for each period at which tomography is performed. We then construct dispersion curves at each $100 \mathrm{~m}$ cell in the tomography map from the high and low bound tomography models for both velocity types [see Figure 3.21 for example]. We then use these bounds to provide an estimate of the misfit value in the 1D shear-wave inversions that constrains all acceptable models in each inversion (Godfrey et al., 2017). These accepted models are then used to calculate the mean shear-wave profile using misfit as a weighting.

The non-linear relationship between surface wave dispersion curves and shear-wave velocity profiles makes it difficult to link CCFs and dispersion curve uncertainty to shear-wave velocity models. Therefore all our error analysis is empirical (Behr, 2011).

By using a weighted mean for the 1D shear-wave profiles we are able to estimate the standard deviation of the velocity and depths of each profile. To do this, we calculate a histogram of shear-wave velocity at $10 \mathrm{~m}$ depth intervals and fit a Gaussian curve to each histogram. Following Behr et al. (2011), we define one standard deviation of every curve as the measure of uncertainty. To evaluate depth uncertainty we 
follow a similar procedure except that the histograms of the depth layers set in the inversion parametrisation are used. The resulting standard deviation of each depth layer is then interpolated at $10 \mathrm{~m}$ intervals. 


\section{Results}

This chapter presents the results of our investigation into the velocity structure of the Whataroa Valley using a temporary geophone array. Cross-Correlation Functions (CCF) of the seismic ambient noise wave-field are used to calculate surface wave dispersion curves. We show back-projected CCFs that reveal a stationary source present in the study area. Rayleigh wave phase velocity maps are then constructed from phase velocity dispersion curves. A pseudo-3D shear-wave velocity model is calculated by inverting dispersion curves constructed from phase velocity maps over an evenly spaced grid and then interpolating the 1D profiles across 3D space.

\subsection{Cross-Correlation Functions}

We computed 53,428 daily CCFs that are stacked into 12,247 final CCFs representing all pairwise station combinations, made up of three days of data; Julian day 017, 018 and 019. The CCFs can be plotted in terms of their lag-time and interstation distance, which we refer to as moveout plots. To view all CCFs on a single plot, we stack them into $25 \mathrm{~m}$ inter-station distance bins to facilitate interpretation [Figure 3.1]. By plotting CCFs as a function of inter-station distance, we observe several phases in the CCFs that originate from both zero and non-zero lag-times. Phases originating from zero are called direct waves and propagate from the virtual source to the receiver in positive lag-time, and from receiver to the source in negative lag-time. A high-frequency phase $(>1 \mathrm{~Hz})$ travelling at an apparent group velocity of $500 \mathrm{~m} / \mathrm{s}$ is present in CCFs at distances up to $3 \mathrm{~km}$. A large reduction in amplitude is apparent after $3 \mathrm{~km}$ [Figure 3.1]. 
Lower-frequency $(<1 \mathrm{~Hz})$ phases appear at shorter lag-times, with a peak occurring at zero. These phases may be a pseudo auto-correlation that forms from a high similarity between longer-period surface waves at close inter-station distances (Chávez García and Rodríguez, 2007). Body waves may also form a peak at zero; these can be removed by selectively removing individual CCFs containing such peaks. Our CCFs contain these peaks for all inter-station distances, and therefore we suspect these features to be pseudo auto-correlations of surface waves rather than crosscorrelations of body waves. Several other phases with a similar moveout slope to the direct phase appear at longer lag-times in CCFs further than $2 \mathrm{~km}$ station separation.

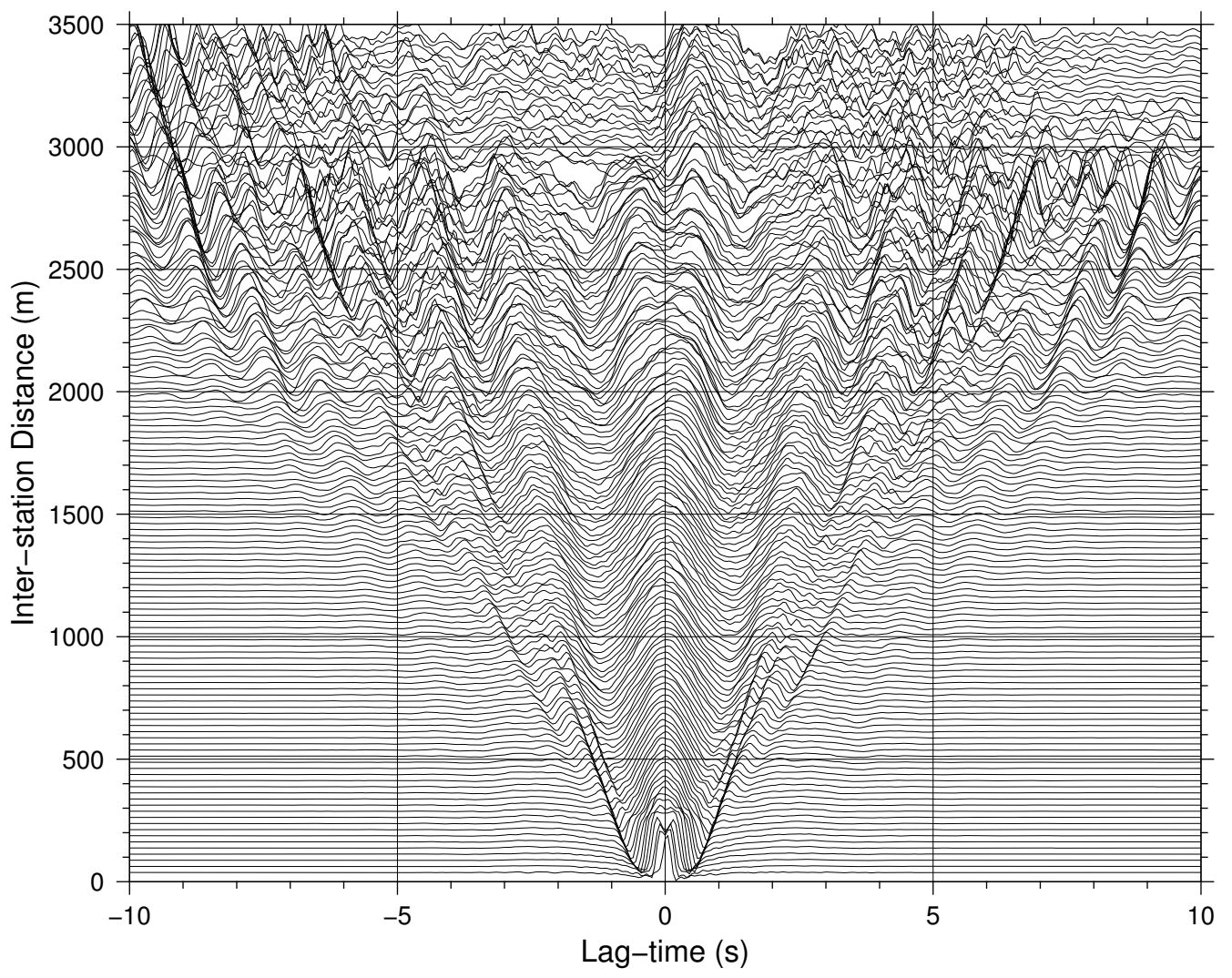

Figure 3.1: Moveout plot of all raw CCFs stacked into $25 \mathrm{~m}$ distance bins.

The pseudo auto-correlation feature present in most CCFs can be removed with a $1 \mathrm{~Hz}$ high-pass filter [Figure 3.2]. The strongest feature is the moveout from zero lag-time of the direct wave at $500 \mathrm{~m} / \mathrm{s}$. There are also phases parallel to the direct 
wave at both shorter and longer lag-times. The parallel phases appearing at longer lag-times are referred to as coda. The direct wave phase has a large reduction in amplitude at $3 \mathrm{~km}$ inter-station distance in Figure 3.2. The attenuation in amplitude of the direct wave is stronger on the positive side than the negative side of lag-time; however due to the orientation of CCFs we cannot distinguish direction in Figure 3.2 and 3.1 .

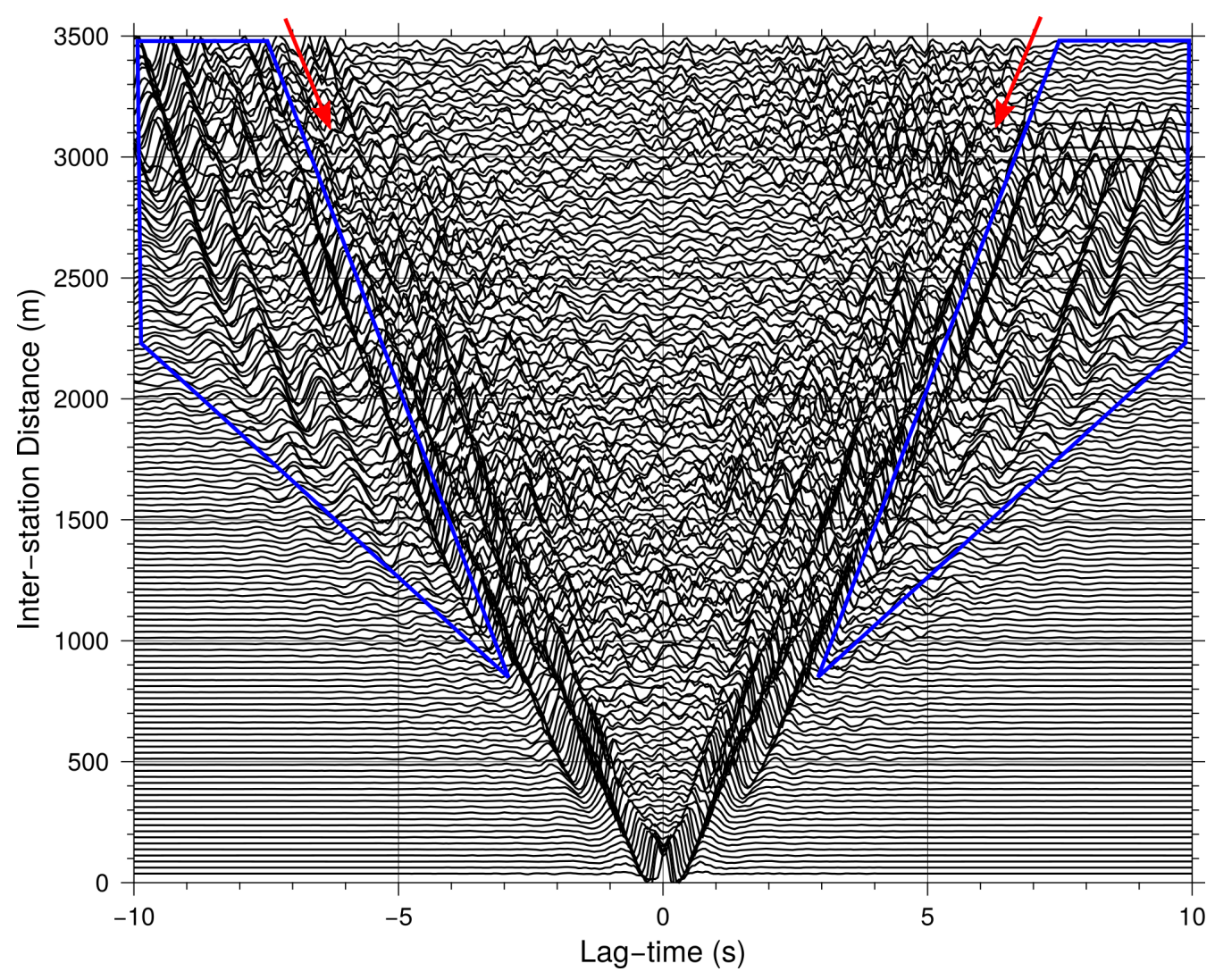

Figure 3.2: Moveout plot of all CCFs stacked into $25 \mathrm{~m}$ distance bins and high-pass filtered at $1 \mathrm{~Hz}$. The red arrows marks the direct wave and the blue polygon show the phases we consider coda.

To investigate spatial variations of CCF features, we plot a selection of different stations as a virtual source against all other stations [Figure 3.3]. These plots allow for the direction of wave propagation energy to be distinguished, giving insight into the symmetry of CCFs and the direction of noise sources. We do not refer to the causal and acausal components when describing plots in Figure 3.3, rather CCFs are plotted as positive or negative inter-station distance if they are north or south of the virtual source. This means that direct wave signals in causal CCFs with a posi- 
tive inter-station distance are travelling away from the virtual source, and signals in the causal CCFs with negative inter-station distance are travelling towards the virtual source. Amplitudes of each CCF are normalised so cannot be compared directly.

Virtual source moveout plots of stations located in the northern part of the array generally exhibit lower quality CCFs [Figure 3.3b and c]. Multiple phases of a similar slope to the direct wave that cross the zero lag-time but do not originate from zero appear in most of these stations; we refer to these signals as the persistent localised source phase [green box in Figure 3.3c and d; see Section 3.1.1]. Although stations east of the Whataroa River are contaminated by this signal, a clear direct wave is usually observed with moderate symmetry [Figure 3.3b]. Within the northern part of the array, stations located north of State Highway 6 [see transparent red box in Figure 3.5b for road location], along the western edge of the Whataroa River are the lowest quality stations in the array [Figure 3.3c]. Weak amplitude direct waves and strong contamination from the persistent localised source phase described above are typical characteristics.

At stations located near the DFDP-2B borehole, a strong direct wave is observed travelling away from the drill-pad [Figure 3.3a]. Strong asymmetry is also observed in most virtual source moveout plots in this area. In other parts of the central area of the array, stations generally have a moderate to strong amplitude direct wave and good symmetry [Figure 3.3f]. The persistent localised source phases are also present in these stations, especially at longer inter-station distances. We observe a causal relationship in virtual source move-out plots where the inter-station distance of the stationary source phase intersection with the direct phase is dependant on the distance of the virtual source from the DFDP-2B site area. As the distance increases, the inter-station distance where the intersection occurs increases [See Figure 3.3d,e and $\mathrm{f}]$.

A moderate amplitude direct wave is observed in virtual source move-out plots lo- 
cated in southern end of the array [Figure 3.3d and e]. Most plots have a weak symmetry with the strongest phase travelling towards the virtual source.

In some plots a coda-like arrival is observed at inter-station distances above $1000 \mathrm{~m}$ [Figure 3.3b, c, d and $\mathrm{f}$. The general relationship observed is that the length of the coda, defined as the difference between the maximum lag-time of the coda and the lag-time of the direct phase, tends to increase with inter-station distance [e.g. Figure 3.3c].

To investigate the signal-to-noise ratio of the CCFs and how it relates to the distribution of noise sources, we plot the signal-to-noise ratio of virtual source move-out plots in Figure 3.3 [see Section 2.1.4 for a definition of the signal-to-noise ratio]. For each move-out plot we calculate the signal-to-noise ratio of the causal and acausal component, where the axis of separation is perpendicular to the down valley axis [Figure 3.4]. Noise source direction and strength can be discriminated in terms of which hemisphere it is coming from. The strong asymmetry observed in Figure 3.3a is evident in Figure 3.4a. In stations down valley (north) of the virtual source there is very low signal-to-noise ratio in CCFs from signal travelling from the down valley direction but high signal-to-noise ratio is observed in these CCF from signal travelling from up valley (South). For stations up-valley of the virtual source, the opposite relationship holds true whereby a high signal-to-noise ratio occurs in the CCFs component for signals travelling from the virtual source to the virtual receiver [Figure 3.4a]. A decay in signal-to-noise ratio as inter-station distance increases is also observed [e.g. Figure 3.4a, c and d]. Localised bands of high signal-to-noise ratio (above 20) are observed in some virtual source move-out plots [Figure 3.4b, c and $\mathrm{f}$ ]. A common feature of these high signal-to-noise ratio bands are that they line up with the area around the DFDP-2B borehole [located near the black star in Figure 3.4a]. In general we observe higher signal-to-noise ratios in direct waves travelling from down valley; however a source within the array appears to be present. 

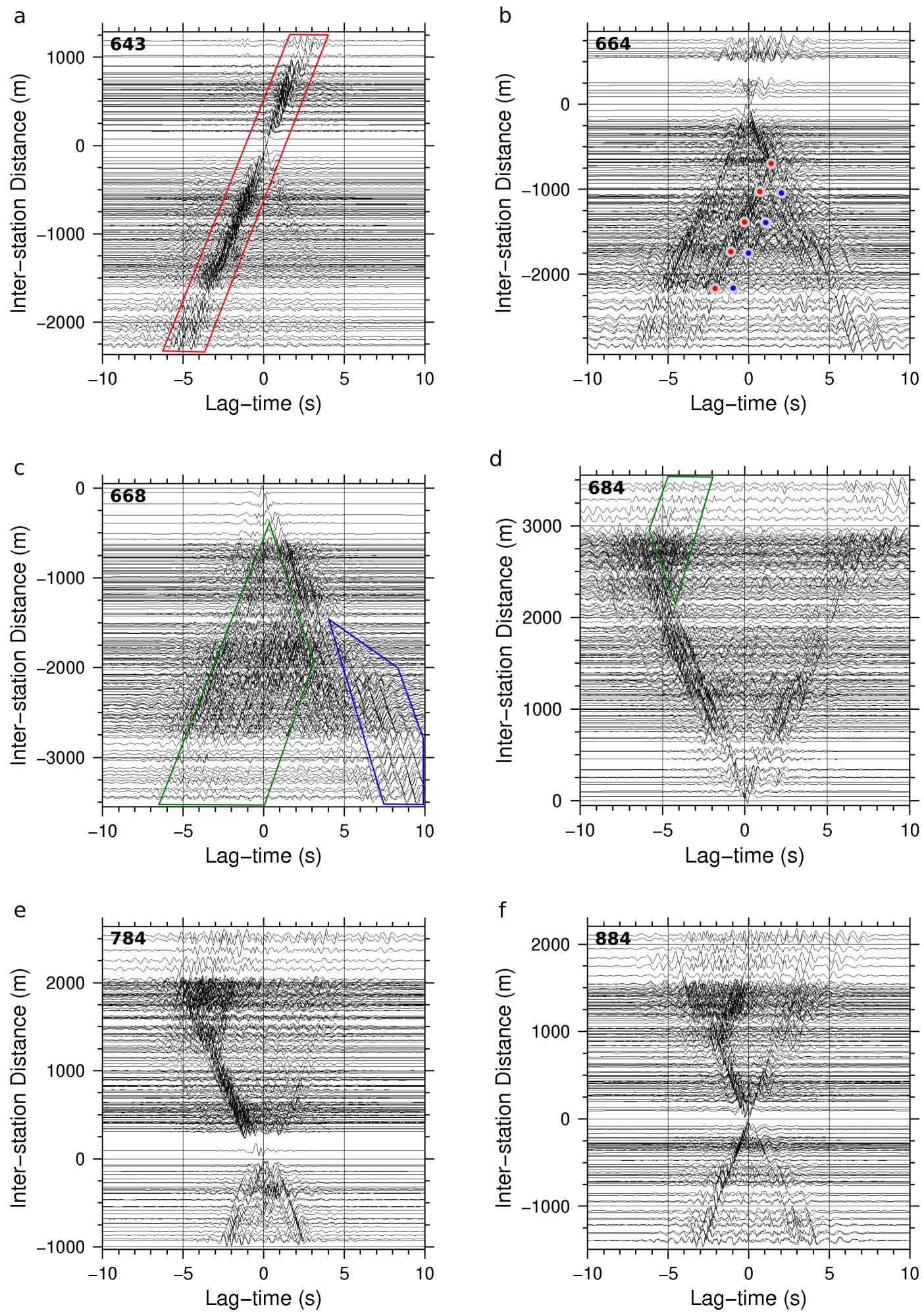

Figure 3.3: Moveout plots of station as a virtual source vs all other stations. Stations as virtual source a) 643, b) 664, c) 668, d) 684, e) 784, and f) 884. Each CCFs has been filtered with a $1 \mathrm{~Hz}$ high-pass. See Figure 3.4 for station locations. The red polygon marks the direct wave, green polygon marks the persistent localised source phases and blue polygon marks the coda. The coloured dots in b show the stationary source phase used in Figure 2.5. 

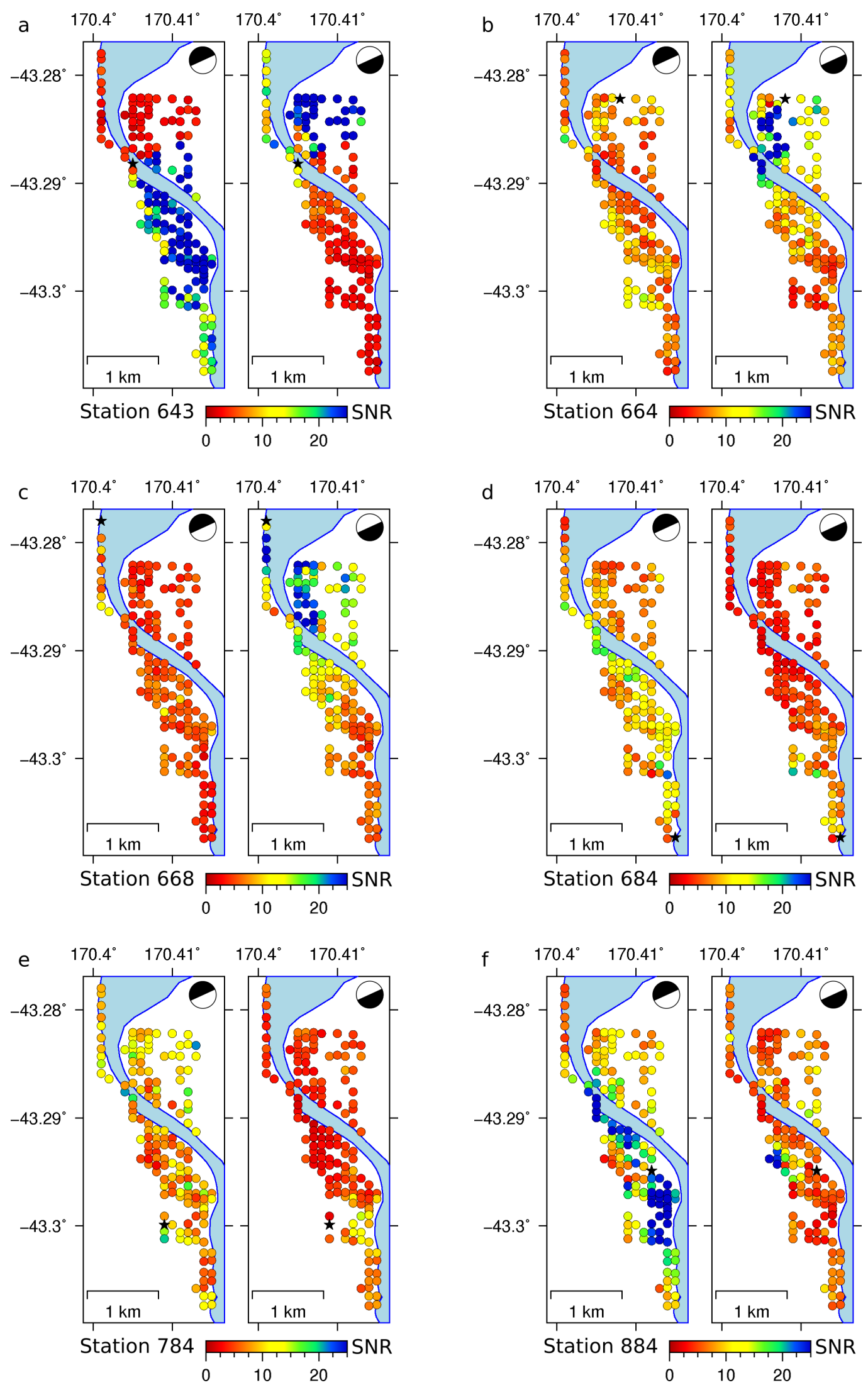

Figure 3.4: Maps of signal-to-noise ratio of stations used in Figure 3.3 as a virtual source (black star). The black half of the beachball in each figure shows the direction the potential signal sources are coming from. For example, signal propagating towards the array from a source located north of the array would be plotted on the left panel of each subplot. By splitting the potential noise source direction in half, we can delineate between signal travelling down and up the valley. 


\subsubsection{Back-projection of Cross-Correlation Functions}

Assuming a constant velocity of $450 \mathrm{~m} / \mathrm{s}$, we apply a back-projection to the CCFs to locate sources of coherent noise from within the array [see Section 2.2 for a description of this technique]. To estimate the velocity constant, we use the slope of the phase identified in Figure 3.3b with red dots. This velocity is consistent with other values observed in similar phase's from different move-out plots. Stacking virtual source back-projections contaminated by zero-crossing phase reveals a highamplitude anomaly [Figure 3.5a], which we call a persistent localised source. To further investigate the location we plot normalised amplitudes above 0.8 , a value found on the basis of trial and error to best represent the extent of the anomaly [Figure 3.5b]. We find the location occurs close to the Whataroa River. Despite evidence for more than one signal [See Figure 2.5 and 3.3b], we are only able to recover one location. Using the method outlined in Section 2.2, we construct symmetric CCFs with the stationary source removed. 

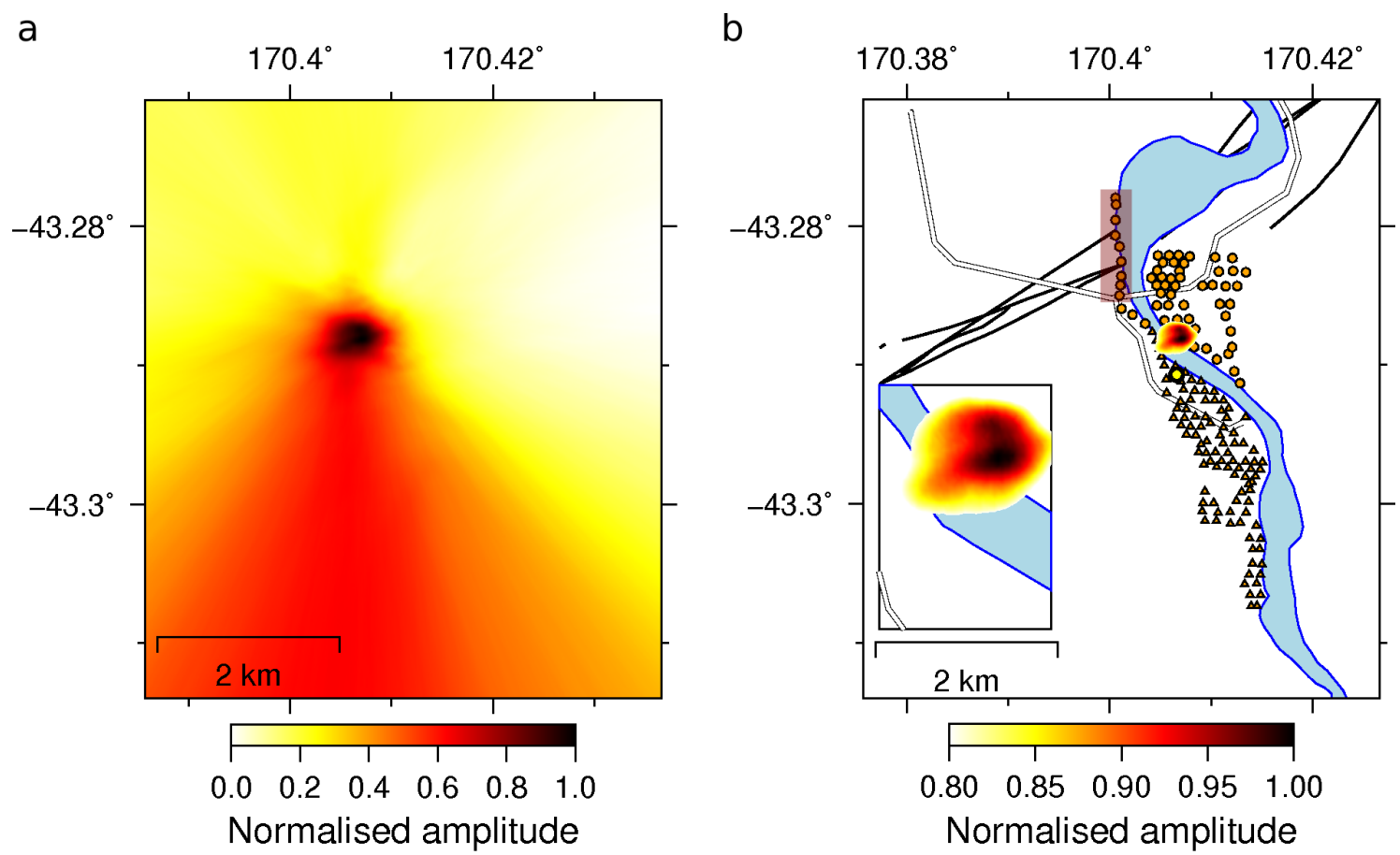

Figure 3.5: a) Back-projection of all contaminated CCFs, and b) Colour scale limited to 0.8-1.0. To better locate the anomaly; stations, the Whataroa River, roads and the Alpine Fault are plotted in (b). Stations treated as a virtual source in the back-projection are plotted as orange circles while those not used are plotted as orange triangles. The transparent red box shows poor quality stations north the road, identified in section 3.1.

\subsection{Rayleigh Wave Dispersion Curves}

After correcting for the stationary source phase, all symmetric CCFs are used to measure dispersion curves, yielding a total of 7758 dispersion curves containing 64 group and phase velocity measurements each. From DFDP-2B well logs, we assume there is a sedimentary-basement contrast within the study area (Sutherland et al., 2015). To model the effect of basement depth on Rayleigh wave dispersion we compute fundamental and first-order higher mode synthetic dispersion curves [Figure 3.6]. The Gpdc software package is used, where our input model is one-layer over a half-space, representing the sedimentary layer and the basement (http://geopsy.org/wiki/index.php/Gpdc, last accessed May 2017). We vary thickness of the first layer from 0 to $300 \mathrm{~m}$ and use a shear-wave velocity of $420 \mathrm{~m} / \mathrm{s}$ for the sedimentary layer and $1500 \mathrm{~m} / \mathrm{s}$ for the basement. A $V_{p} / V_{s}$ ratio of 1.75 is used 
to calculate compressional-wave velocity and the density is calculated using Garners equation [see Figure 2.4].

Fundamental mode dispersion of group velocity shows a large jump due to the velocity contrast in the model [Figure 3.6]. The depth of this contrast controls the period where the jump occurs. A decrease in velocity at periods shorter than the jump period is observed which is consistent with simplified theoretical group velocity models (Stein and Wysession, 2009). Fundamental mode phase velocity dispersion shows a less abrupt increase in velocity than group dispersion although the period where the increase occurs also increases with basement depth [Figure 3.6]. Highermode dispersion is more complex, especially group velocity where rapid increases and decreases in velocity are separated by a constant velocity whose period appears to be controlled by basement depth. Phase dispersion for the first higher mode has a higher degree of similarity to the fundamental mode than group velocity does. The main difference between phase dispersion modes is that the fundamental mode shows an exponential increase in velocity and the first-order mode is cubic-like. The model with no overlying sediment [marked as 0 in Figure 3.6] is not present in higher mode group and phase velocity curves as there is no dispersion in a homogeneous half-space (Stein and Wysession, 2009). 
a

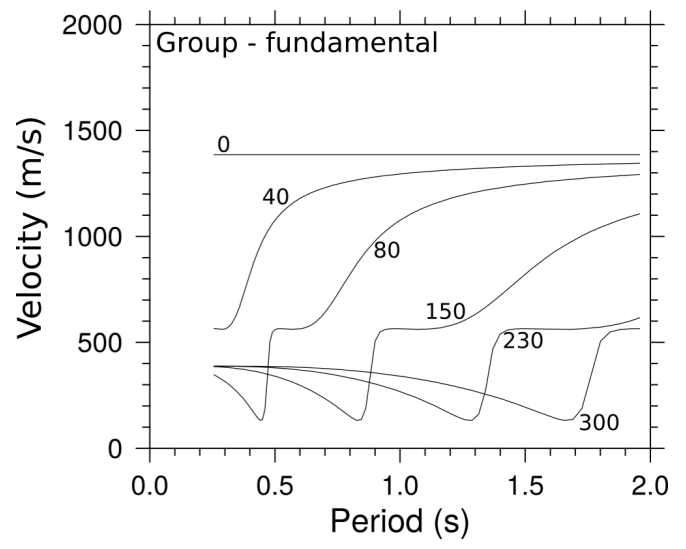

C

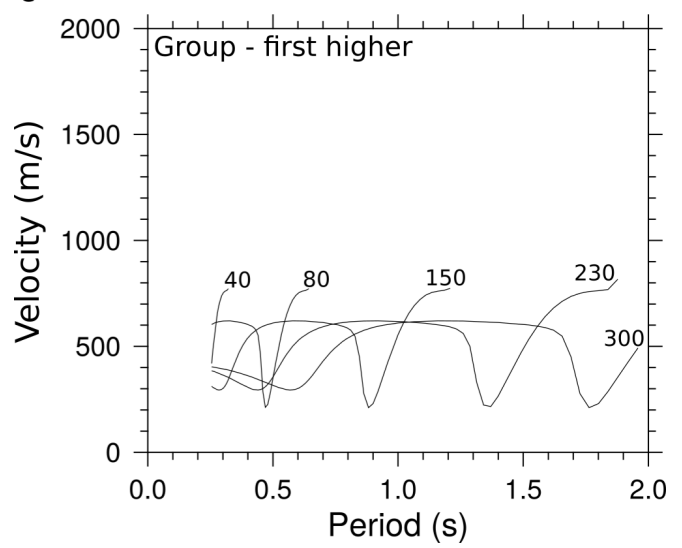

b

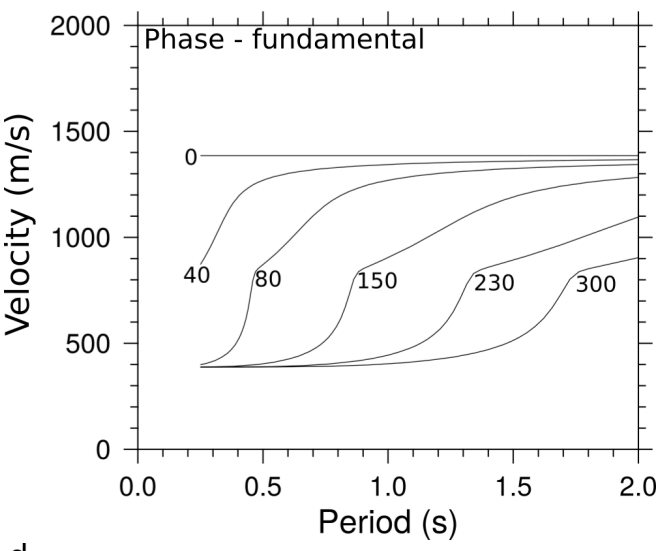

d

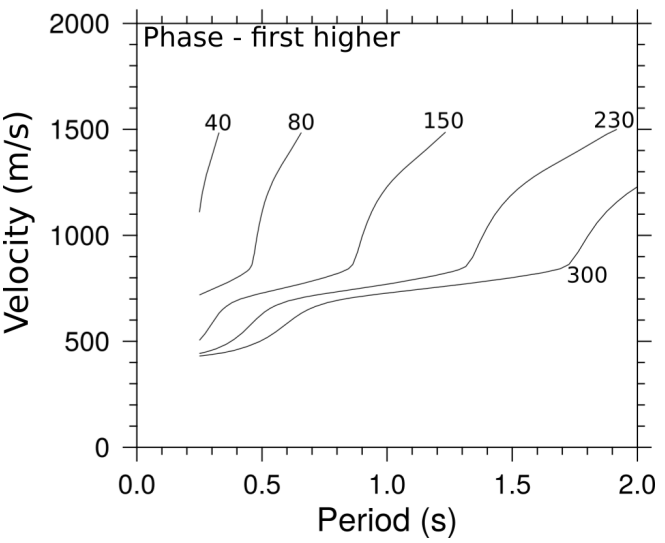

Figure 3.6: Synthetic Rayleigh wave dispersion curves a) group velocity - fundamental mode, b) phase velocity - fundamental mode, c) group velocity dispersion - first order higher mode, and d) phase velocity - first order mode. Individual curve labels specify the depth in meters at which the velocity contrast occurs, representing the basement contact.

A selection of individual station pair dispersion curves, representing different raypaths, is plotted in Figure 3.7 [see Figure 3.8 for ray paths]. Clean dispersion measurements from station pairs with a shorter inter-station distances are observed, allowing a broad range of azimuths due to the shorter periods of the surface wave train [Figure 3.7a and b]. Measurements from station pairs with an inter-station distance less than $1000 \mathrm{~m}$ generally have group velocities of 400-600 m/s and phase velocities of $600-800 \mathrm{~m} / \mathrm{s}$.

Dispersion measurements are also obtained from station pairs with inter-station distances of between 1000 and $2000 \mathrm{~m}$ [Figure 3.7c and d]. Both station pairs have a clear mode with an amplitude between 97 and $100 \mathrm{~dB}$ for the picked dispersion curve. Another mode may also be present at higher velocities, although the energy 
of the amplitude is lower at 90 to $97 \mathrm{~dB}$.

Longer periods are observed for station pairs with an inter-station distance greater than $2000 \mathrm{~m}$, reaching up to $2.0 \mathrm{~s}$ for group velocity in Figure 3.7e and f. Group velocities of up to $800 \mathrm{~m} / \mathrm{s}$ are observed in station pairs 670-785 and 672-690 [Figure $3.7 \mathrm{~d}$ and $\mathrm{f}]$. Higher phase velocities are also observed, with measurements up to $1700 \mathrm{~m} / \mathrm{s}$ observed at longer periods [Figure 3.7e]. 

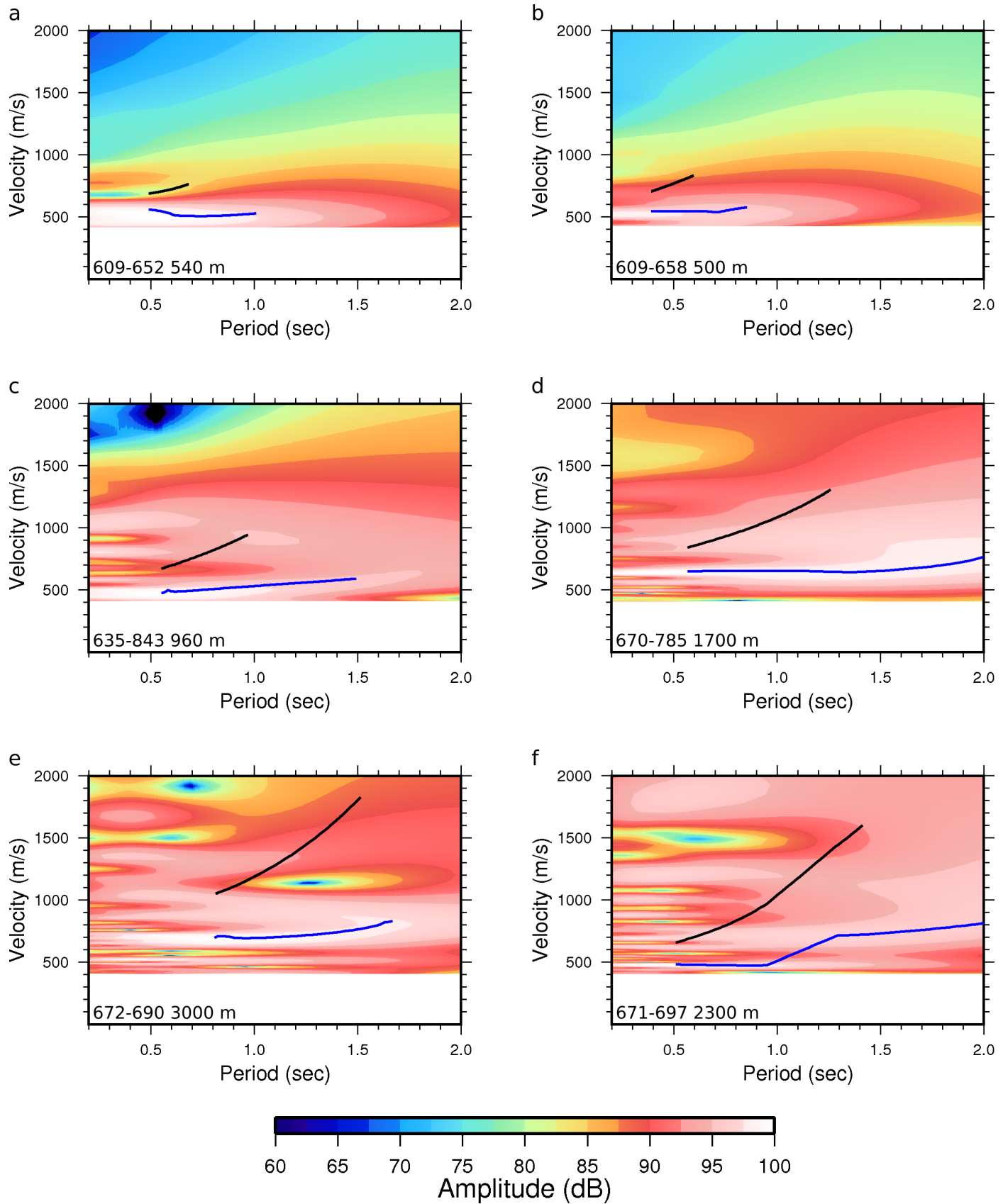

Figure 3.7: Rayleigh wave group (blue) and phase (black) velocity dispersion curves from individual station pairs a) 609-652, b) 609-658, c) 635-843, d) 670-785, e) 672690, and f) 671-697. A Selection criteria of 1 wavelength and a signal-to-noise ratio minimum of 10 is applied to all measurements. See Figure 3.8 for ray-path locations.

We apply selection criteria of one wavelength and a Signal to Noise Ratio (SNR) minimum of 15 to all dispersion curves, resulting in 5981 group and 4560 phase velocity dispersion curves [Figure 3.9a and b]. Group velocity measurements show a range of velocities of between 400 to $2000 \mathrm{~m} / \mathrm{s}$ and period ranges from 0.3 to $2.0 \mathrm{~s}$. Phase velocity measurements generally have a higher velocity than group velocity with a maximum velocity of $2500 \mathrm{~m} / \mathrm{s}$ observed. The maximum period observed is 
shorter than that of the group velocity at $1.5 \mathrm{~s}$, as expected due to the minimum wavelength criteria applied. A strong velocity variation is observed in group and phase velocity measurements [Figure 3.9a and b].

The broad range in group velocity values suggest the persistent localised source phase(s) has not been completely removed from the data [see Section 2.2]. To test this, we remove all dispersion measurements that use any station located in the northern part of the array [defined as grey triangles in Figure 3.8]. The total number of group and phase velocity measurements reduces to 2952 [Figure 3.9c] and 2260 [Figure 3.9d] respectively; we hereby call this the sub-array [Figure 3.8]. There is a clear in reduction in the variation of velocities observed, suggesting that persistent localised source phases remain in symmetric CCF. 


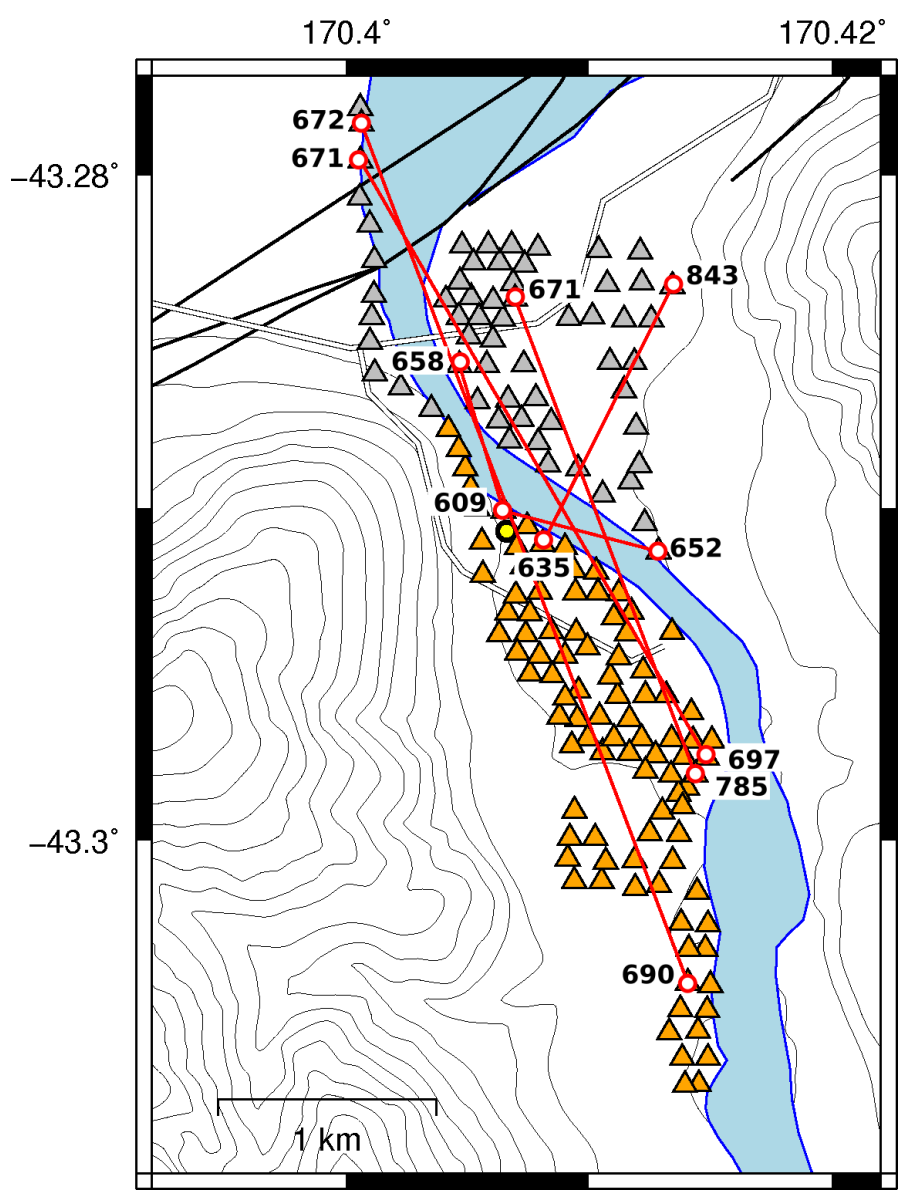

Figure 3.8: Map of station paths used in Figure 3.7 [red lines]. Triangles with orange fill are stations used in the sub-array and grey fill are rejected stations. The Whataroa River, roads, Alpine Fault surface trace, DFDP-2B and $50 \mathrm{~m}$ topographic contours are marked in blue, white/black, thick black, yellow and thin black colours respectively. 
a

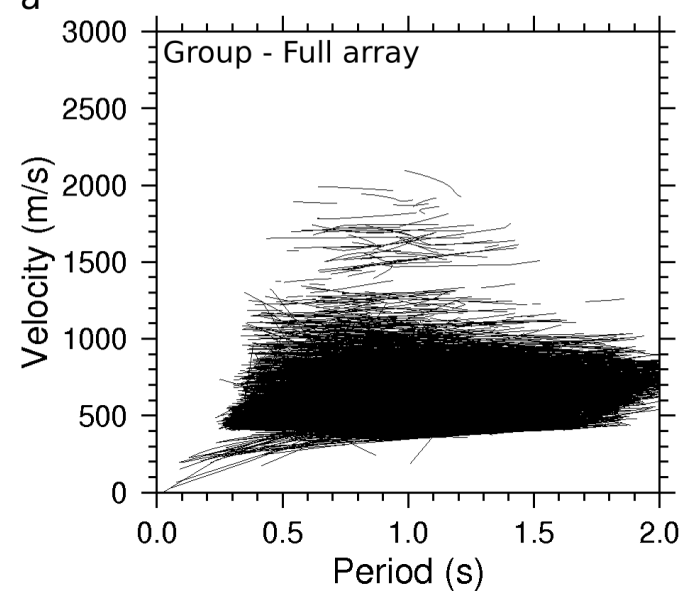

b

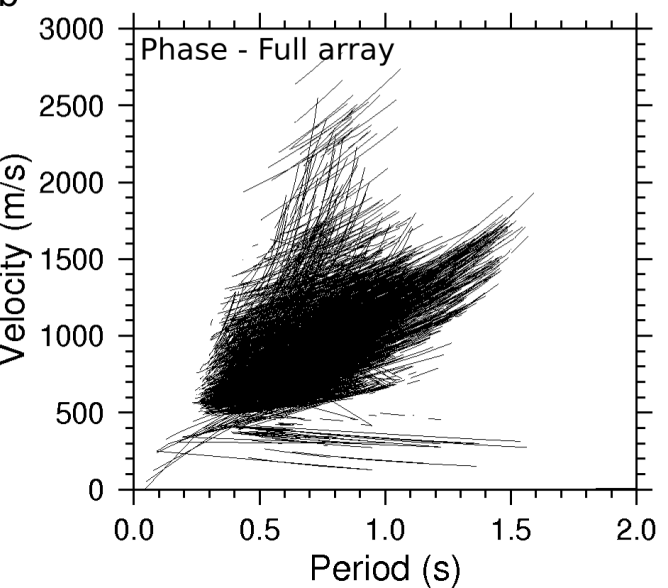

C

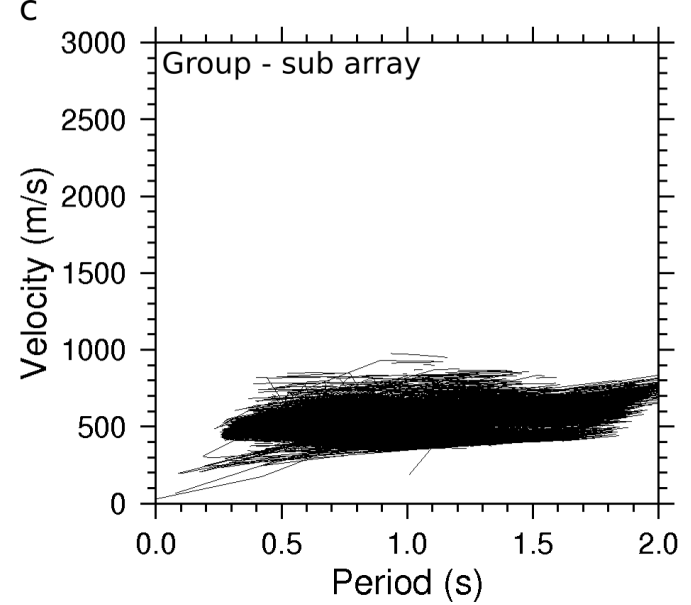

d

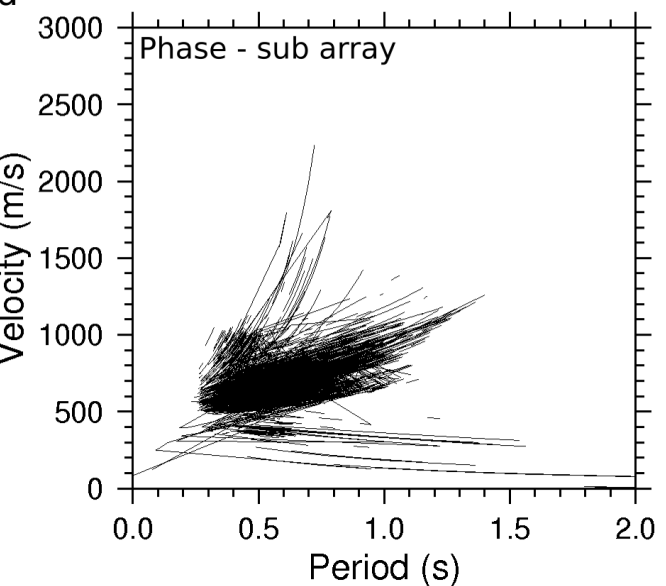

Figure 3.9: Rayleigh wave group and phase velocity dispersion curves a) group velocity - full array, b) phase velocity - full array, c) group velocity - sub array, and d) phase velocity - sub array. A selection criteria of one wavelength and a minimum SNR of 15 is applied. The top panels are measurements from the full array and the bottom panels are taken from station pairs not contaminated by noise from the river [see Figure 3.5].

There is a reduction in steep phase dispersion curves between the full-array and the sub-array, although a number still remain [Figure 3.9]. We test for cycle skipping in phase velocity measurements by plotting travel time vs. inter-station distance [Figure 3.10]. Cycle skipping will introduce a $2 \pi N$ error when the phase velocity reference curve used to calculate the number of wave cycles, $N$ in Equation 2.6, varies from the actual values Lin et al. (2008). As we only use one reference curve, and show through synthetics that variation in basement depth results in different dispersion curves [Figure 3.6b], it is important to test for cycle skipping. A clear lin- 
ear trend is observed in dispersion measurements from the sub-array [Figure 3.10b]. This trend is less clear in measurements from the entire array [Figure 3.10a], with a high degree of scattering linked to the high velocity measurements observed in Figure $3.9 \mathrm{a}$ and $\mathrm{b}$. The parallel branch structure of measurements of a similar slope to the main branch step out at near equal intervals of $0.6 \mathrm{~s}$, suggesting these measurements have a $2 \pi N$ error [Figure $3.10 \mathrm{~b}$ ].
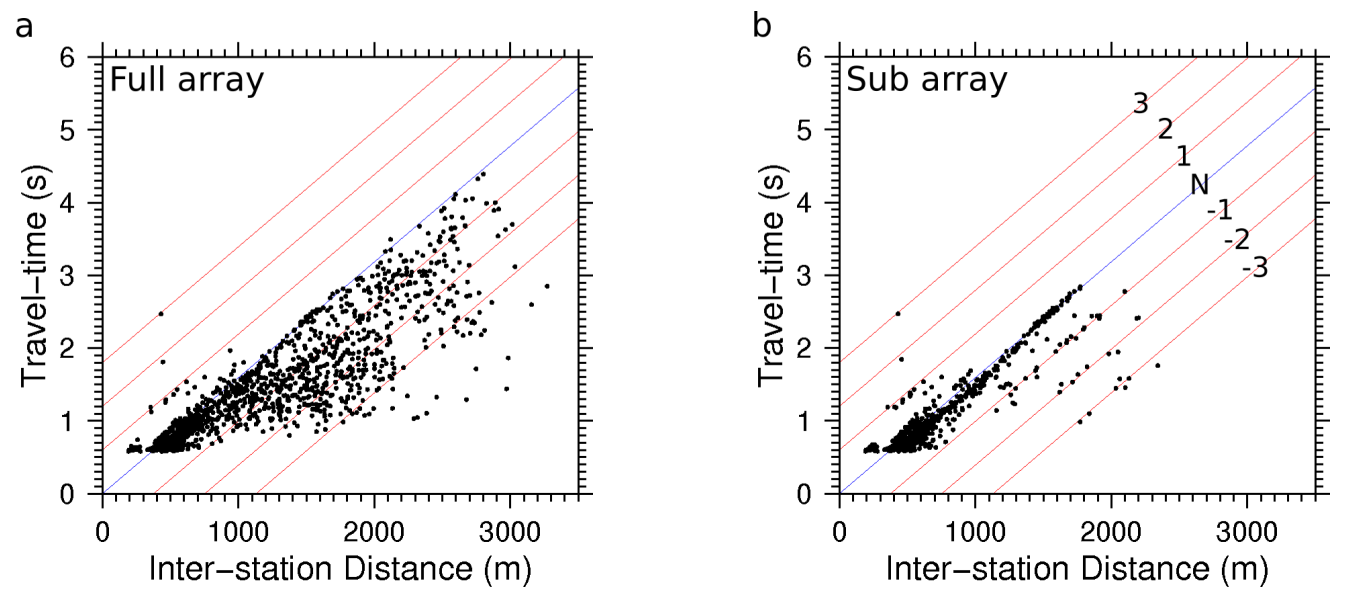

Figure 3.10: Travel-time vs. interstation distance plot of all period measurements at $0.6 \mathrm{~s}$ period a) full array, and b) sub-array. The red lines are plotted at $0.6 \mathrm{~s}$ increments, showing the correct number of cycles $N$ [blue line in figure] plus $x$, where $x$ is $\pm 1,2,3$ the number of cycles skipped.

\subsection{Rayleigh Wave Velocity Maps}

Straight ray travel-time tomography is applied to discrete phase and group dispersion curve measurements from 0.3 to $1.0 \mathrm{~s}$ period and 0.3 to $1.8 \mathrm{~s}$ period respectively. We do not interpolate between measurements to recover the desired period and instead only select dispersion measurements that are within $0.02 \mathrm{~s}$ of the stated period. Due to the ambiguity of dispersion curve measurements using the full array [see Figure 3.10a], only dispersion curves from the sub-array are used for tomography. Stations used in the sub-array are marked as orange triangles in Figure 3.8 and rejected stations are marked as grey triangles. Measurements with cycle skipping are removed from phase measurements as we have enough path coverage in the cycle skipping range of 0.4 to $0.8 \mathrm{~s}$ period. A maximum period of $1.0 \mathrm{~s}$ is used for phase 
velocity tomography as there are not enough measurements for complete ray-path coverage at higher periods. Due to slower velocities, group tomography can be extended to $1.8 \mathrm{~s}$ period while maintaining good ray-path coverage. From here on, we refer to the area covered by the sub-array as the study area.

\subsubsection{Resolution}

Resolution of the tomography results was tested using checkerboard tests for phase [Figure 3.11] and group [Figure 3.12] velocities. We also plot ray path density and azimuth coverage for each tomography cell. A two-velocity model is used in the checkerboard tests with a low velocity of $600 \mathrm{~m} / \mathrm{s}$ and high velocity of $900 \mathrm{~m} / \mathrm{s}$ in $200 \mathrm{~m}$ cells [Figure 3.11a].

Phase velocity checkerboard tests resolved velocities with a higher degree of accuracy in the centre of the valley [Figure 3.11]. Increased smearing and damping occurs towards the outer edge of the study area [Figure 3.11]. At $0.3 \mathrm{~s}$ period the input velocity is poorly recovered with only 3 cells resolved in the centre of the study area [Figure 3.11b]. The recovered cells are also smeared in a north-west/south-east direction [Figure $3.11 \mathrm{~b}$ ]. At 0.5 and $0.9 \mathrm{~s}$ period the centre of the study area is well resolved with evidence of a small degree of velocity damping [Figure 3.11c and d]. A small degree of north-west/south-east smearing in the centre of the study area is evident in both 0.5 and $0.9 \mathrm{~s}$ period tests. The outer edges of the 0.5 and $0.9 \mathrm{~s}$ period models are poorly resolved, particularly at the southern extent of the study area.

The best resolved test for group velocity is at $1.3 \mathrm{~s}$ period, with a small degree of smearing and damping in the centre of the study area, increasing towards the outer edges [Figure 3.12d]. Compared to phase velocity tests [Figure 3.11], the $1.3 \mathrm{~s}$ period is able to resolve more of the input model in the southern part. The $0.3 \mathrm{~s}$ period test is poorly recovered with only two cells resolved, and high degrees of damping and smearing occur in a north-west/south-east direction [Figure 3.12a]. The $0.5 \mathrm{~s}$ period 
group velocity test [Figure 3.12b] appears as well resolved as the $0.5 \mathrm{~s}$ period phase velocity test [Figure $3.11 \mathrm{c}$ ]. $0.9 \mathrm{~s}$ period is better resolved than $0.5 \mathrm{~s}$ period but still has a small degree of north-west/south-east direction smearing [Figure 3.12c].

The best ray-path coverage occurs at $0.5 \mathrm{~s}$ period for phase velocity [Figure 3.13b] and $0.9 \mathrm{~s}$ period for group velocity [Figure 3.13f]. All maps show low path densities at the edges of the study area, with density increasing towards the centre. Phase velocity path coverage at $0.3 \mathrm{~s}$ period is very low in the south of the study area, but path density increases up to 100 paths per cell in the north of the study area [Figure $3.13 \mathrm{a}]$. At 0.5 and $0.9 \mathrm{~s}$ periods, the distribution of paths is less skewed than at $0.3 \mathrm{~s}$ period and is centred in the middle of the study area for both phase and group velocity [Figure $3.13 \mathrm{~b}, \mathrm{c}, \mathrm{e}, \mathrm{f}]$. The phase velocity at $0.5 \mathrm{~s}$ period reaches a density of 150 paths per cell in the centre, in comparison to the $0.3 \mathrm{~s}$ period, fewer ray paths are located in the northern area. At $0.9 \mathrm{~s}$ period, phase velocity has the poorest ray path density with a density of less than 50 for much of the area [Figure 3.13c]. $0.3 \mathrm{~s}$ period for group velocity shows the same increase in path density in the north as the phase $0.3 \mathrm{~s}$ period, however path density for group peaks at 100 [Figure 3.13d]. The peak in path density of $0.5 \mathrm{~s}$ period group velocity moves south compared to $0.3 \mathrm{~s}$ period, occurring in the centre of the study area, reaching 150 at its peak [Figure 3.13e]. Group velocity at $0.9 \mathrm{~s}$ period has the highest path density which is greater than 200 in the centre and reduces to 20 around the edges [Figure 3.13f]. 

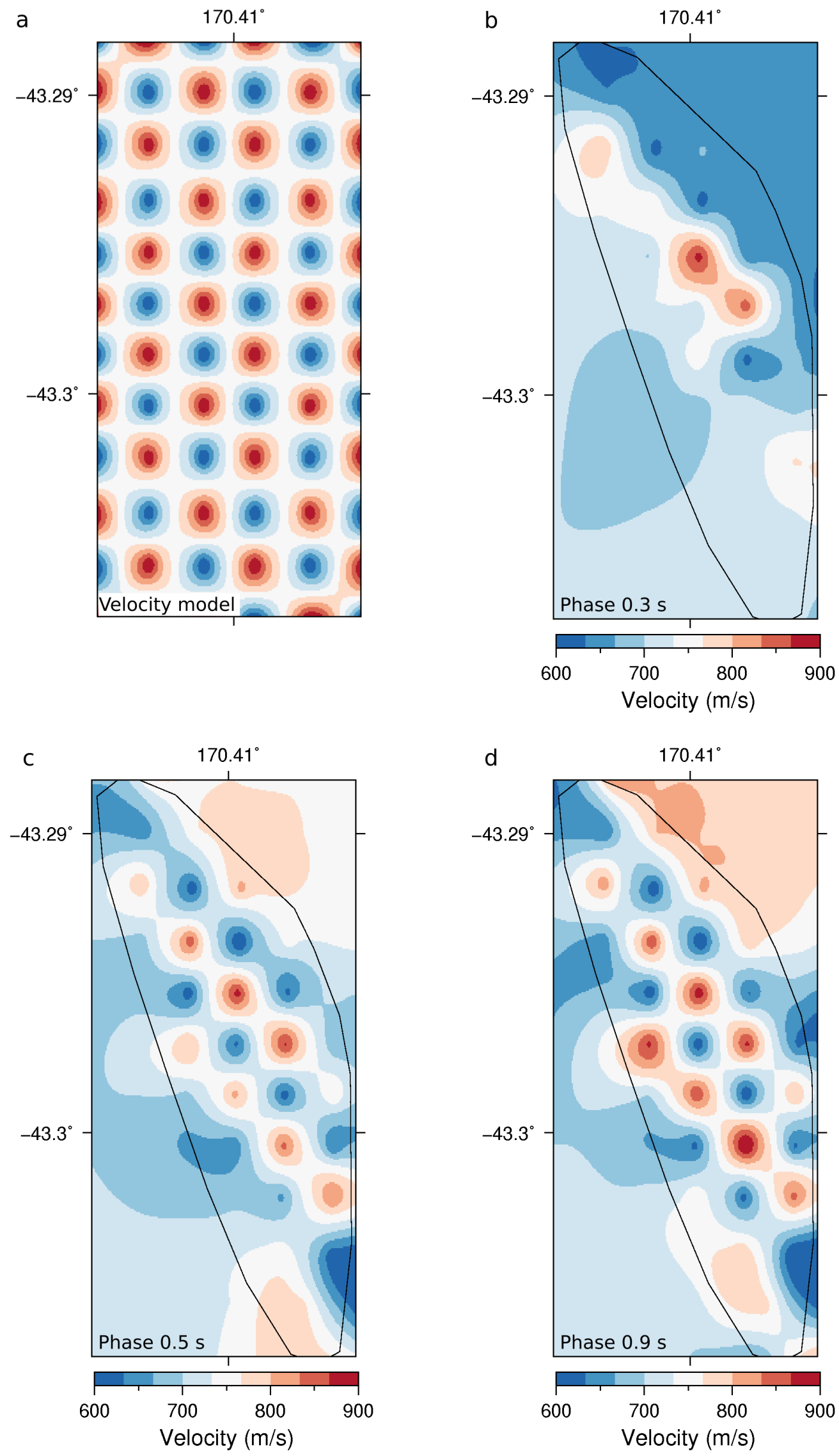

Figure 3.11: Rayleigh wave phase velocity checkerboard test a) input velocity model - blue is $600 \mathrm{~m} / \mathrm{s}$ and red is $900 \mathrm{~m} / \mathrm{s}$, b) 0.3, c) 0.5, and d) $0.9 \mathrm{~s}$ period. The black polygon shows the bounds of the tomography model. 

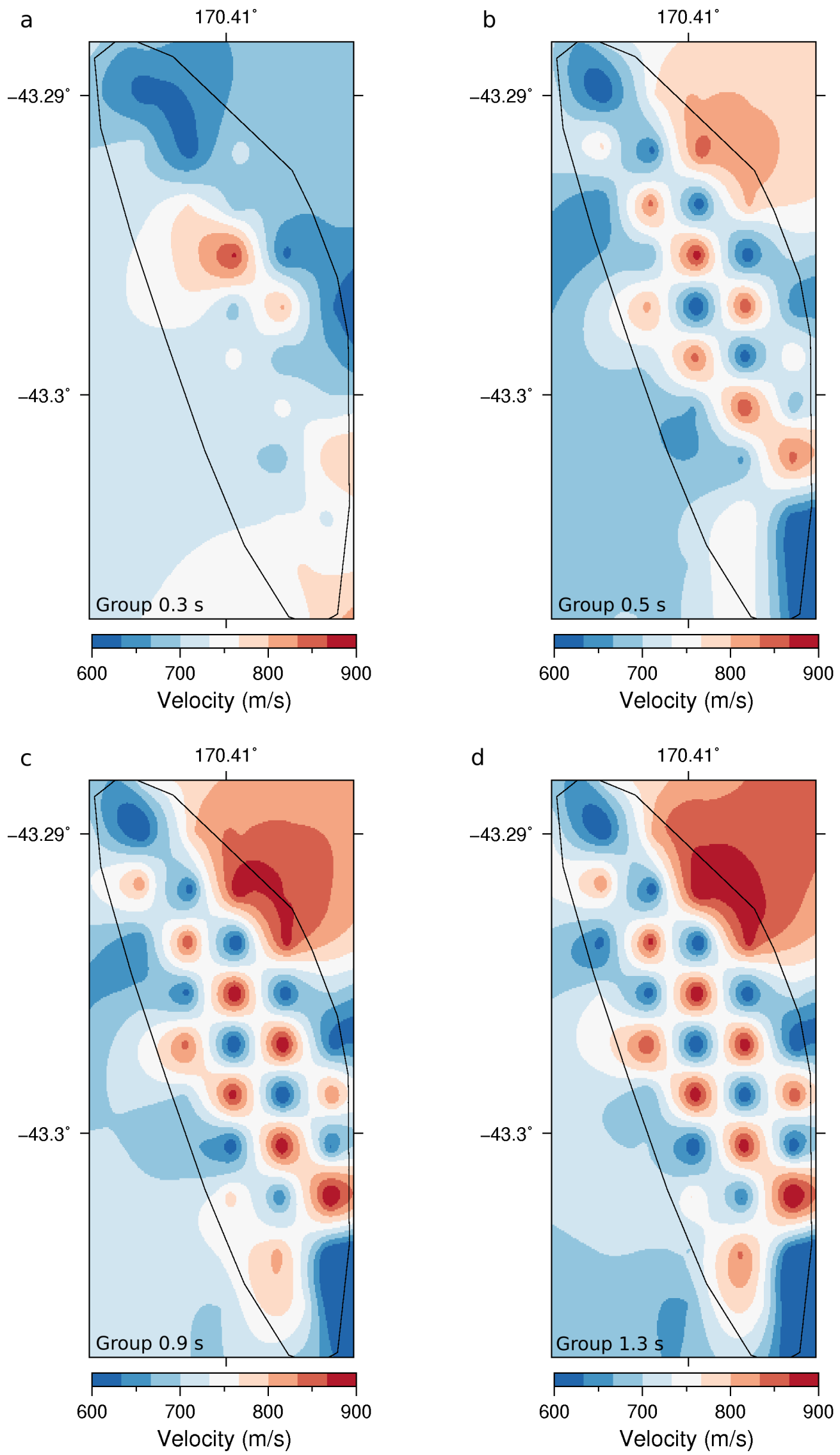

Figure 3.12: Rayleigh wave group velocity checkerboard test a) 0.3 , b) 0.5 , c) 0.9 , and d) $1.3 \mathrm{~s}$ period. The input velocity model used is shown in Figure 3.11. The black polygon shows the bounds of the tomography model. 

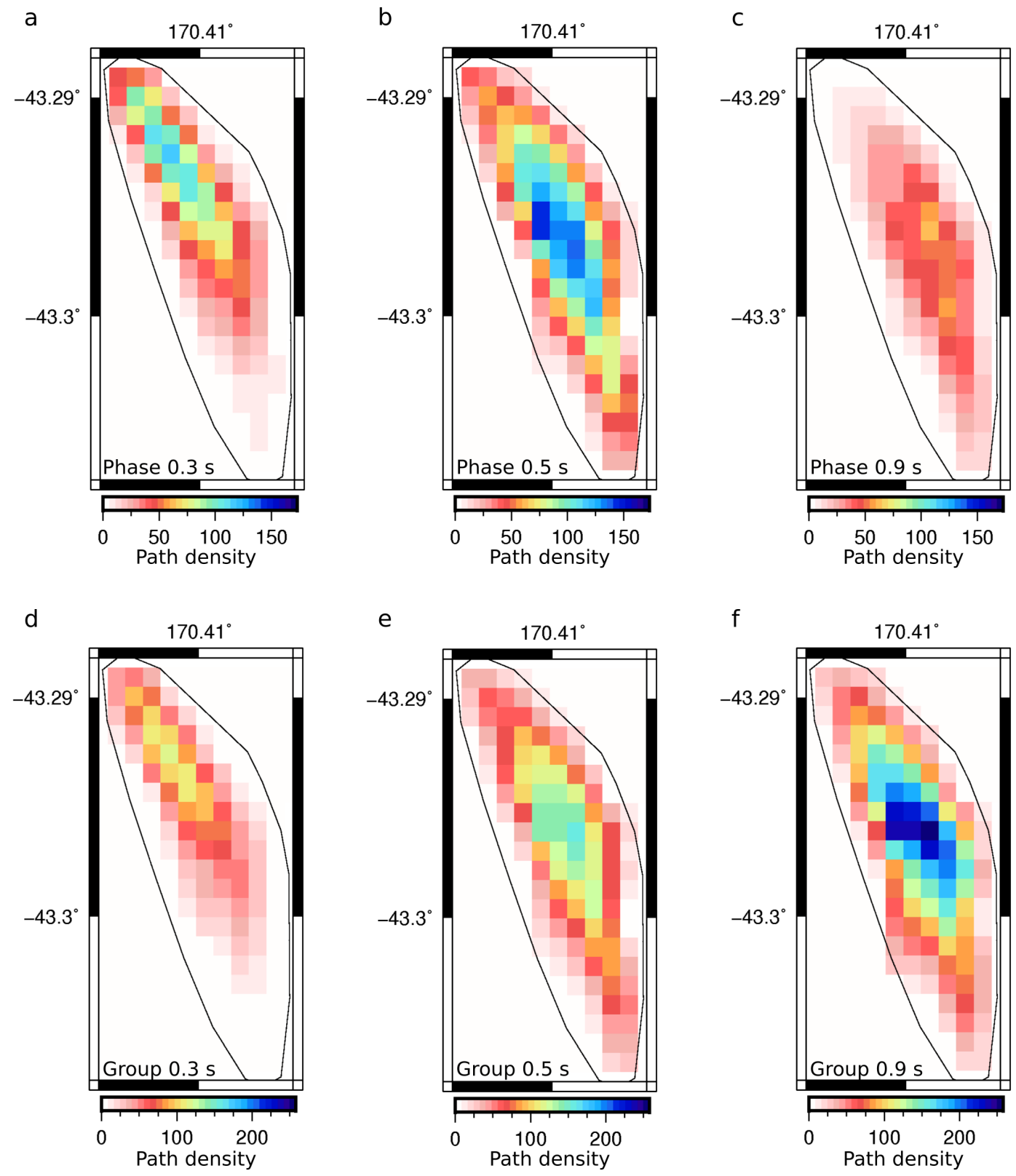

Figure 3.13: Rayleigh wave phase and group velocity tomography path density a) phase velocity $-0.3 \mathrm{~s}, \mathrm{~b})$ phase velocity $-0.5 \mathrm{~s}, \mathrm{c}$ ) phase velocity $-0.9 \mathrm{~s}, \mathrm{~d}$ ) group velocity $-0.3 \mathrm{~s}, \mathrm{e})$ group velocity $-0.5 \mathrm{~s}$, and f) group velocity $-0.9 \mathrm{~s}$. The black polygon shows the bounds of the tomography model.

The best azimuthal coverage occurs at a period of $0.5 \mathrm{~s}$ for both the phase and group velocities [Figure 3.14b and e]. Both maps show coverage increasing towards the centre of the study area, where in two patches north and south of the centre, values reach almost $100 \%$ coverage. The $0.3 \mathrm{~s}$ period for both velocities shows blanket coverage of around 25\% [Figure $3.14 \mathrm{a}$ and $\mathrm{d}$ ]. For the $0.9 \mathrm{~s}$ period, the phase velocity reaches just under $50 \%$ coverage in the centre while the group reaches $80 \%$ in isolated cells [Figure 3.14c and f]. 

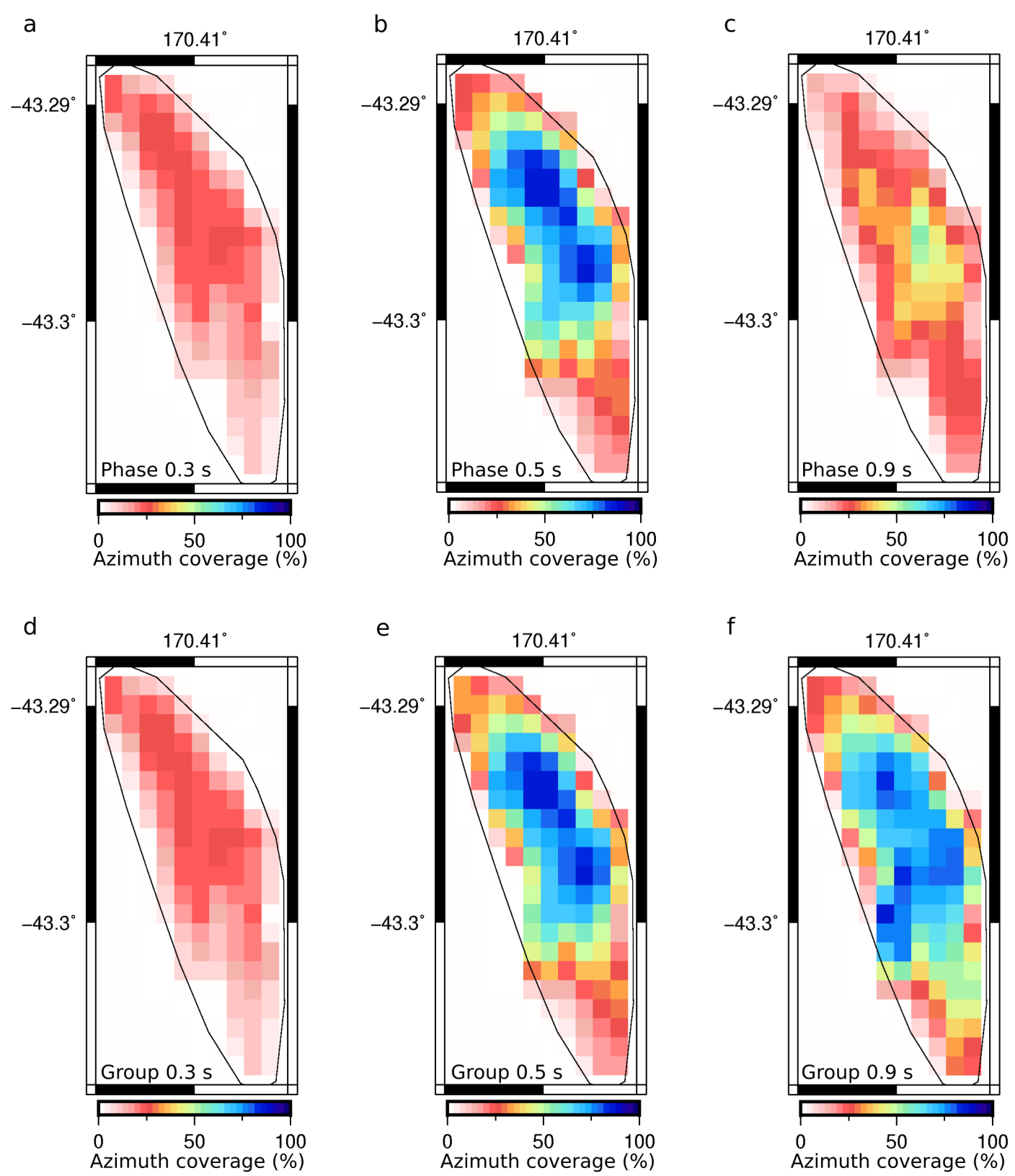

Figure 3.14: Rayleigh wave phase and group velocity tomography azimuth coverage a) phase velocity $-0.3 \mathrm{~s}, \mathrm{~b}$ ) phase velocity $-0.5 \mathrm{~s}$, c) phase velocity $-0.9 \mathrm{~s}, \mathrm{~d}$ ) group velocity $-0.3 \mathrm{~s}$, e) group velocity $-0.5 \mathrm{~s}$, and f) group velocity - $0.9 \mathrm{~s}$. Azimuth calculated using $10^{\circ}$ bins and is plotted as a percentage where $100 \%$ corresponds to $180^{\circ}$ coverage. The black polygon shows the bounds of the tomography model.

\subsubsection{Velocity Maps}

As period increases, Rayleigh wave phase velocity also increases [Figure 3.15]. At $0.3 \mathrm{~s}$ period phase velocity is $600 \mathrm{~m} / \mathrm{s}$, with the exception of an area of increased phase velocity from the DFDP-2B borehole westward, where velocity is $700 \mathrm{~m} / \mathrm{s}$ 
[Figure 3.15a]. As the period increases a gradient of increasing velocity becomes apparent from the centre of the valley toward the valley walls [e.g. Figure 3.15b]. At the $0.7 \mathrm{~s}$ period, the largest range in velocity was found, with a peak in the northwestern side at $1100 \mathrm{~m} / \mathrm{s}$, while the centre of the valley is $700 \mathrm{~m} / \mathrm{s}$ [Figure 3.15c]. At this period the velocity only appears sensitive to the western valley wall. In contrast, at a period of $0.9 \mathrm{~s}$ the velocity begins to reflect both sides of the valley [Figure $3.15 \mathrm{c}$ and $\mathrm{d}$ ]. At $0.9 \mathrm{~s}$ period a low velocity region localises in the centre of the valley [Figure 3.15d]. Velocity peaks at $1100 \mathrm{~m} / \mathrm{s}$ along the western valley wall and decreases to $900 \mathrm{~m} / \mathrm{s}$ towards the east [Figure $3.15 \mathrm{~d}$ ].

Group velocity maps show a smaller increase in velocity with increasing period compared to phase velocity. Velocities observed in periods less than $1 \mathrm{~s}$ are in the range of 400 to $650 \mathrm{~m} / \mathrm{s}$ [Figure 3.16]. At $0.3 \mathrm{~s}$ period the velocity across the whole valley is $400 \mathrm{~m} / \mathrm{s}$, except for a slight increase to $450 \mathrm{~m} / \mathrm{s}$ in the north-western corner [Figure 3.16a]. At the $0.5 \mathrm{~s}$ period, two lobes of low velocity appear at the valley floor with areas parallel to the valley walls increasing to $550 \mathrm{~m} / \mathrm{s}$ [Figure 3.16b]. The velocity from the borehole to the west increases to $600 \mathrm{~m} / \mathrm{s}$ while the high velocity area in the north-west increases to $650 \mathrm{~m} / \mathrm{s}$ [Figure 3.16b]. At $0.7 \mathrm{~s}$ period both low velocity lobes decrease in extent, the southern lobe maintains a velocity of $650 \mathrm{~m} / \mathrm{s}$ and is greatly reduced in extent, while the northern lobe increases to $600 \mathrm{~m} / \mathrm{s}$ and is marginally reduced in size [Figure 3.16c]. A south-east to north-west gradient exists from $650 \mathrm{~m} / \mathrm{s}$ in the centre of the valley to $700 \mathrm{~m} / \mathrm{s}$ in the north west corner [Figure 3.16c]. At $0.9 \mathrm{~s}$ period the velocity at the center of the valley is $650 \mathrm{~m} / \mathrm{s}$ and increases to $780 \mathrm{~m} / \mathrm{s}$ towards to the valley walls [Figure $3.16 \mathrm{~d}$ ].

Group velocity periods greater than $1 \mathrm{~s}$ (1.1 and $1.3 \mathrm{~s})$ have the largest range in velocity [Figure 3.17a and b]. From the centre of valley to the western edge, an increase of $500 \mathrm{~m} / \mathrm{s}$ is observed [Figure $3.17 \mathrm{a}$ and b]. At $1.1 \mathrm{~s}$ period this velocity increase is distributed more evenly towards the valley walls, while at $1.3 \mathrm{~s}$ period this increase occurs over a shorter distance around the area of the borehole [Figure 3.17a 
and b]. At 1.5 and $1.7 \mathrm{~s}$ period the velocity range decreases to $200 \mathrm{~m} / \mathrm{s}$, with both periods peaking at $700 \mathrm{~m} / \mathrm{s}$ in the north-western corner [Figure $3.17 \mathrm{c}$ and $\mathrm{d}$ ].

The velocity maps show a trend of lower velocity at the centre of the valley with higher velocities occurring in the north-western corner and towards the valley walls. The group velocity peaked at $900 \mathrm{~m} / \mathrm{s}$ (1.1 and $1.3 \mathrm{~s}$ period) while phases velocity peaked at $1100 \mathrm{~m} / \mathrm{s}(0.7 \mathrm{~s})$. The lowest velocity found in group velocity measurements was $400 \mathrm{~m} / \mathrm{s}(0.3 \mathrm{~s}$ period) and $600 \mathrm{~m} / \mathrm{s}$ for phase velocity $(0.3 \mathrm{~s}$ period). The phase velocities were overall higher than the group velocity. A change in velocity gradient is observed parallel to the valley walls [e.g. Figure 3.17b]. 

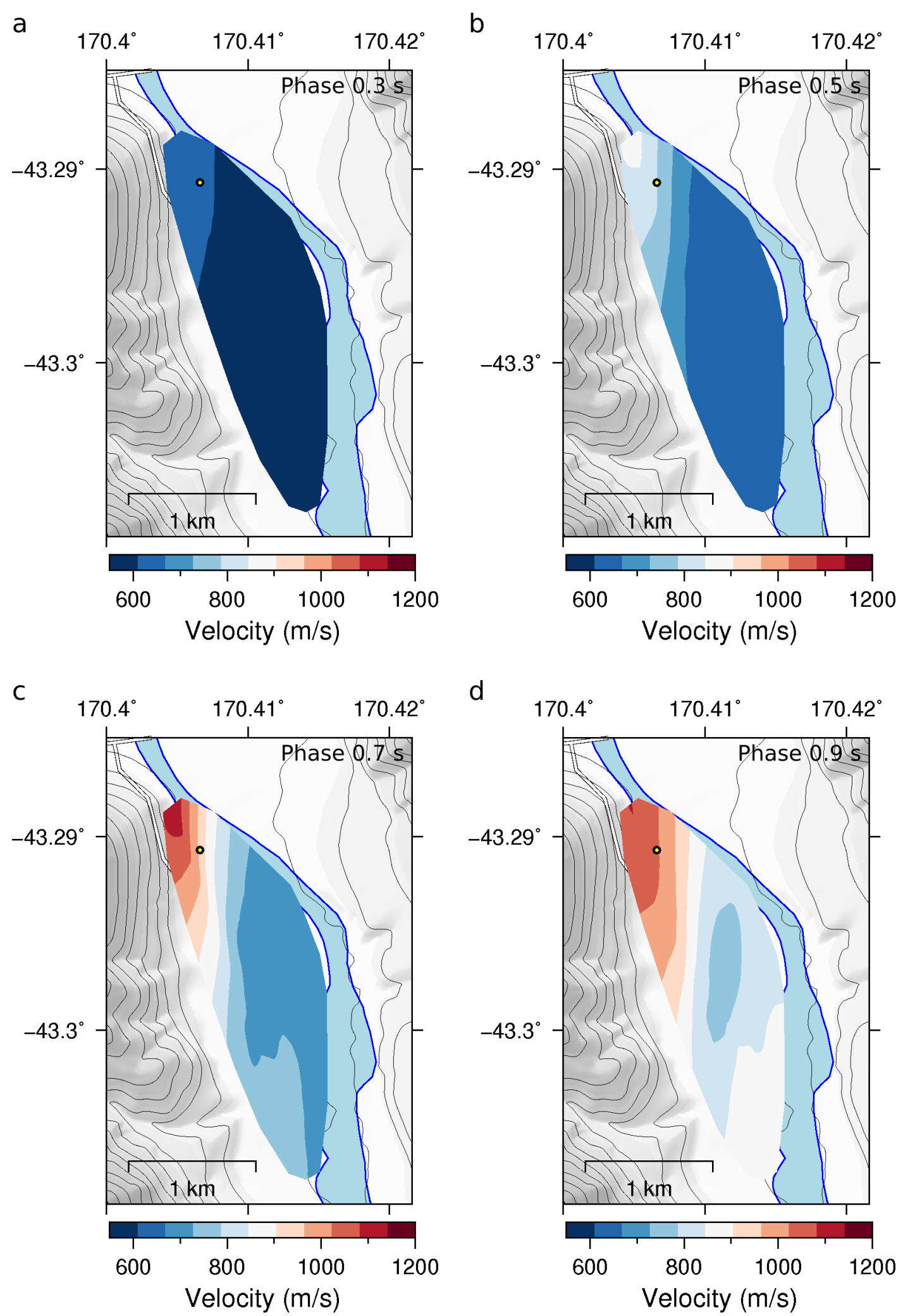

Figure 3.15: Rayleigh wave phase velocity maps a) $0.3 \mathrm{~s}$, b) $0.5 \mathrm{~s}$, c) $0.7 \mathrm{~s}$ and d) $0.9 \mathrm{~s}$. The Whataroa River is plotted in blue, roads are plotted in white and DFDP-2B marked as a yellow dot. The topographic contours are spaced at $50 \mathrm{~m}$. 

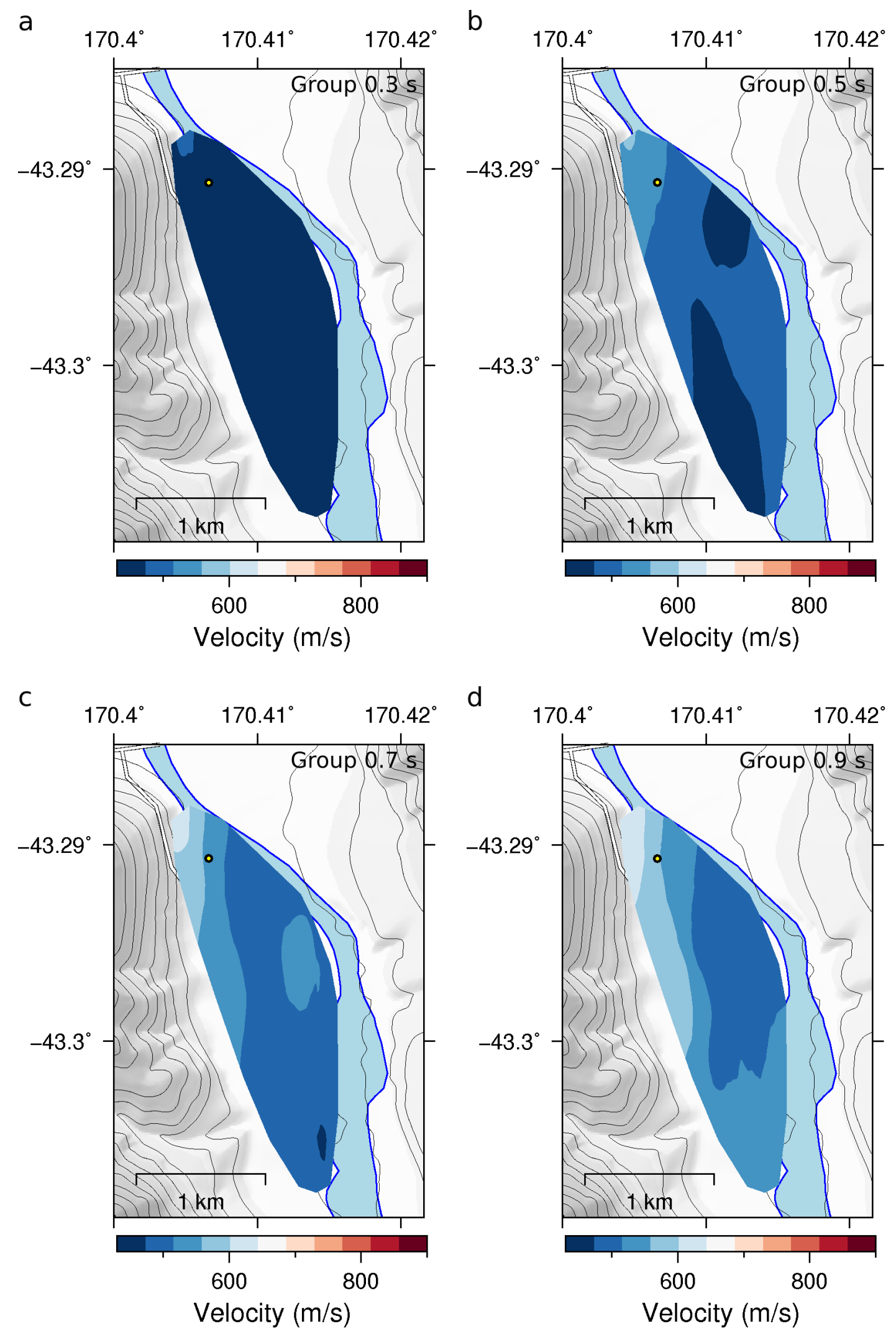

Figure 3.16: Rayleigh wave group velocity maps a) $0.3 \mathrm{~s}, \mathrm{~b}) 0.5 \mathrm{~s}, \mathrm{c}$ ) $0.7 \mathrm{~s}$ and d) $0.9 \mathrm{~s}$. The Whataroa River is plotted in blue, roads are plotted in white and DFDP-2B marked as a yellow dot. The topographic contours are spaced at $50 \mathrm{~m}$. 

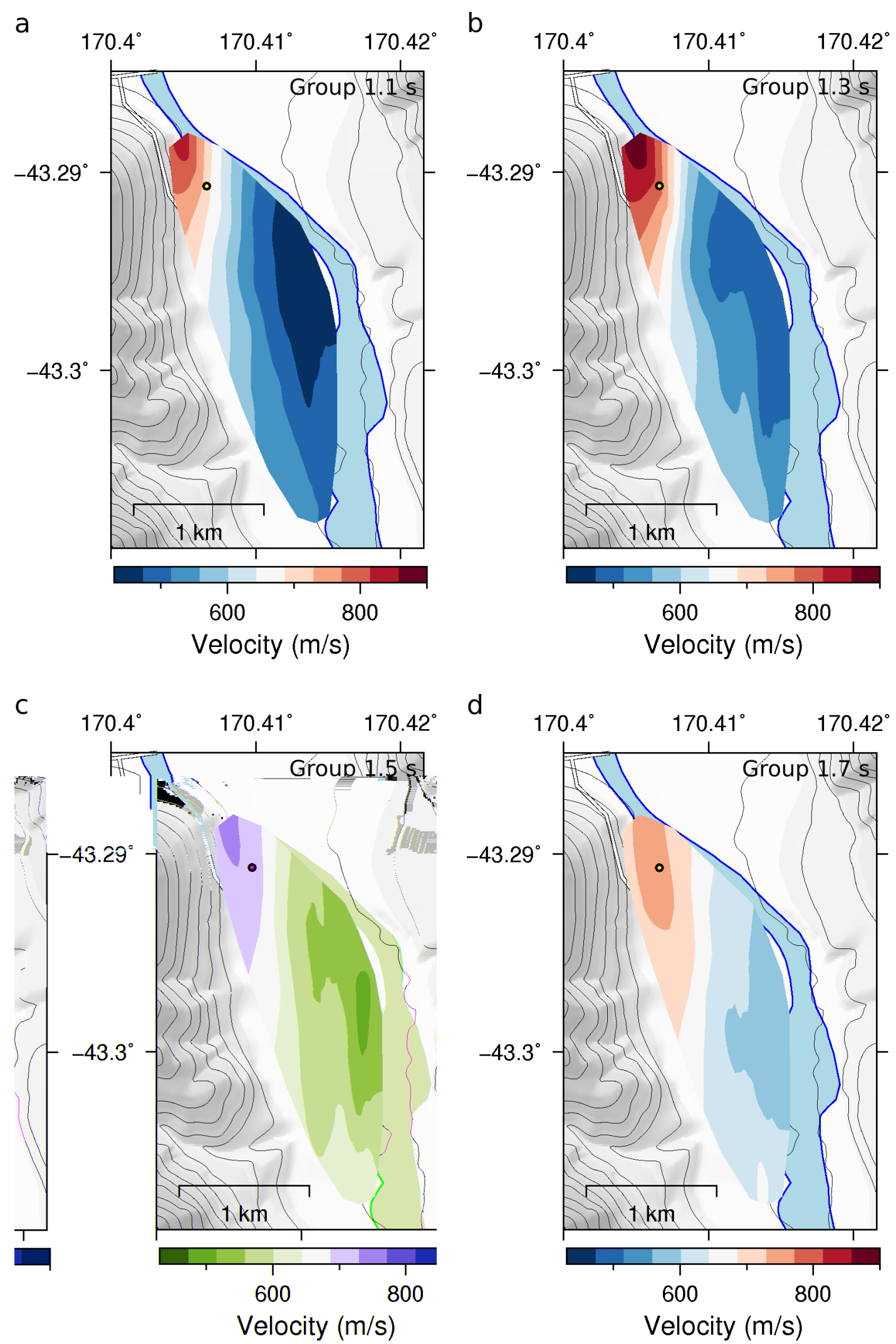

Figure 3.17: Rayleigh wave group velocity maps a) $1.1 \mathrm{~s}, \mathrm{~b}) 1.3 \mathrm{~s}, \mathrm{c}$ ) $1.5 \mathrm{~s}$ and d) $1.7 \mathrm{~s}$. The Whataroa River is plotted in blue, roads are plotted in white and DFDP-2B marked as a yellow dot. The topographic contours are spaced at $50 \mathrm{~m}$. 
A regularization smoothing factor of $4 \times 10^{6}$ is used to smooth the tomography maps. By plotting the smoothing factor against the travel-time misfit, we observe a steep change in misfit value [Figure 3.18]. In both phase and group velocity plots, a rapid increase in misfit is observed as the smoothing factor is increased [Figure 3.18]. Across all periods, misfit appears to stabilise at approximately $4 \times 10^{6}$. We also plot velocity maps with a smoothing factor that is higher and lower than $4 \times 10^{6}$ [Figure 3.19]. A low smoothing factor of $4 \times 10^{5}$ results in unrealistic velocity anomalies in both phase and group velocity [Figure 3.19a and b]. A high smoothing factor of $4 \times 10^{7}$ results in a model that is too smooth [Figure 3.18a and b]. By visual inspection of velocity maps and plotting the travel-time misfit against the smoothing factor, a value of $4 \times 10^{6}$ is used as this is a good compromise between realistic velocities and a smooth velocity gradient across the maps.

a

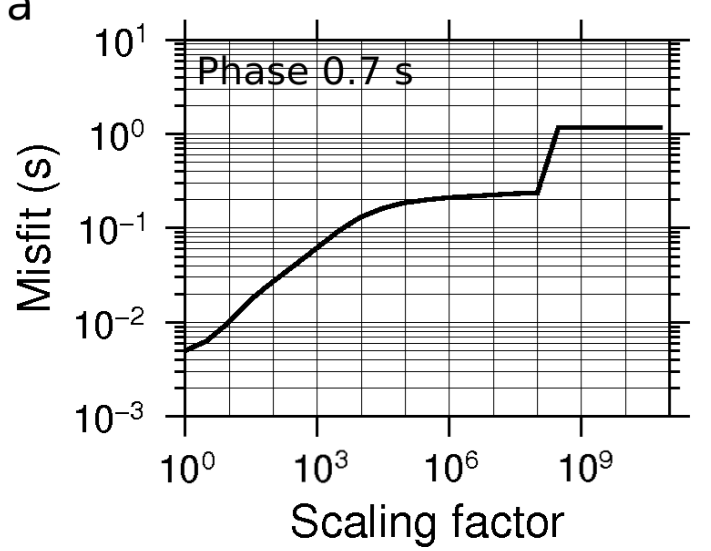

b

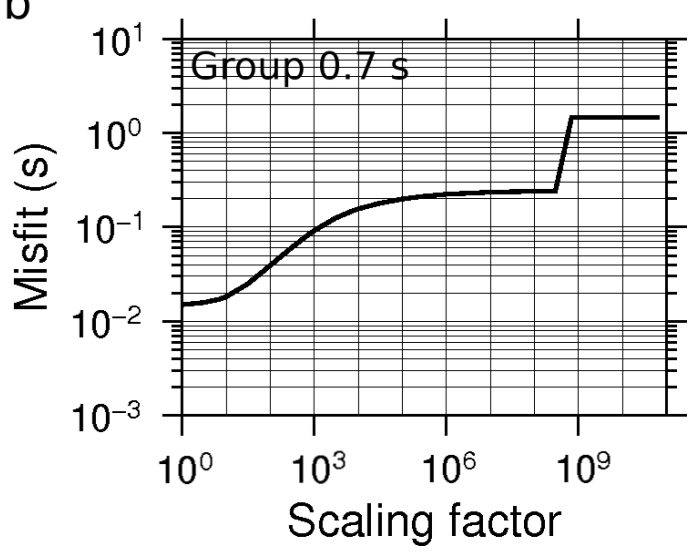

Figure 3.18: Travel-time misfit and smoothing factor applied to Rayleigh wave a) phase and b) group velocity maps at $0.7 \mathrm{~s}$ period. 

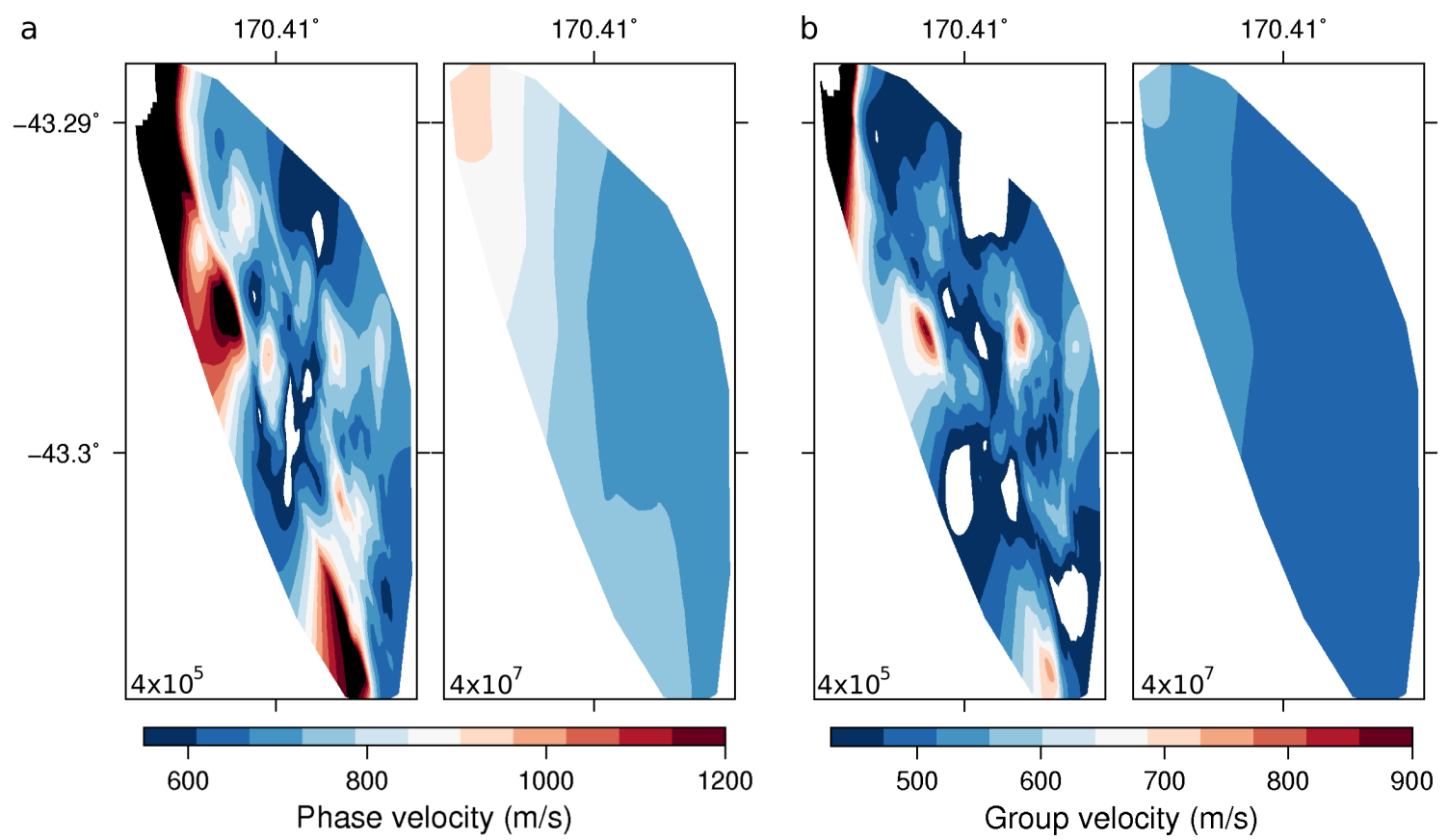

Figure 3.19: Regularization smoothing factor applied Rayleigh wave a) phase and b) group velocity maps at $0.7 \mathrm{~s}$ period. The number in each plots is the smoothing factor applied to the tomography map.

\subsection{Shear-Wave Velocity Inversions}

Phase and group velocity dispersion curves were constructed using a $100 \mathrm{~m}$ bin size from each velocity map [Figure 3.15 for phase and Figure 3.16 and 3.17 for group velocity; Note: we only show odd number periods but we include even number periods in the construction of dispersion curves]. We start by inverting phase velocity dispersion curves and then invert group and phase dispersion curves jointly, allowing us to probe the subsurface down to $1000 \mathrm{~m}$ compared to $300 \mathrm{~m}$ using phase dispersion measurements alone.

\subsubsection{D Shear-Wave Velocity Profiles}

During the inversion process, 50000 models were computed as the inversion explores the full parameter space. Instead of using the model corresponding to the lowest misfit, we follow Behr et al. (2011) and compute a weighted mean profile using misfit values as weights. For phase velocity inversions, a misfit threshold value is chosen 
based on the velocity error of the observed dispersion curves, as we consider all models below this value as valid (Godfrey et al., 2017). For the joint inversion, this method is somewhat difficult as the dispersion curves have different errors so we use a constant misfit value of 0.4 (decimal percentage) for all profiles.

Phase velocity dispersion curves from 0.3 to $1.0 \mathrm{~s}$ period are inverted using two layers over a half space parametrisation and 50 iterations [see Section 4.1.4 for discussion on parametrisation]. A selection of three inversions are presented in Figure 3.20, representing the north-west, central and south-east portions of the study area. Misfit values for inversions near in the north-west region are higher than other areas as illustrated in Figure 3.20a-c where a misfit of 0.03 is obtained for the north-west area compared to 0.01 for other areas. The observed dispersion curve error is also higher for this region when compared to the other areas [Figure 3.20a-c]. A $200 \mathrm{~m} / \mathrm{s}$ error is observed in the north-west section observed dispersion curve at period of $0.5 \mathrm{~s}$, reducing to $100 \mathrm{~m} / \mathrm{s}$ for other periods. A smaller error is observed for other dispersions curves in the order of 10-50 m/s [Figure 3.20b-c].

The shear-wave velocity depth profiles are constrained to two-layers over a halfspace. The bottom of the upper layer is in the upper $20 \mathrm{~m}$ in Figure $3.20 \mathrm{~d}$ and $\mathrm{f}$ whereas it is located deeper at $80 \mathrm{~m}$ in Figure 3.20e. The bottom of the lower layer follows a similar pattern where it occurs at 220-240 m in Figure 3.20d and $\mathrm{f}$ and at $260 \mathrm{~m}$ in Figure 3.20e. Very low velocities of $150-250 \mathrm{~m} / \mathrm{s}$ are observed in the upper layer of Figure 3.20d and f, before rapidly increasing to 800 and $700 \mathrm{~m} / \mathrm{s}$ in the lower layer. A higher velocity of $500 \mathrm{~m} / \mathrm{s}$ is observed in the upper layer of Figure $3.20 \mathrm{e}$ before an increase to $700 \mathrm{~m} / \mathrm{s}$ to the lower layer. The half-space velocity is highest in the north-west profile at $1200 \mathrm{~m} / \mathrm{s}$ [Figure 3.20d]. In the south-east profile it is slightly less at $1150 \mathrm{~m} / \mathrm{s}$ [Figure 3.20e] and in the central profile it is lowest at $1000 \mathrm{~m} / \mathrm{s}$ [Figure 3.20f]. 


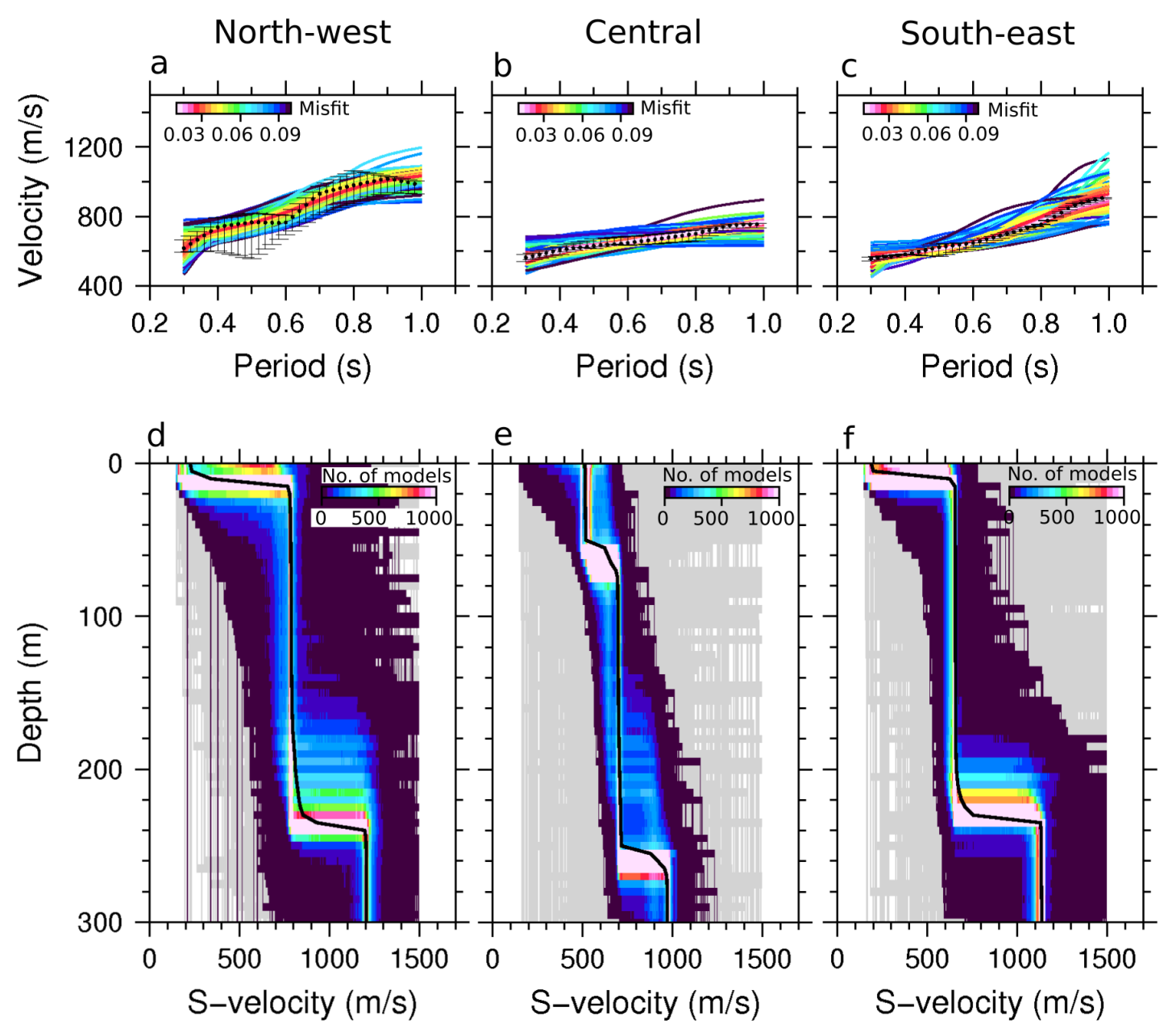

Figure 3.20: Shear wave inversion results from selected geographic locations using phase velocity dispersion curves. Plots a-c show 1000 random theoretical dispersion curves for each inversion, coloured by velocity misfit (decimal percentage), and the observed dispersion curve and its error bar [black dots]. The random dispersion curves are drawn from the set of dispersion curves that correspond to each shearwave profile. Shear wave depth profiles are plotted from d-f and correspond to plots a-c with misfit values of $0.35,0.07$ and 0.15 . The shear-wave profiles are plotted as number of models per cell, with a cell size of $10 \mathrm{~m}$ by $10 \mathrm{~m} / \mathrm{s}$. The grey profiles are those above the defined misfit threshold. The location of each inversion profile is marked on Figure 3.22 .

Group and phase dispersion curves from periods of 0.3 to $1.8 \mathrm{~s}$ and 0.3 to $1.0 \mathrm{~s}$ respectively are jointly inverted using a 4 layer over a half space model parametrisation and 500 iterations [See section 4.1.4 for discussion on parametrisation]. Higher misfit values are observed in the joint inversion compared to phase inversions, particularly in the northern area [Figure 3.21a]. Group velocity dispersion generally has a lower error than phase dispersion, although some cells show the opposite [e.g. Figure 3.21f]. 
In the shear-wave profiles, velocities between $500 \mathrm{~m} / \mathrm{s}$ and $700 \mathrm{~m} / \mathrm{s}$ are found in the upper $100 \mathrm{~m}$ of the north-west and central study areas [Figure $3.21 \mathrm{~g}$ and $\mathrm{h}$ ]. In south-east area this layer extends to depths of 140 to $160 \mathrm{~m}$ [Figure 3.21i]. A jump in velocity to $900 \mathrm{~m} / \mathrm{s}$ in the second layer is observed in the north-west and southwest [Figure $3.21 \mathrm{~g}$ and i]. The velocity of this layer in the central profile is $700 \mathrm{~m} / \mathrm{s}$ [Figure 3.21i]. The depth of this layer is $300 \mathrm{~m}$ in the north-west and central profiles [Figure $3.21 \mathrm{~g}$ and $\mathrm{h}$ ], and $400 \mathrm{~m}$ in the south-east profile [Figure 3.21i]. There is a rapid increase in velocity of $500 \mathrm{~m} / \mathrm{s}$ between the second and third layer in the north-west and south-east profiles [Figure 3.21g and i]. The increase in velocity from the second to third layer in the central area is $400 \mathrm{~m} / \mathrm{s}$ [Figure 3.21h]. The third layer extends to a depth of $1000 \mathrm{~m}$ in the north-west profile and has a velocity of $1400 \mathrm{~m} / \mathrm{s}$ [Figure $3.21 \mathrm{~g}$ ]. In the central profile it extends to $600 \mathrm{~m}$ at $1100 \mathrm{~m} / \mathrm{s}$, before a gradual increase in velocity to $2000 \mathrm{~m} / \mathrm{s}$ occurs over a depth range of $200 \mathrm{~m}$ [Figure 3.21h]. The south-east profile is similar to the central profile, except the third layer velocity is the same as the north-west profile and the gradual velocity increase does not occur until $800 \mathrm{~m}$ depth [Figure 3.21i]. 
a

North-west
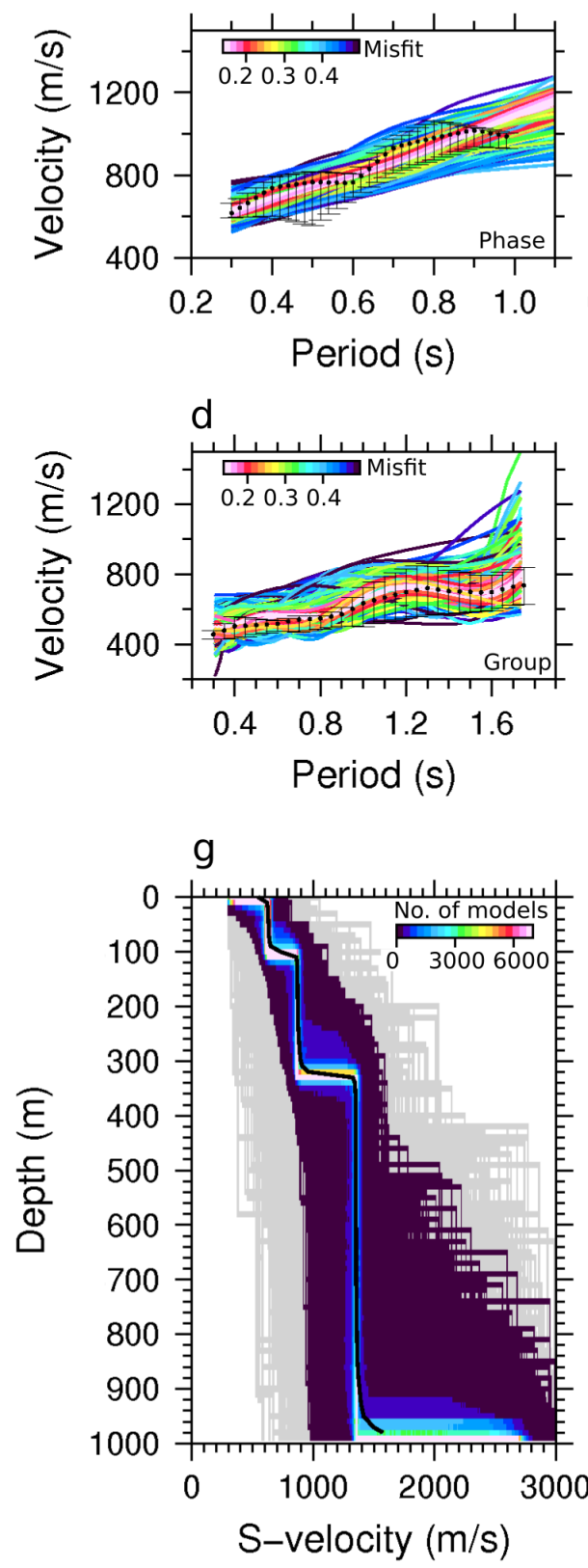

b

Central

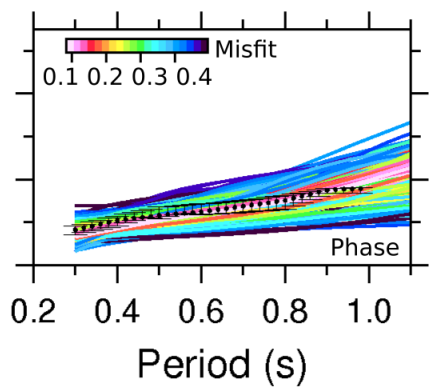

e

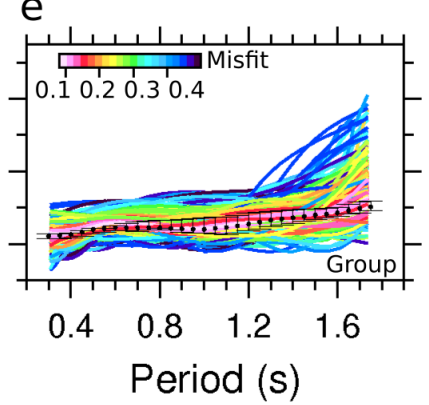

C

South-east

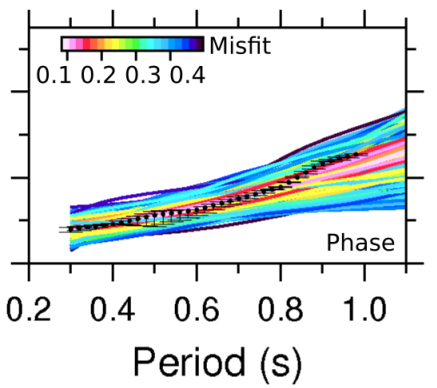

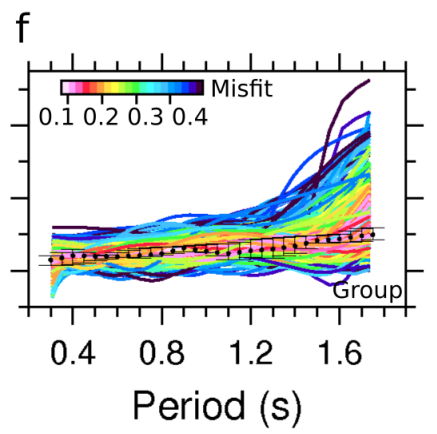

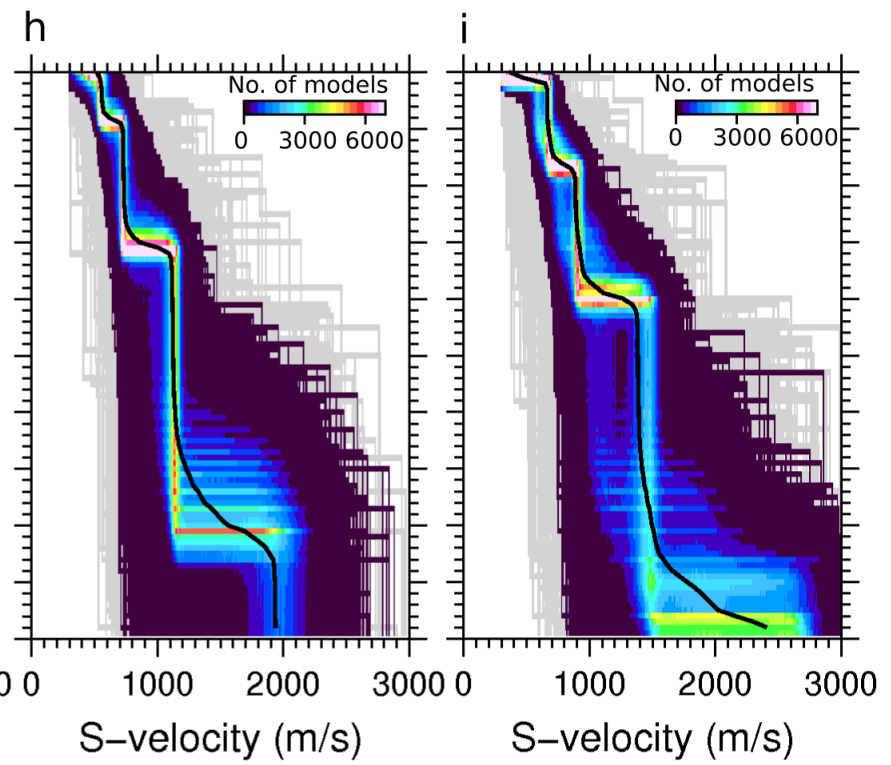

Figure 3.21: Shear wave inversion results from the same geographic locations as Figure 3.20, using phase and group velocity dispersion curves. The dispersion curves plots and shear-wave depth profiles are constructed using the same method as Figure 3.20. The only difference is a constant misfit threshold of 0.4 is used. Plots a-c and d-f show phase and group velocity dispersion curves for each inversion. Shear wave depth profiles are plotted from g-i and correspond to plots a-f. Note the observed phase dispersion curve is identical to Figure 3.20a-c 


\subsubsection{Pseudo-3D Shear-Wave Velocity Profiles}

A pseudo-3D shear-wave velocity model is constructed from 129 weighted mean 1D depth profiles [e.g. Figure 3.21] which represent the average shear-wave velocity in each $100 \mathrm{~m}$ cell of the velocity maps. We choose to use the joint inversion over the phase inversion for the construction of our pseudo-3D model [see Section 2.3.2]. From this model, 2D profiles along west-east and south-north orientations are extracted to evaluate the velocity structure. To better visualise the velocity structure we construct a fence diagram made up of four west-east profile and three south-north profiles [Figure 3.22].

As our main aim in this thesis is to investigate the sedimentary-basement contact structure in the Whataroa Valley, we choose a colour scheme that best highlights sharp changes in velocity gradient, indicative of an strong impedance contrast. The consequence is we are not able to view shallow layers such as the layer at $100 \mathrm{~m}$ depth identified in Figure 3.21 [see Section 4.3]. The pseudo-3D model shows two sharp velocity transitions [Figure 3.22]. The first is present across the entire model and has a jump in velocity from $750 \mathrm{~m} / \mathrm{s}$ to $1250 \mathrm{~m} / \mathrm{s}$ in the north-west and south-east areas, with a depth range of $300 \mathrm{~m}$ to $400 \mathrm{~m}$. The contrast is present in the central area; however its velocity increase is from $750 \mathrm{~m} / \mathrm{s}$ to $1100 \mathrm{~m} / \mathrm{s}$. While the first velocity transition is relatively planar, the second is bulge-like and occurs at the lower depth limit of our model where a transition to velocities above $1600 \mathrm{~m} / \mathrm{s}$ occurs. The peak of the second transition is along the north-south axis, reaching a minimum depth of $650 \mathrm{~m}$ [see central south-north profile in Figure 3.22]. The transition becomes deeper to south-east and north-west where it tapers to a thin slice along the edges of the study area. One exception to this is along the south-west edge of the study area where the transition maintains a depth range of 650 to $900 \mathrm{~m}$. An interesting feature of the central area is the velocity zone between the two velocity transitions described above. The zone has a velocity range of 1100 to $1250 \mathrm{~m} / \mathrm{s}$ which extends down to $800 \mathrm{~m}$ in some areas [Figure 3.22]. 


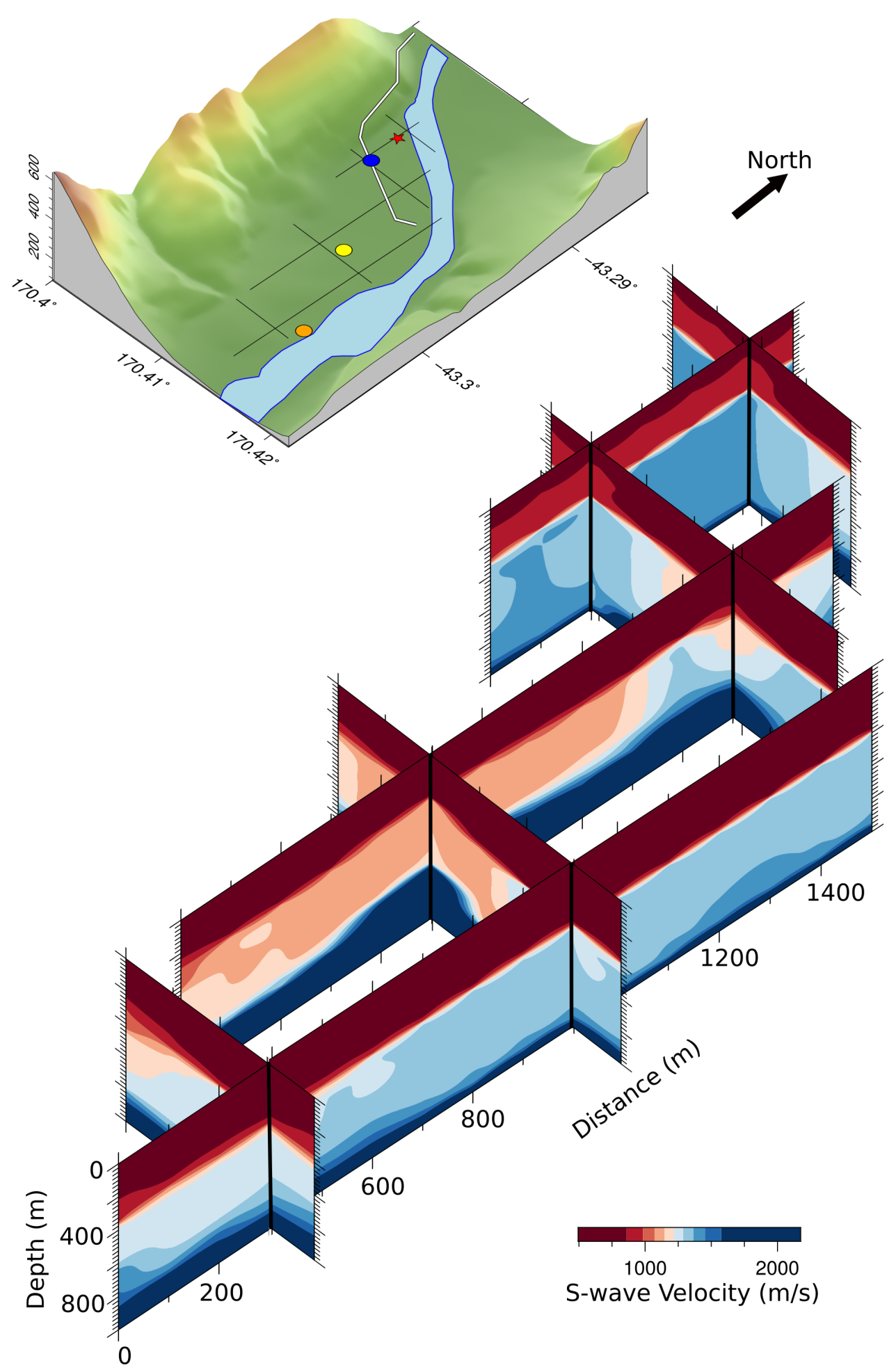

Figure 3.22: Fence plot of shear-wave velocity depth profiles of the Whataroa Valley using joint shear-wave inversions of phase and group velocity dispersion curves. Profile transects are marked on the map along with profile locations for Figure 3.20 and 3.21 marked as coloured circles and the red star is DFDP-2B. The blue circle refers to the north-west profile, yellow to the central profile and orange to the southeast profile. 


\section{Discussion}

This chapter provides a discussion on the limitations and considerations of the results presented in the previous chapter. We then interpret the shear-wave velocity model before comparing our findings to those of previous studies.

\subsection{Data Analysis and Considerations}

Here we discuss the limitations and considerations of the four main components of this study; cross-correlations, dispersion curves, tomography and shear-wave velocity inversions.

\subsubsection{Cross-correlation Functions}

The data used in this study were not recorded with the intention of performing ambient noise analysis, therefore this study is in part a test of whether a short deployment of a few days can be used to perform this type of analysis. The length of recording time is an important consideration when cross-correlating seismic ambient noise. A CCF constructed from a single or small number of correlations will not be an accurate approximation of the Green's Function, whereas stacking all individual cross-correlations will start to represent an approximated Green's Function as a increasing number of individual Cross-Correlation Functions (CCF) are stacked (Lin et al., 2006). Although there is no way to empirically calculate the number of individual CCFs required, it is possible the four days of data we use in this thesis may not be enough to achieve a stable CCF. To counter this limitation we extend the standard processing techniques recommended by Bensen et al. (2007) to test phase 
coherence based methods of phase-weighted stack and phase cross-correlation. We observe higher signal-to-noise ratio in CCFs by employing the phase weighted stack method [Figure 4.1]. For virtual sources located at the northern and southern extent of the array, a larger difference in signal-to-noise ratio is observed than for virtual sources located near the persistent localised source. We showed in Figure 3.4 that the persistent localised source location acts as a strong source which suggests the small signal-to-noise ratio difference observed in the central part of the array [for Figure $4.1 \mathrm{a}$ and $\mathrm{b}]$ is due to the strong source, as is the lower signal-to-noise ratio difference for virtual sources in the central part of the array [Figure 4.1c]. In some virtual source plots, such as Figure 4.1a, the signal-to-noise ratio difference can be related to the inter-station distance where the difference increases with distance. This suggests that with increasing inter-station distance, the phase-weighted stack improves the CCF at a greater rate than linear stacking. There is no evidence to suggest that the phase weighted stack allows us to observe new signals, but rather signals observed will be cleaner and thus result in more reliable dispersion curves. 

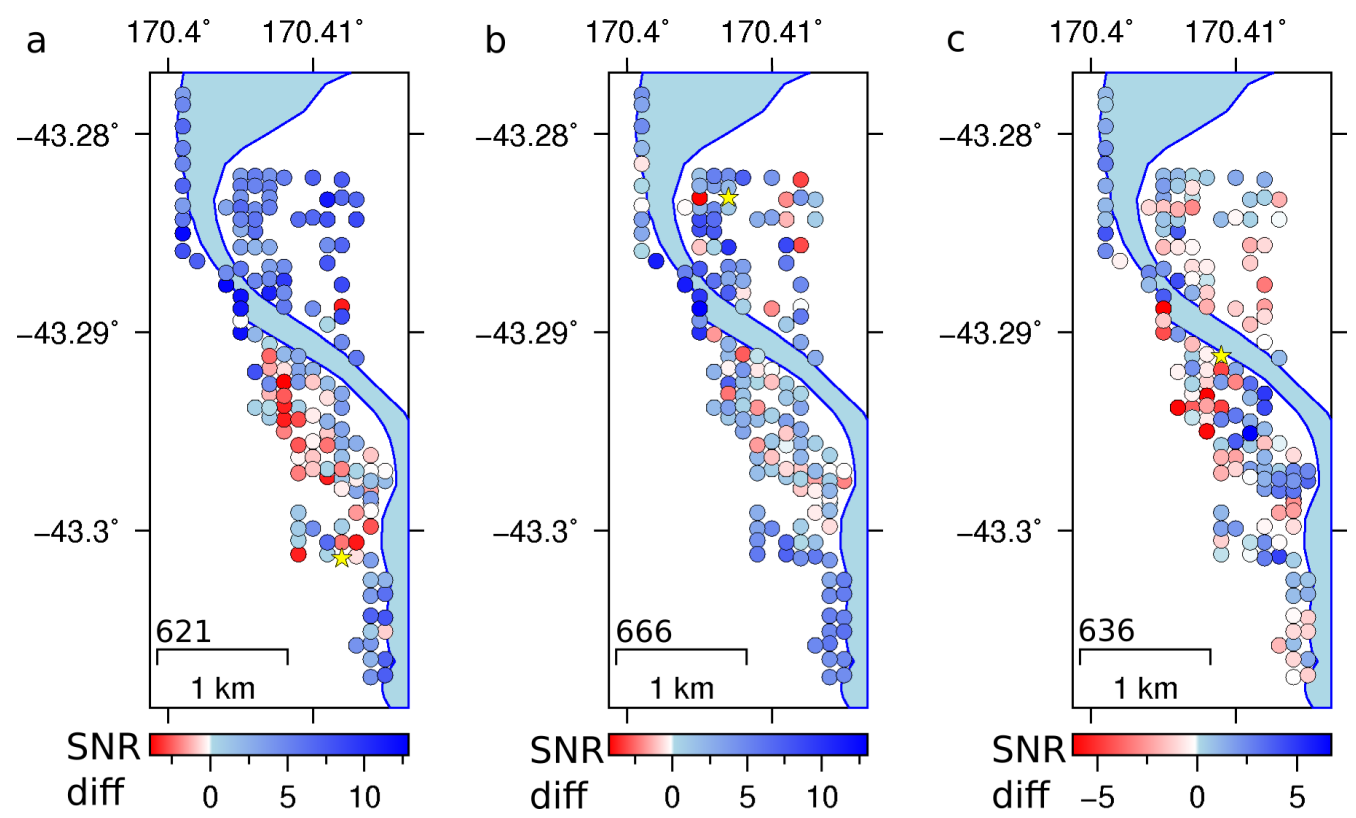

Figure 4.1: Signal-to-noise ratio difference between linear and phase-weighted stacked CCF. Each plot shows a different station treated as a virtual source with the signal-to-noise ratio calculated from moveout plots similar to Figure 3.3 a) station $621, \mathrm{~b}$ ) station 666, and c) station 636. Virtual source location is marked as a yellow star and its station written above the map scale. The Whataroa River is also marked for reference. Positive means phase-weighted stack has a higher signal-to-noise ratio than the linear stack.

Using both cross correlation methods, we observe the same signal propagating at an apparent group velocity of $500 \mathrm{~m} / \mathrm{s}$ [Figure 4.2]. A comparison of CCFs at different inter-station distances shows phase cross-correlations have a higher correlation coefficient than conventional CCFs. The low frequency peak at zero lag-time is absent in phase cross-correlations, except for the $3.44 \mathrm{~km}$ example [Figure $4.2 \mathrm{~d}$ ]. Schimmel et al. (2011) show the phase cross-correlation method is better at correlating the entire wave-train as it is sensitive to small waveform changes whereas the conventional CCFs is biased by high amplitude phases and thus the correlation may have a peak at this phase. The presence of the high amplitude peak in our CCFs suggests that our preprocessing steps of RMS clipping and spectral whitening have not been entirely successful in removing high amplitude arrivals. It is likely the peak is a pseudo auto-correlation of long-wavelength arrivals that are very similar at both source and receiver (Chávez García and Rodríguez, 2007). We have attempted to mitigate this by limiting the spectral range of frequencies in our cross-correlation in the preprocessing steps, but the zero lag-time peak is $0.5 \mathrm{~Hz}$, thus at the edge of 
our spectral range defined as 0.5 to $5 \mathrm{~Hz}$ during whitening [see Figure 2.2]. An improvement in the processing flow could be to use dynamic whitening bounds chosen to correspond to a minimum frequency set by a wavelength criterion. The presence of a high amplitude direct phase in both types of CCF leads us to use the conventional method over the phase cross-correlation method. The conventional method provides a robust result at all inter-station distance whereas phase cross-correlation works very efficiently at short inter-station distances but appears to reduce in effectiveness as inter-station distance increases [Figure 4.2d]. Through the adoption of the non-conventional processing techniques of phase weighted stacking, we have shown that a short deployment of temporary instruments can be used to perform ambient noise analysis. 

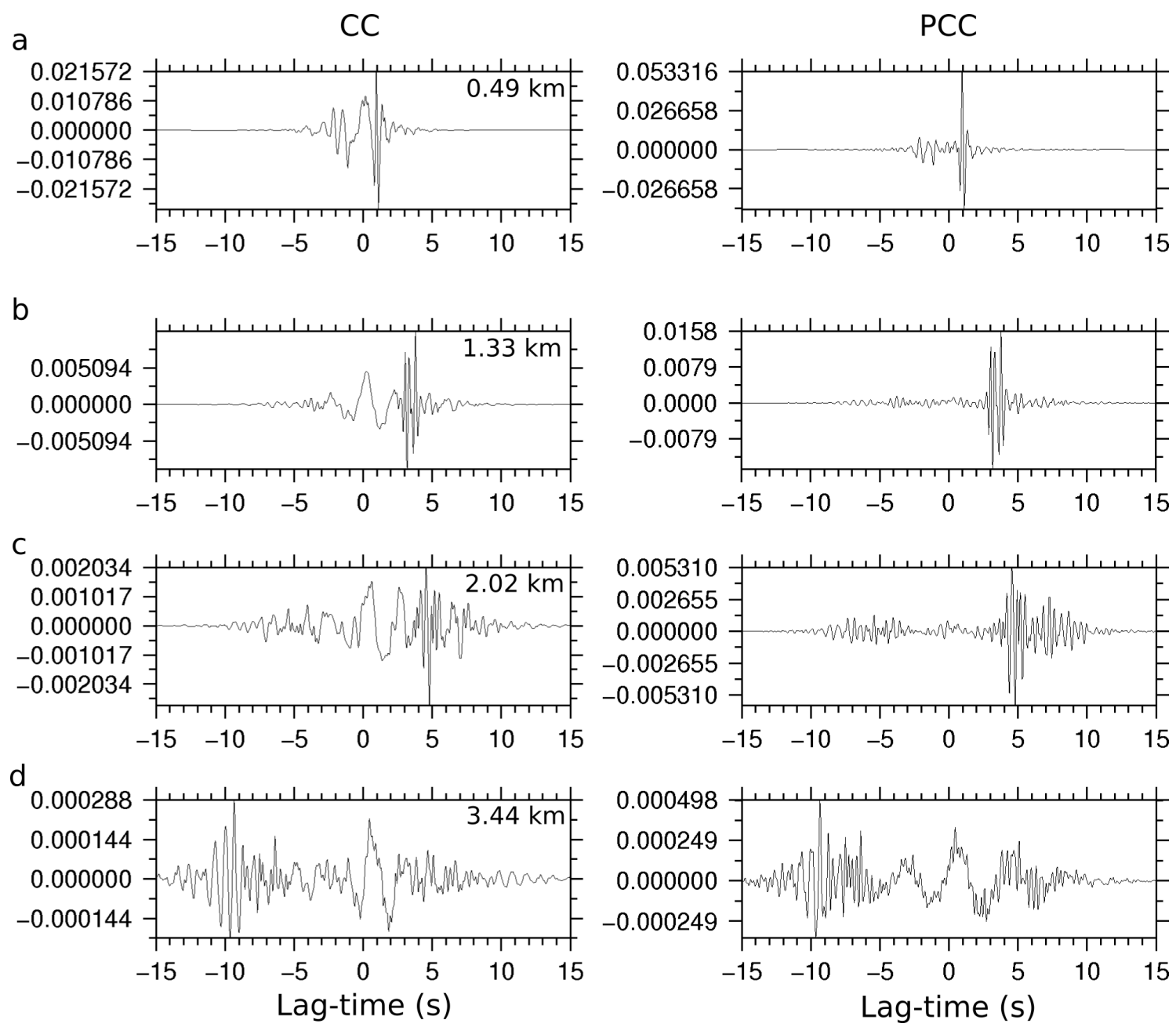

Figure 4.2: Comparison of sample CCFs at different inter-station distances calculated using conventional cross-correlation and phase cross-correlation methods a) $0.49 \mathrm{~km}$. b) $1.33 \mathrm{~km}$, c) $2.02 \mathrm{~km}$, and d) $3.44 \mathrm{~km}$. Conventional cross-correlation are in the left panel and phase cross-correlation are on the right panel with inter-station distance of CCFs marked in the top right corner of plots on left panel. The y-axis of each plot is the correlation co-efficient of the CFFs.

The quality of CCFs varies with station location in terms of contamination by phases such as the persistent localised source located in Section 3.1.1, and variations in amplitude. We find stations located in the northern section of the array have lower quality CCFs than those in the central and southern section. Lower amplitude CCFs may be affected by poor coupling and higher attenuation of seismic waveforms. The damage zone surrounding the Alpine Fault may be leading to high attenuation of surface waves due to fractured rock (Toy et al., 2015). In CCFs from stations deployed on the stop bank along the western side of the Whataroa River, North of state highway 16, a sudden reduction in amplitude is observed [Figure 3.1 
and 3.2]. This may be due to either high attenuation of the Alpine Fault or poor coupling of geophones as the stop-bank is made up of river gravels so is likely to poorly consolidated. Determining the attenuation coefficient of the Alpine Fault damage zone and principle slip zone is beyond the scope of this thesis, and thus at this point the cause of this reduction in phase amplitude is unresolved.

Using back-projection of CCFs we are able to locate one persistent localised source, but some moveout plots show multiple phases of a similar character, likely to be from multiple sources [see Figure 3.3c]. A comparison of moveout plots [Figure 3.3b and c] and their back-projection [Figure 4.3a and b], shows we are able to confidently locate stationary source phases with a clean signal in both amplitude and signal-to-noise ratio [Figures $3.3 \mathrm{~b}$ and $4.3 \mathrm{a}$ ]. In plots with a lower quality signal, the back-projection is less clear, resulting in a scattered distribution of high amplitude locations [Figures 3.3c and 4.3b]. The assumption of a constant velocity is likely a contributing factor to only being able to locate one stationary source. The use of a 2D velocity model may improve our locations and enable us to identify more than one persistent localised source. We interpret the stationary source located in Figure 3.5 as rapids in the Whataroa River. We know from field observation during the deployment that rapids are located east of this site. The offset of the high amplitude anomaly is probably due to the assumption of a constant velocity; however we deem it accurate enough to make the interpretation.

In a spatially inhomogeneous noise distribution, such as the seismic ambient noise wave-field, a non-symmetric cross-correlation is expected (Shapiro and Campillo, 2004). We observe this in our CCFs to varying degrees with some CCFs showing strong asymmetry [Figure 3.3a] and others moderate symmetry [Figure 3.3f]. Outside of the array, signal predominantly originates from the northern side of the array with higher signal-to-noise ratio observed for southward-travelling signals than for northward-travelling signals [e.g. Figure 3.4d]. The persistent localised source, located in a back-projection, also serves as a source to stations located nearby, at 
which both high signal-to-noise ratio and strong CCF asymmetry are observed [e.g. Figure 3.4a]. More localised bands of high signal-to-noise ratio are observed for virtual sources located in the northern section of the array [e.g. Figure 3.4b and c]. The localised bands of high signal-to-noise ratio are generally inline with the persistent localised source and virtual source location, with nearly all other stations having lower signal-to-noise ratios. This evidence suggests that the persistent localised source is acting as a strong source when located in the stationary phase zone of an individual CCF (Snieder, 2004). The presence of the persistent localised source in our data shows that the river can act as a ambient noise source within the frequency range we are using, and as such the many rivers in the local area are probably important contributors to the signals recorded (e.g. Burtin et al., 2010). The weak symmetry observed in our CCFs shows that we have reasonable azimuthal distribution of signal sources. Shapiro and Campillo (2004) and subsequent studies by other authors have shown robust observations can be made from partially diffuse ambient seismic noise and we believe our CCFs fit this criterion.

a

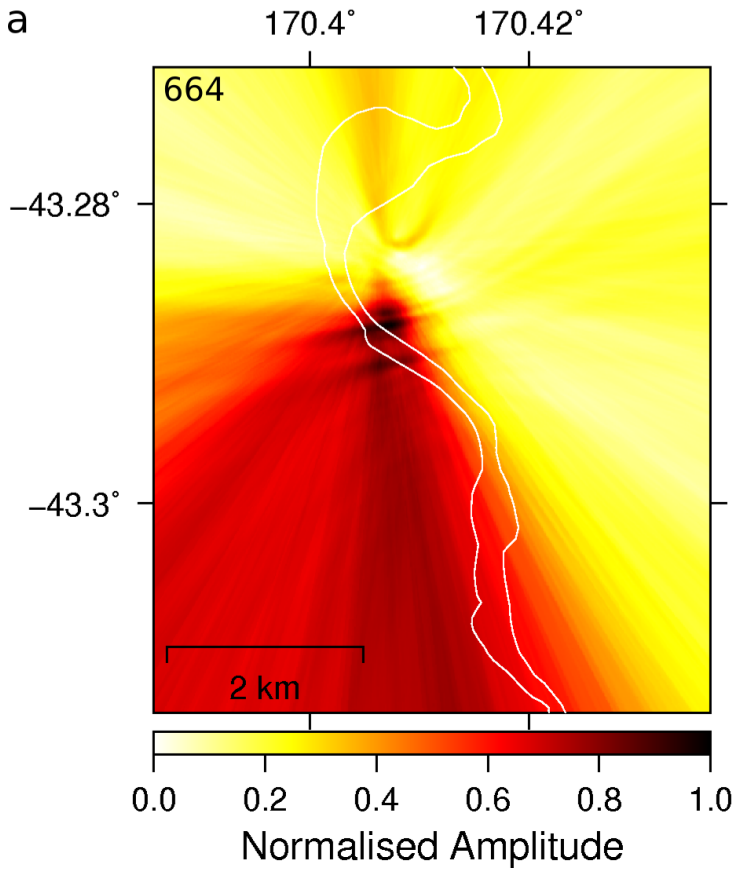

b

$-43.3^{\circ}$

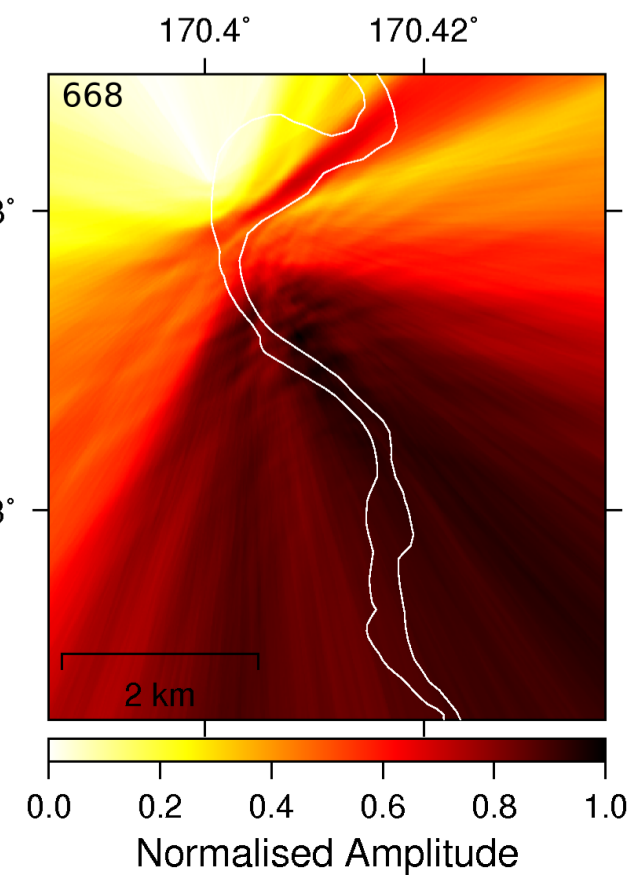

Figure 4.3: Comparison of CCFs back-projection for virtual source move-out plots in Figure 3.3b and c. a) back-projection of virtual source station 664, and b) backprojection of virtual source station 668. The Whataroa River outline is plotted in white. 


\subsubsection{Dispersion Curves}

As discussed above, we only find one persistent localised source location despite move-out plots suggesting the presence of more. The large variation in group velocity dispersion curves is likely due to this as we cannot confidently remove all persistent localised source phases from CCF component(s) with only one location. For this reason, we have chosen to use the sub-array for further analysis [see Figure 3.8].

The presence of a strong velocity contrast has been shown to excite higher modes in the surface wave-field (Boaga et al., 2013). From the DFDP-2B borehole measurements, we know that the basement-sediment boundary is a sharp density contrast (Sutherland et al., 2015), suggesting a high velocity contrast and thus the potential for higher modes to be present in our CCFs. At inter-station distances less than $1000 \mathrm{~m}$ we confidently identify our dispersion curves as being fundamental mode Rayleigh waves as the spectral amplitude of the frequency-time analysis shows a clear high-energy anomaly associated with group velocity dispersion [Figure 3.7a and b]. At longer inter-station distances (1000-2000 m), several high amplitude bands form, suggesting higher modes may be present in CCFs with an inter-station distance greater than $1000 \mathrm{~m}$ [Figure 3.7c-f]. To explain the jump in group dispersion velocity between two amplitude bands in Figure 3.7f, we model synthetic dispersion curves using a two-layer input model with varying basement depth. We found a good match between fundamental mode synthetic and observed dispersion, which suggests the velocity jump in group velocity is due to the velocity contrast between the sedimentary layer and the basement.

Daily dispersion curves can be used as a proxy for dispersion curve reliability and error [Figure 4.4]. We find a good fit between daily and full-stack dispersion, particularly in station pairs with no jump in group velocity [see Figure 3.7], as observed in Figure 4.4c. Station pairs with a jump in group velocity show a small degree of 
variation in daily dispersion curves at periods where the jump occurs [Figure 4.4a and b]. At periods where there is a jump, most of our dispersion curves have missing measurements where we cannot measure reliable dispersion. The start, end and width of this gap has small variations between each station pair daily dispersion curves. As we interpret some of the noise source to be from river sources, small fluctuations in the spectral content of dispersion around the jump may be due to changes in the spectral content of the river source due to water-levels controlled by rainfall and snowfall (Burtin et al., 2010). As the west coast has very high precipitation, this exerts a control on river water level (e.g. Henderson and Thompson, 1999), which in turn could control the excitement of signal from rapids (Burtin et al., 2010).
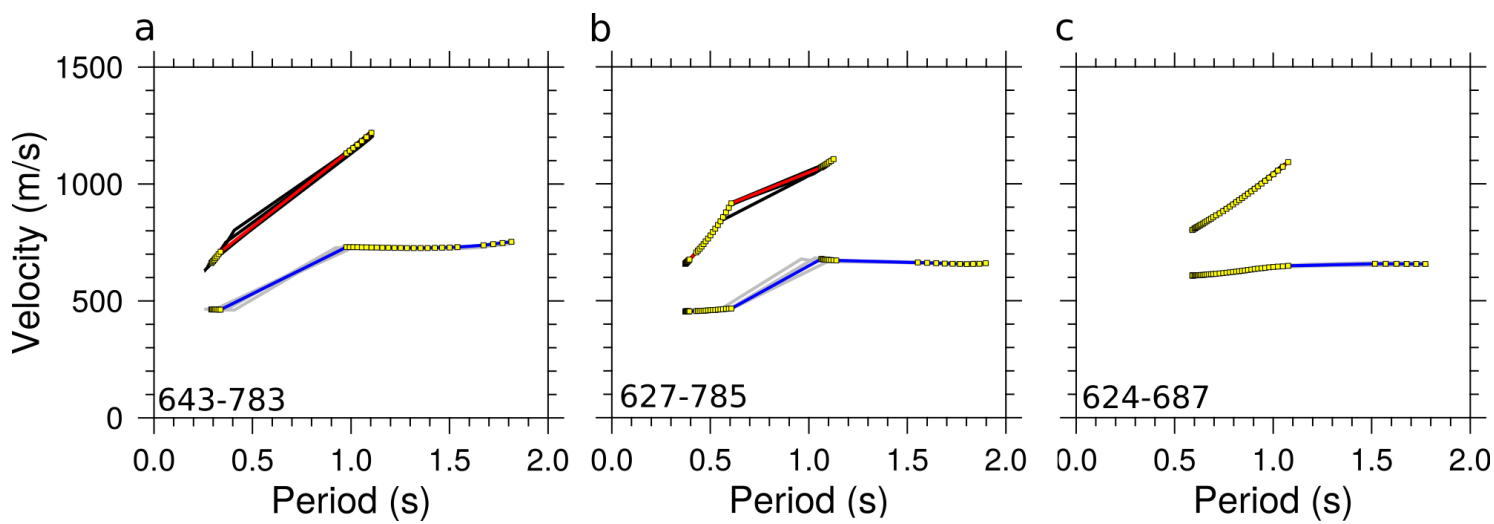

Figure 4.4: Daily dispersion curves of phase (red) and group (blue) velocity a) Station pair 643-783, b) 627-785, and c) 624-687. The yellow squares mark periods where a measurement is recorded in the full stack dispersion curve that is within criterion outlined in Section 3.2.

\subsubsection{Tomography}

We are able to recover most of the input checker-board model for most periods in both phase and group velocity, with exception of $0.3 \mathrm{~s}$ period where poor recovery occurs [Figures 3.11 and 3.12]. The area resolved usually coincides with areas of high ray path density and azimuthal coverage for both velocity types [Figures 3.13 and 3.14]. We can resolve structure down to $200 \mathrm{~m}$ in the centre of the valley for periods above $0.3 \mathrm{~s}$. At $0.3 \mathrm{~s}$ period we expect a high degree of smearing in phase and group velocity. At periods above $0.3 \mathrm{~s}$, a small degree of north-west south-east 
smearing is expected at most periods. The correlation of cells with high ray density and azimuthal coverage suggest a high degree of path crossing, essential for good resolution in tomographic models (Rawlinson and Sambridge, 2003). Due to the array geometry, we have more ray-paths travelling down or up the valley than across it. This suggests that while we have good correlation between ray-path density and azimuth, the angle between crossing paths is likely to be less than the desirable $90^{\circ}$. We believe this is the cause of the small degree of north-west south-east smearing that occurs in most of checkerboard tests. Through our checkerboard tests we conclude that we can resolve structures in the central and northern sections of the array for phase velocity tomographic models with resolution increasing with period. For group velocity, we can also resolve parts of the southern section of the study area at periods above $0.9 \mathrm{~s}$. In both models, we cannot resolve the edges which is consistent with the lack of ray path density and azimuth in Figures 3.13 and 3.14.

The limitation of straight ray tomography is it does not take reflection and diffraction into consideration when calculating travel-time (Rawlinson and Sambridge, 2003). Through the centre of the valley we consider the straight ray approximation acceptable as we expect most geology structure to be sub-horizontal. Along the edges of the valley, particularity near the DFDP-2B borehole, a sub vertical geologic structure may exist (Jenkins, 2017). In this area we consider the straight ray approximation to be inappropriate. This limitation is reflected in the velocity variation of the observed dispersion curves constructed from the surface wave velocity maps [see Section 2.3.4, Figure 3.21a-f]. Around the DFDP-2B borehole and north-west extent of the study area, larger uncertainty in the observed dispersion curve is observed compared to other areas [Figure 3.21a and d]. The lower values in the centre of the study area give us confidence that the straight ray approximation is acceptable in most of the study area [Figure 3.21b,c,e,f], with the exception of around the DFDP-2B borehole.

We find good agreement between phase and group velocity tomography models [Figures 3.15, 3.16 and 3.17]. The main observation of an increasing velocity at 
longer periods is observed in both types of velocity. The lateral increase in velocity from the western side to the centre of the valley is also observed in both. One variation between the velocity types is the low velocity zone that forms at longer periods in the centre of the valley. For phase velocity, the anomaly is circular and does not touch the edge of the study area, while for group velocity a similar shape is observed but it covers the eastern edge of the study area. The difference in geometry is likely from a combination of different depth sensitivity between phase and group velocity (Bensen et al., 2007), and low resolution along the eastern edge of the study area [see Section 3.3.1].

\subsubsection{Shear-wave Velocity Inversions}

The neighbourhood algorithm used to invert dispersion curves for shear-wave velocity explores the parameter space defined a priori to the inversion to find the best fitting model (Wathelet, 2008). Therefore it is important to integrate prior knowledge into the parametrisation as the inversion process explores the full space. Search ranges that are too large will result in unstable results while those that are too narrow might converge on a local minimum, missing the best solution and resulting in poor misfit (Wathelet, 2008). The geologic units, including the basement depth, within the DFDP-2B borehole are well defined, however gravity modelling suggests the lateral distribution of the basement depth changes towards the centre of the valley, becoming deeper than the $240 \mathrm{~m}$ depth in the borehole (Jenkins, 2017). With this knowledge we include with a large depth range of 50 to $400 \mathrm{~m}$. The shallow depths this study probes are difficult to parametrise as we expect strong lateral and vertical variations, so we allow a broad search range of all parameters in all layers. The 2-D compressional-wave velocity profile modelled by Lay et al. (2016) provides an estimate of shear-wave velocity although the $V_{p} / V_{s}$ ratio is unknown so we choose to give compressional-wave velocity a broad range.

For the inversion of phase velocity dispersion, we use a two-layers over a half space [Table 4.1]. The simple model used in the phase inversion gives a well constrained 
Table 4.1: Parametrisation of phase velocity inversion. We link a single compressional-wave $(\mathrm{m} / \mathrm{s})$ layer to shear-wave layer two and allow Poisson's ratio $(\nu)$ to range between $0.2-0.5$. Density is fixed at $2000 \mathrm{~kg} / \mathrm{m}$ as it is the least important parameter (Wathelet, 2008).

\begin{tabular}{|l|l|l|l|}
\hline Layer & Vs range $(\mathbf{m} / \mathbf{s})$ & Vp range $(\mathbf{m} / \mathbf{s})$ & Depth range $\mathbf{( m )}$ \\
\hline 1 & $150-1000$ & & $1-150$ \\
\hline 2 & $500-2500$ & $500-5000$ & $50-400$ \\
\hline Halfspace & $500-3000$ & $500-5000$ & \\
\hline
\end{tabular}

model with low misfit values [Figure 4.5a]. In simple models such as our phase parametrisation, the use of constant compressional-wave, Poisson's ratio $(\nu)$ and density is acceptable, except in the case where a strong velocity contrast is expected (Wathelet, 2008). From DFDP-2B and our dispersion curves and velocity maps we expect a strong velocity contrast so choose to parametrise a compressional-wave layer linked to the shear-wave layer of the velocity contrast for our phase inversions. We find that using one layer over a half-space to explain how the basement depth led to the inversion process converging to velocities that were unrealistic at shallow depths, so we add a shallow layer to allow low velocities to be fitted. Lay et al. (2016) observed very low $(<500 \mathrm{~m} / \mathrm{s})$ compressional velocity in the upper $100 \mathrm{~m}$ of their model which justifies integrating a shallow low velocity layer. In our models, this shallow layer occurs at very low depths of $20 \mathrm{~m}$ and has a very low velocity in the north-west and south-east regions, whereas in the central model it occurs at $60 \mathrm{~ms}$ and has a higher velocity. The difference in velocity and depth suggests that the layer has been forced to fit the north-west and south-east models but is likely to be real in the central model where it is consistent with depths observed by Lay et al. (2016).

For the joint inversion we use four-layers over a half-space [Table 4.2]. Group velocity dispersion curves have a larger bandwidth than those of phase velocity, going up to periods of $1.8 \mathrm{~s}$ compared to $1.0 \mathrm{~s}$ for phase velocity so we can parametrise deeper layers. The simple parametrisation used in the phase inversion was inadequate for the joint inversion as large variations in layer thickness and velocity resulted in a poorly constrained model with low misfit. Instead for every shear-wave layer, we linked a compressional, $\nu$ and density layer to the shear-wave layer. We found the 
Table 4.2: Parametrisation of joint inversion. We link compressional-wave, Poisson's ratio $(\nu)$ and density to each shear-wave layer and allow them a range of $200-5000 \mathrm{~m} / \mathrm{s}, 0.2-0.5$ and $2000 \mathrm{~kg} / \mathrm{m}$ respectively. By linking compression-wave velocity, $\nu$ and density to each shear-wave velocity layer, we ensure the change in all parameters occurs at the same depth.

\begin{tabular}{|l|l|l|}
\hline Layer & Vs range $\mathbf{( m / s )}$ & Depth range $(\mathbf{m})$ \\
\hline 1 & $150-700$ & $1-100$ \\
\hline 2 & $300-1500$ & $50-400$ \\
\hline 3 & $300-2000$ & $150-600$ \\
\hline 4 & $500-2500$ & $400-1000$ \\
\hline Halfspace & $500-3000$ & \\
\hline
\end{tabular}

four layer model gave the best results in terms of misfit values and was reproducible for multiple inversions.

We observe lower misfit in the phase inversion compared to the joint inversion [Figure 4.5]. The reason for this is only one dispersion curve has to be fitted at each point compared to two for the joint inversion. To achieve reasonable misfit values in the joint inversion we required 500 iterations, as opposed to 50 for the phase inversion. A more complicated parametrisation in the joint inversion means a larger parameter space has to be explored, thus taking longer to converge to the best model. A similar relationship in the relative change in misfit values for each cell is observed in phase and joint inversions [Figure 4.5]. In general the highest values are located in the north-east and the lowest in the central study area. The difference in relative misfit between the two inversions is in the southern area where low misfit is observed in the joint inversion whereas a higher misfit is observed in the phase inversion. Areas of high misfit correlate well with uncertainty in the observed dispersion curve [Figure 3.21a and e]. 

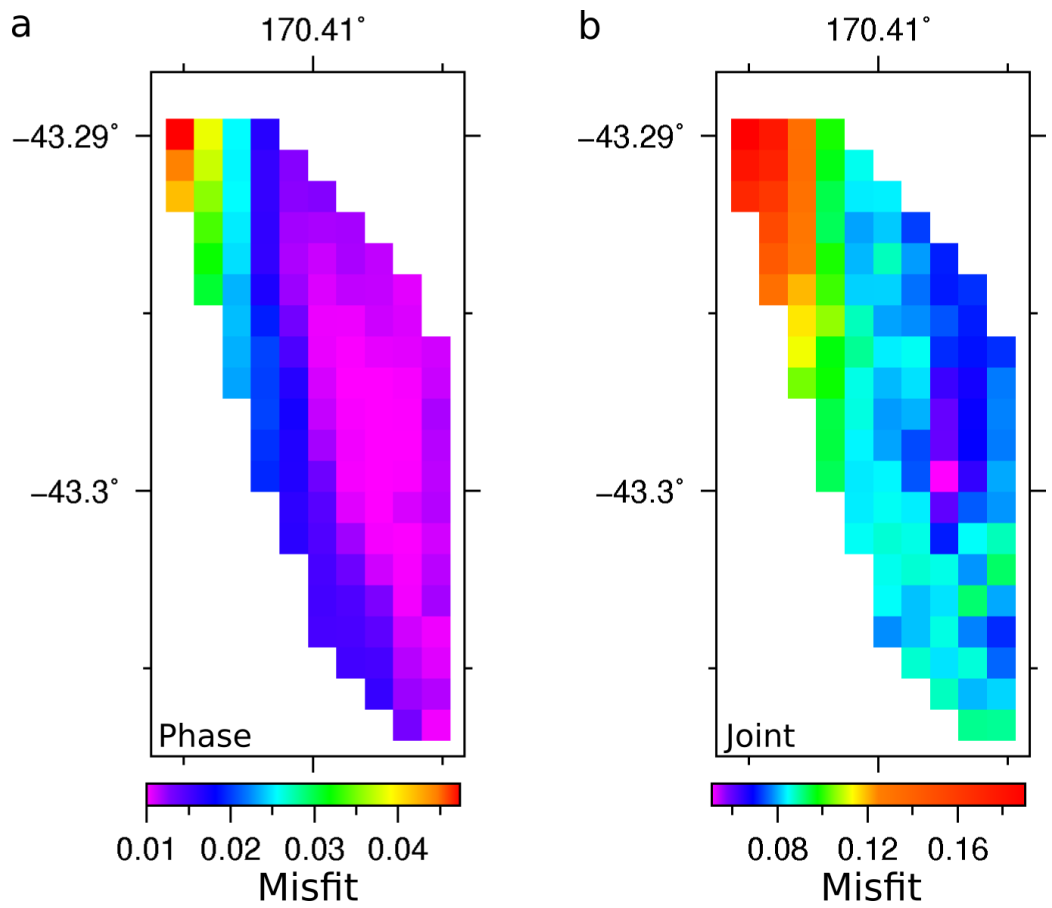

Figure 4.5: Comparison of misfit (decimal percentage of velocity) for the best model a) phase velocity inversion, and b) joint velocity inversion.

The larger uncertainty in the phase velocity dispersion curves than the group velocity curves leads us to adopt the joint inversion as our proposed model for interpretation. By only using phase velocity we expose the inversion to large uncertainty in the 0.5 to $0.6 \mathrm{~s}$ bandwidth [e.g. Figure 3.20a]. Using a joint inversion with group velocities that have lower uncertainty [e.g. Figure 3.21d-f] allows us to have more confidence in the inversion result as it can be better constrained with two dispersion curves. The longer periods of group velocities also allow us to model greater depths than when using phase velocities alone.

Employing the method of Behr et al. (2011) to calculate weighted mean shear-wave profiles we can compute the standard deviation of acceptable models for depth and shear wave error [see Section 2.3.4]. Standard deviation of depth is within $30 \mathrm{~m}$ for the upper $400 \mathrm{~m}$ of the pseudo-3D velocity model [Figure 4.6]. Below this there is an increase to $50 \mathrm{~m}$ in the central part of the study area. Values remain fairly constant with depth along the eastern and western edges of the model [Figure 4.6a]. The values around $50 \mathrm{~m}$ observed in the central part of the study area extend the full extent of the north-south profile [Figure 4.6b]. It is likely that the standard deviation 
of depth along the eastern and western extent of the study area are underestimated when compared to the central area. A higher-velocity anomaly is observed in the central area which means the inversion process may have taken longer to converge on an best-fitting model, leading to a larger variability of acceptable models with the misfit threshold we defined. The anomaly does not appear along the margins of the velocity model so the inversion has probably converged faster on the best fitting models here.

Depth profiles of the standard deviation of shear-wave velocity shows three distinct zones: the upper $300 \mathrm{~m}, 300$ to $800 \mathrm{~m}$ and below $800 \mathrm{~m}$ [Figure 4.7]. The upper $300 \mathrm{~m}$ of the velocity model have a standard deviation of $50 \mathrm{~m} / \mathrm{s}$, although there is a distinctive band of higher values around $100 \mathrm{~m}$ depth [Figure 4.7]. Between 300 and $800 \mathrm{~m}$, values of 100 to $150 \mathrm{~m} / \mathrm{s}$ are observed along the full extent of the south-north profile but are isolated to the central part of the east-west profile. Below $800 \mathrm{~m}$, the standard deviation increases to above $200 \mathrm{~m} / \mathrm{s}$ for most of the model, except along the eastern and western edges.
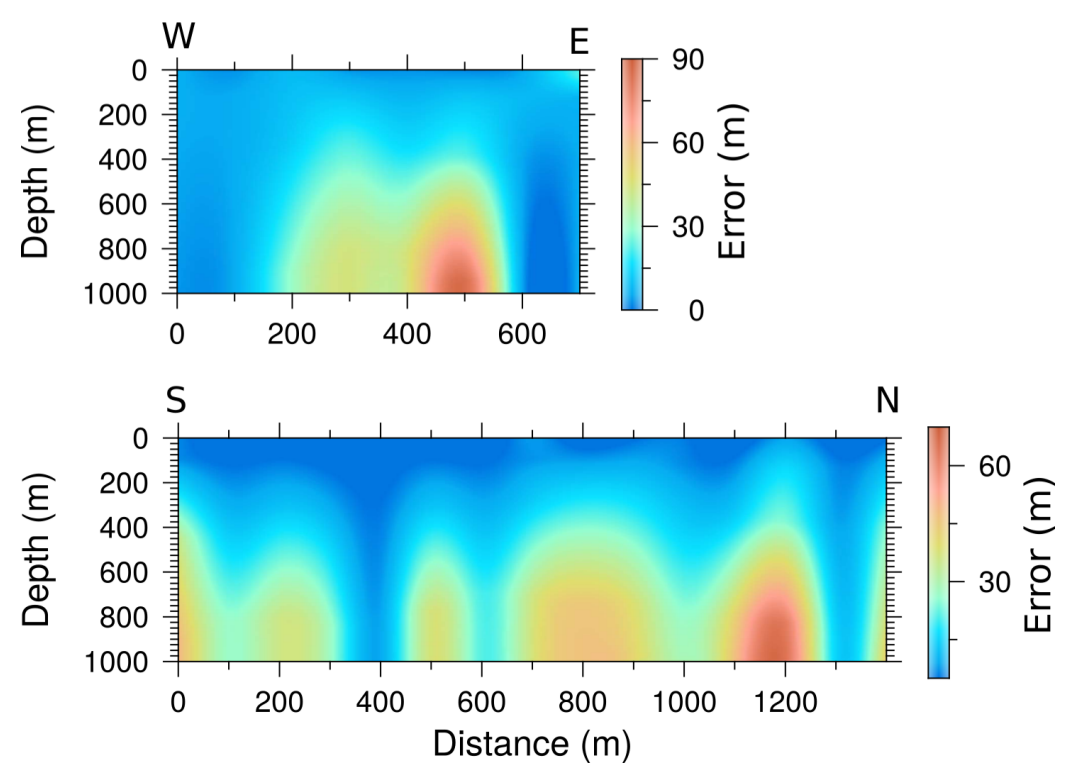

Figure 4.6: Standard deviation of depth from the pseudo-3D shear-wave velocity model. See Figure 4.8 for profile locations. 

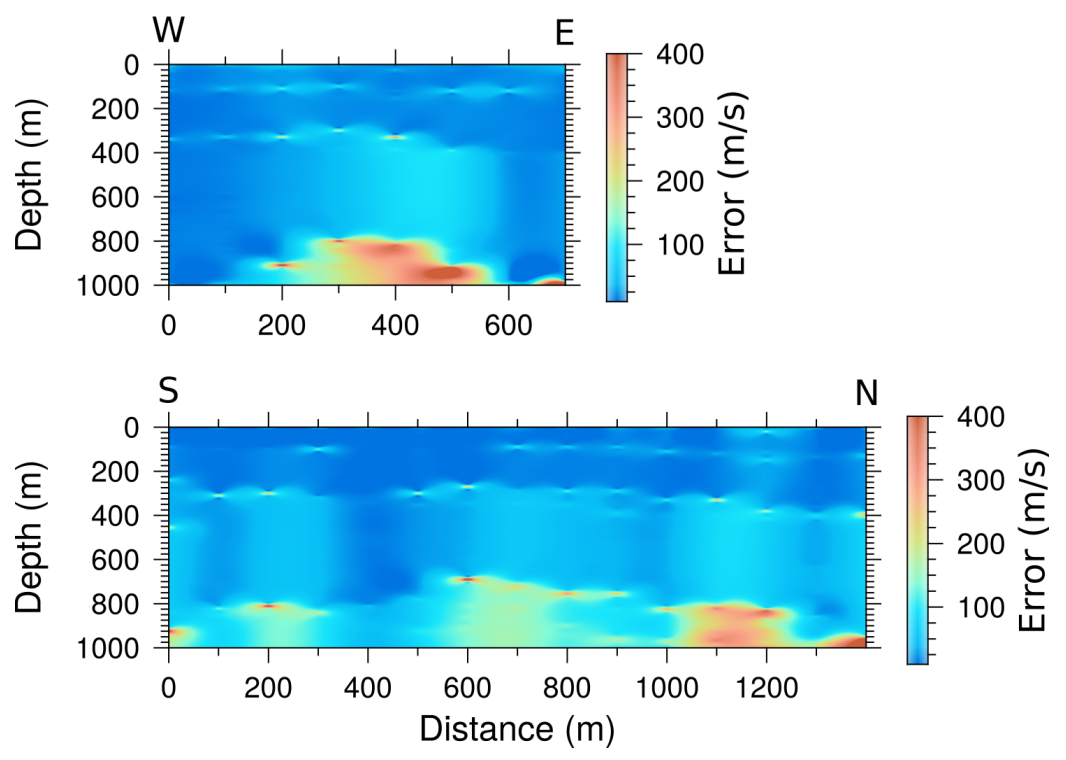

Figure 4.7: Standard deviation of shear-wave velocity from the pseudo-3D shearwave velocity model. See Figure 4.8 for profile locations.

\subsection{Interpretation of Velocity Models}

In this section we interpret Rayleigh wave tomography models of group and phase velocity, and then interpret the pseudo-3D shear wave velocity model constructed from the tomography models.

The steep change in velocity contours from low to high in the north-western section in both phase and group velocity maps is difficult to interpret as it occurs in a poorly sampled area [see Section 4.1.3]. The rapid change in velocity may be a transition in lithology from sedimentary to basement rock, as observed in DFDP2B (Sutherland et al., 2015). As period increases, the observed change in velocity moves to the east which suggests the basement-sediment interface is deepening in this direction [Figure 4.8]. We suggest fundamental Rayleigh waves become sensitive to basement in the north-east at $0.7 \mathrm{~s}$ period for phase velocity and at $1.1 \mathrm{~s}$ period for group velocity [Figure 4.8]. At these periods the velocities at increasing periods appear to stabilise in the $0-250$ meter distance section of the profiles in Figure 4.8. The discrepancy in group velocity between the 1.1 and $1.3 \mathrm{~s}$ period contour and the 1.5 and $1.7 \mathrm{~s}$ period contour is likely an artefact [e.g. Figure 3.12]. 
Lay et al. (2016) observe a low-velocity zone in the upper basement within this area, but we are not confident enough in the tomography of this area (or depth) to suggest a link from the current results. The low-velocity zone in the central and eastern edge of phase and group models is interpreted to have deeper sedimentary cover than the north-eastern sector. The circular nature of the anomaly suggests it could be the thickest part of the overlying sedimentary sequence in the study area.
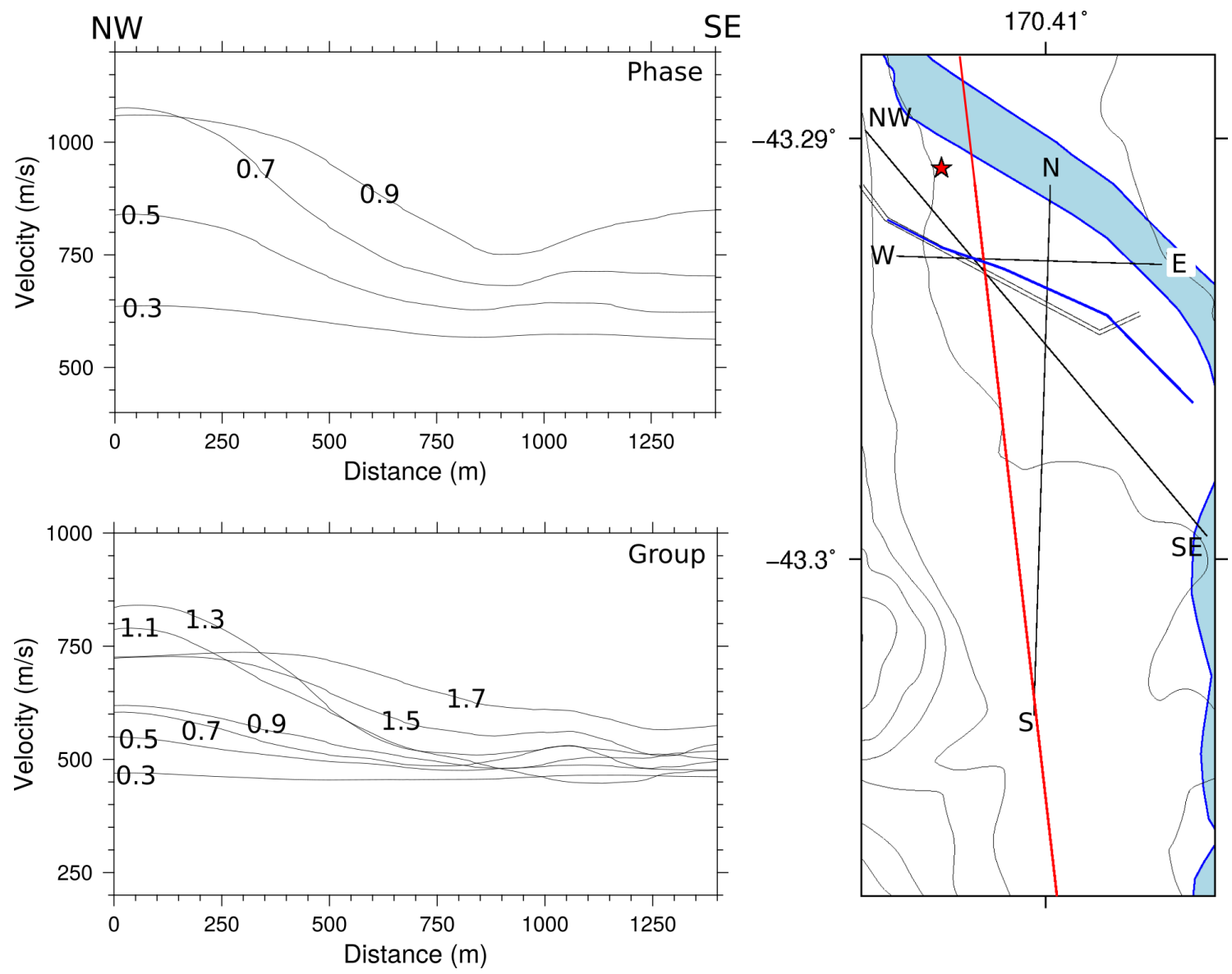

Figure 4.8: Velocity tracks at discrete periods from phase and group velocity maps. The line markings signify the period of each line in the left panel plots. The right panel shows a map of the track profile marked as NW-SE and the E-W and N-S markings show the track of the error profiles in Figure 4.6 and 4.7. The p-wave tomography model transect from (Lay et al., 2016) is marked by the red line and the seismic reflection line 2 transect from Lepine (2016) is marked by the blue line.

From the fence diagram of 2D profiles extracted from the pseudo-3D model we are able to identify structures within the study area [Figure 3.22]. We identify four main layers within the velocity model; three sedimentary layers and a basement layer. The first sedimentary layer was identified in Figure 3.21 as having a depth of 
$100 \mathrm{~m}$ and velocity range of 500 to $700 \mathrm{~m} / \mathrm{s}$. The equivalent layer is identified in the pseudo-3D velocity model as having a upper velocity of $720 \mathrm{~m} / \mathrm{s}$ [Figure 4.12c]. We extract the isosurface of this velocity from the psuedo-3D velocity model and find the layer deepens from $100 \mathrm{~m}$ to nearly $120 \mathrm{~m}$ in the centre of the valley [Figure 4.9]. Sedimentary logging of the DFDP-2B borehole by Sutherland et al. (2015) found an alluvial layer of river gravels and sands deposited from $60 \mathrm{~m}$ depth to the surface. Below this layer lacustrine silty sand sediments are deposited down to the basement contact at $240 \mathrm{~m}$. We interpret our $720 \mathrm{~m} / \mathrm{s}$ depth isocontour as the contact between the silty sand and the gravels.

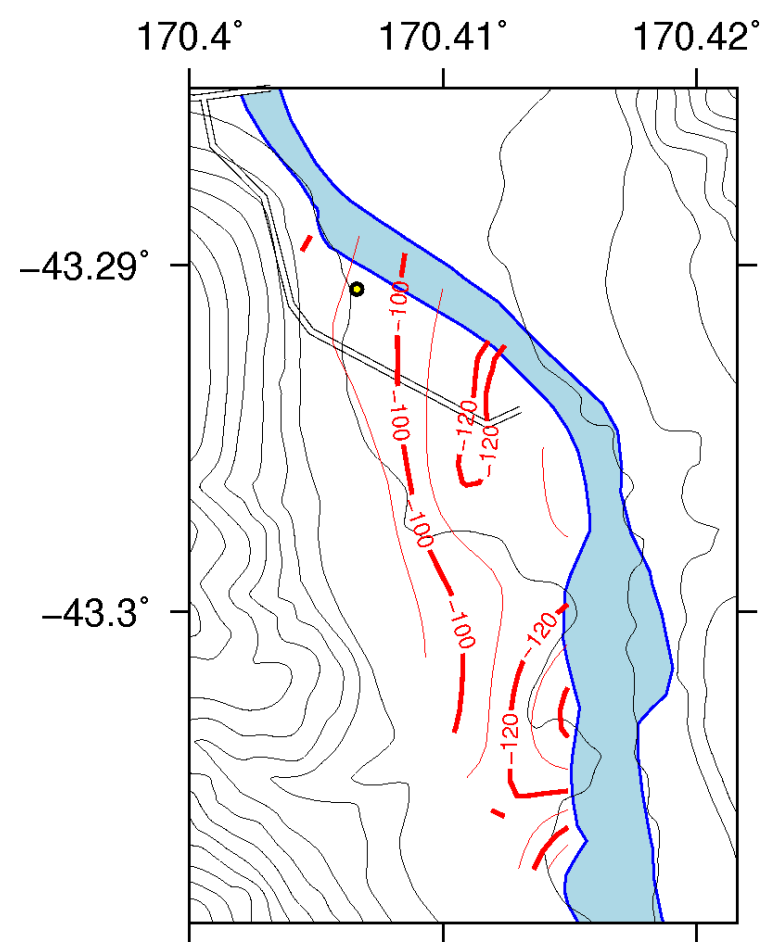

Figure 4.9: Smooth velocity contours of the $720 \mathrm{~m} / \mathrm{s}$ isosurface, extracted from the psuedo-3D velocity model. The red contour lines are the isosurface in meters and the black contours are $50 \mathrm{~m}$ topographic contours. The Whataroa River, road and DFDP-2B (yellow circle) are marked for reference. The isosurface is smoothed using a $200 \mathrm{~m}$ wide filter to remove short wave-length features.

The second sedimentary layer is interpreted to be the lacustrine silty sand sediments identified by Sutherland et al. (2015). The velocity range of this layer is 720 to $1100 \mathrm{~m} / \mathrm{s}$ and its lower depth isocontour is plotted using a velocity of $1100 \mathrm{~m} / \mathrm{s}$ [Figure 4.10a]. The isocontour shows a fairly constant gradient dipping to the west 
across our study area. The shallowest point is to the south of DFDP-2B at $300 \mathrm{~m}$ and the deepest point occurs along the eastern edge at $400 \mathrm{~m}$. We identify a third sedimentary layer that has velocity range of 1100 to $1250 \mathrm{~m} / \mathrm{s}$ and a maximum depth of $700 \mathrm{~m}$. The lateral distribution of the middle sedimentary layer is confined to the central part of the Whataroa Valley. Lepine (2016) observed a similar structure in a seismic reflection line where a sedimentary sequence similar to our third sedimentary layer thins to $25 \mathrm{~m}$ within the western flank of our study area [Figure 4.13a].
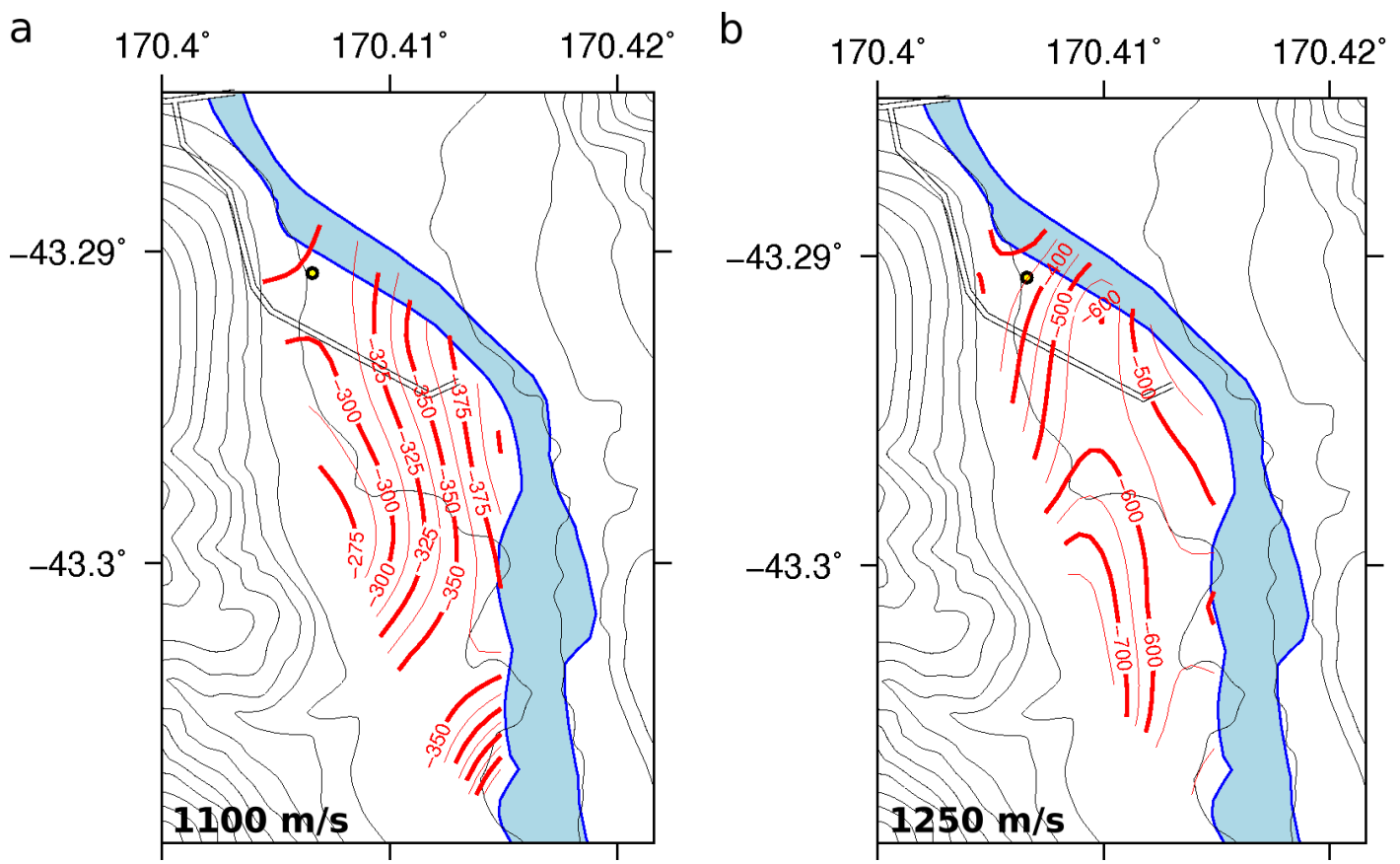

Figure 4.10: Smooth velocity contours of the a) 1100 and b) $1250 \mathrm{~m} / \mathrm{s}$ isosurface, extracted from the pseudo-3D velocity model. The red contour lines are the isosurface in $\mathrm{m}$ and the black contours are $50 \mathrm{~m}$ topographic contours. The Whataroa River, road and DFDP-2B (yellow circle) are marked for reference. The isosurface is smoothed using a $200 \mathrm{~m}$ wide filter to remove short wave-length features.

Basement velocities of $1250-1650 \mathrm{~m} / \mathrm{s}$ are observed down to $1000 \mathrm{~m}$ in most of our study area, except for the high velocity anomaly in the central area which reaches velocities of $2200 \mathrm{~m} / \mathrm{s}$. This anomaly is associated with an error of $\pm 150 \mathrm{~m} / \mathrm{s}$ so is likely an over-estimate. Due to the high error, we choose to interpret the basement as a single layer.

We provide two interpretations of the depth to basement. The first uses the $1100 \mathrm{~m} / \mathrm{s}$ velocity contour which separates the second sedimentary layer from the basement 
layer, we call this interpretation one [Figure 4.10a]. The second uses the $1250 \mathrm{~m} / \mathrm{s}$ contour which includes the third sedimentary layer, we call this interpretation two [Figure 4.10b]. These interpretation models are also presented in a schematic showing the interpreted basement depths [Figure 4.11]. Interpretation one shows a fairly constant gradient dipping to the west across our study area. The shallowest point is to the south of DFDP-2B at $275 \mathrm{~m}$ and the deepest point occurs along the western edge at $400 \mathrm{~m}$. Interpretation two has a far steeper gradient than interpretation one, reaching $700 \mathrm{~m}$ depth along the south-western edge of the study area. The geometry of the surface appears to be bowl-like with steep sides [Figure 4.10b]. Both of our basement depth interpretations suggest a large amount of glacial erosion has taken place. Similar depths have been observed in other glacial valleys where a deep U shaped valley have been carved by the glaciation (e.g. Benn et al., 2014). Similar thickness has been observed in Tasman Glacier, where historical seismic reflection profiles suggest the glacier may have been up to $700 \mathrm{~m}$ thick (Kirkbride and Warren, 1999).

For each interpreted layer we are able to estimate depth and shear wave velocity error based on standard deviations calculated in Figure 4.6 and 4.7. The velocities of the first and second sedimentary layers are estimated to have an uncertainty of $\pm 50 \mathrm{~m} / \mathrm{s}$ and depth uncertainty of $\pm 15 \mathrm{~m}$. The third sedimentary layer has a higher uncertainty of $\pm 75 \mathrm{~m} / \mathrm{s}$ and $\pm 25 \mathrm{~m}$. The basement has large variability in the potential uncertainty as it includes the high velocity anomaly which has a high uncertainty. We chose to provide two uncertainty estimates for the basement, the first for the high velocity anomaly with velocities above $1600 \mathrm{~m} / \mathrm{s}$ and the second the basement with velocity between 1250 and $1600 \mathrm{~m} / \mathrm{s}$. For the high velocity anomaly the uncertainty is $\pm 150 \mathrm{~m} / \mathrm{s}$ and $\pm 30 \mathrm{~m}$. The remainder of the basement has an uncertainty of $\pm 75 \mathrm{~m} / \mathrm{s}$ and $\pm 20 \mathrm{~m}$. 


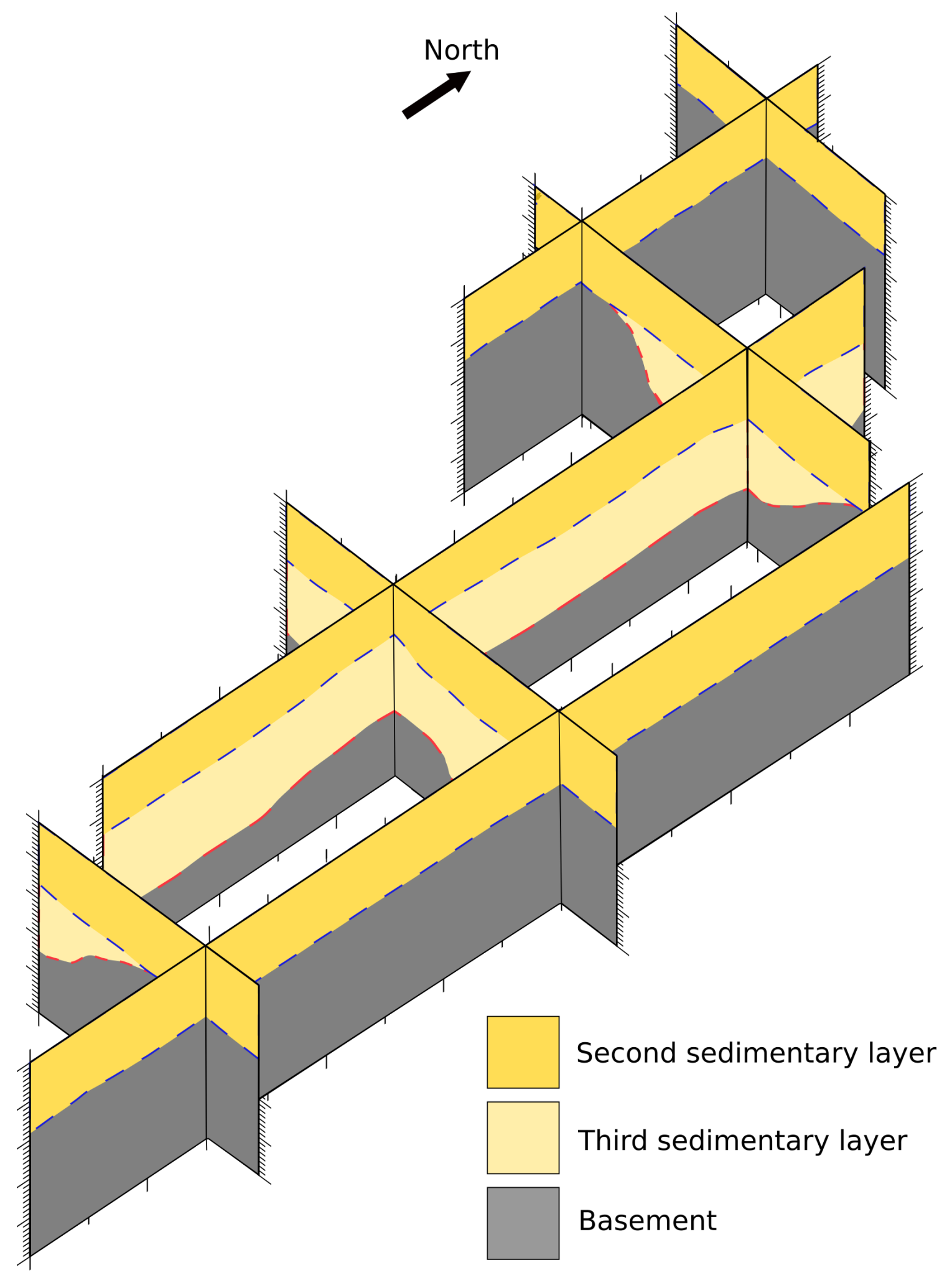

Figure 4.11: Schematic geological interpretation of the pseudo-3D shear-wave velocity model in Figure 3.22. The dashed blue line refers to basement depth interpretation one and the dashed red line refers to basement depth interpretation two. We do not show the first sedimentary layer as it is not visible in Figure 3.22. 


\subsection{Comparison to Previous Studies}

Here we compare our velocity model and interpretations with previous studies of Jenkins (2017), Lay et al. (2016), Lepine (2016), and Sutherland et al. (2015). Overall, we find our shear-wave velocity model is in somewhat of an agreement with past studies.

As the only direct measurement of the subsurface within our study area, we first compare our results to DFDP-2B (Sutherland et al., 2015). The true basement depth at the borehole is $240 \mathrm{~m}$, which is shallower than our velocity interpretations, which estimate it to be between 290 and $310 \mathrm{~m}$ based on the 1100 and $1250 \mathrm{~m} / \mathrm{s}$ velocity contours [Figure 4.12a and b]. The borehole does not help us to determine the more reliable model of our two interpretations as both estimate the depth to be deeper than seen at the borehole. An interesting feature of the velocity profile through the borehole location is to trace the velocity contour at $240 \mathrm{~m}$ (at the borehole) in the velocity model across the profile. In Figure 4.12 this contour is approximately represented by the transition from the darkest red to the next darkest red. Tracing this contour along the profile shows a rapid decrease in depth just west of the borehole. To explain a steep Bouguer anomaly gradient between the borehole and the western hillside, Jenkins (2017) modelled a steeply dipping basement or a reverse fault at this location. As the rapid change in velocity occurs along a different contour we are not confident making this interpretation in our model. The uncertainty of our measurements in the area to the west of DFDP-2B is large so it is likely that we do not have the resolution to make such an observation. 


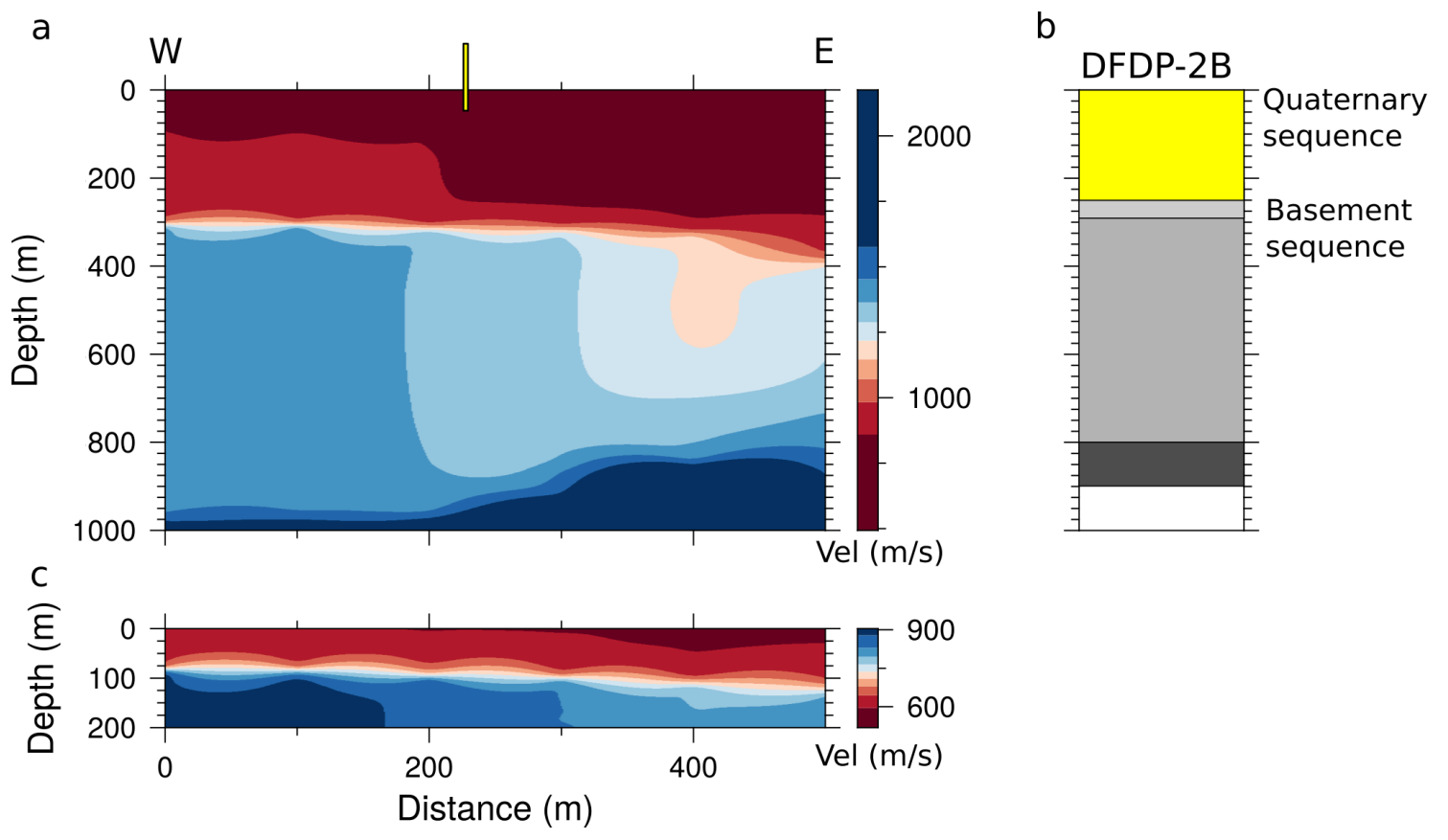

Figure 4.12: Comparison of the shear-wave velocity model to the DFDP-2B core log. a) shear-wave velocity profiles from west to east and transect the DFDP-2B borehole, marked as a yellow line on the profile. b) A simplified DFDP-2B core log with the major units encountered. The transition from yellow to grey marks the sediment to basement transition.

As outlined in section 4.2, our second interpretation using the $1250 \mathrm{~m} / \mathrm{s}$ contour is consistent with observations made by Lepine (2016). His interpretations suggests a two layered sedimentary model above the basement, with a steeply dipping basement down to $550 \mathrm{~m}$. Unlike our model, the second layer is present across the entire profile. We believe the equivalent layer in our model, the third sedimentary layer, is below the $25 \mathrm{~m}$ resolution so it is unlikely that we can resolve it across our entire velocity model. Basement interpretation one is more consistent with the observations made by Jenkins (2017). The $1100 \mathrm{~m} / \mathrm{s}$ contour suggests the basement is thickest in the centre of the valley and along the western edge of our study area. The Bouguer anomaly low calculated by Jenkins (2017) occurs in a similar location, although it extends to the west of our study area.

In comparing our results to previous studies we can evaluate the efficiency of ambient noise tomography in imaging a target geologic structure. For surveys using a similar sized array to this study, we recommend that ambient noise tomography be used 
as a secondary method to model surface and shear wave velocities. For the target frequencies $(>0.5 \mathrm{~Hz}$ for this arrays aperture), there can be no guarantee that there will be a reliable noise source and as such deploying an array with the aim of using ambient noise tomography as primary means of surveying should be considered high risk. Through our results we have shown that deploying a continuously recording array when performing a reflection seismology experiment should be considered as ambient noise tomography may be able to provide a reliable shear wave velocity model. 
a

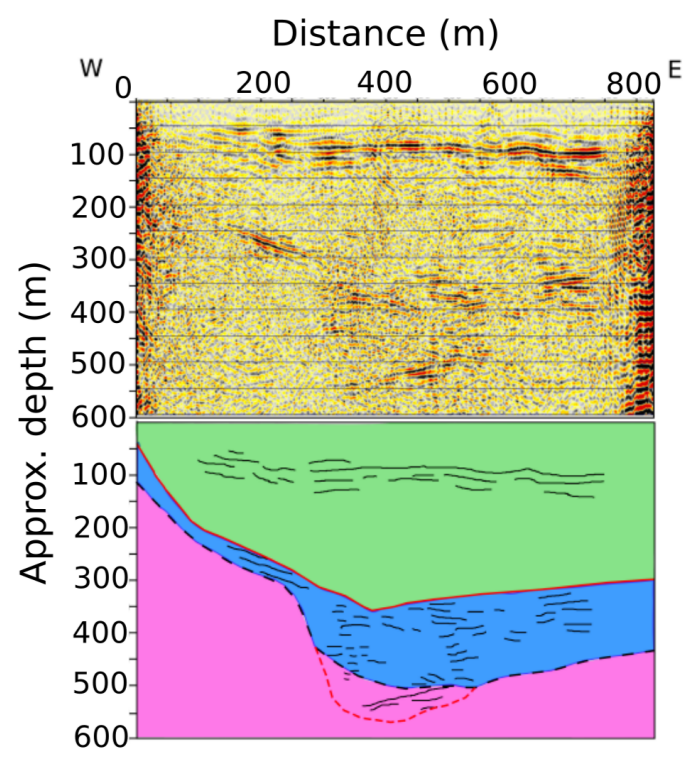

b

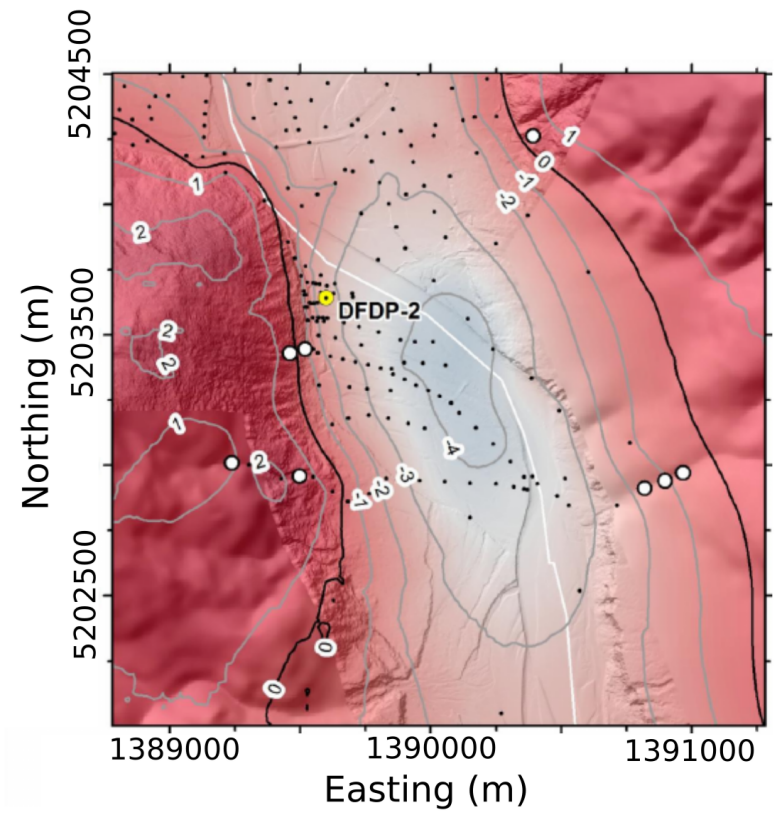

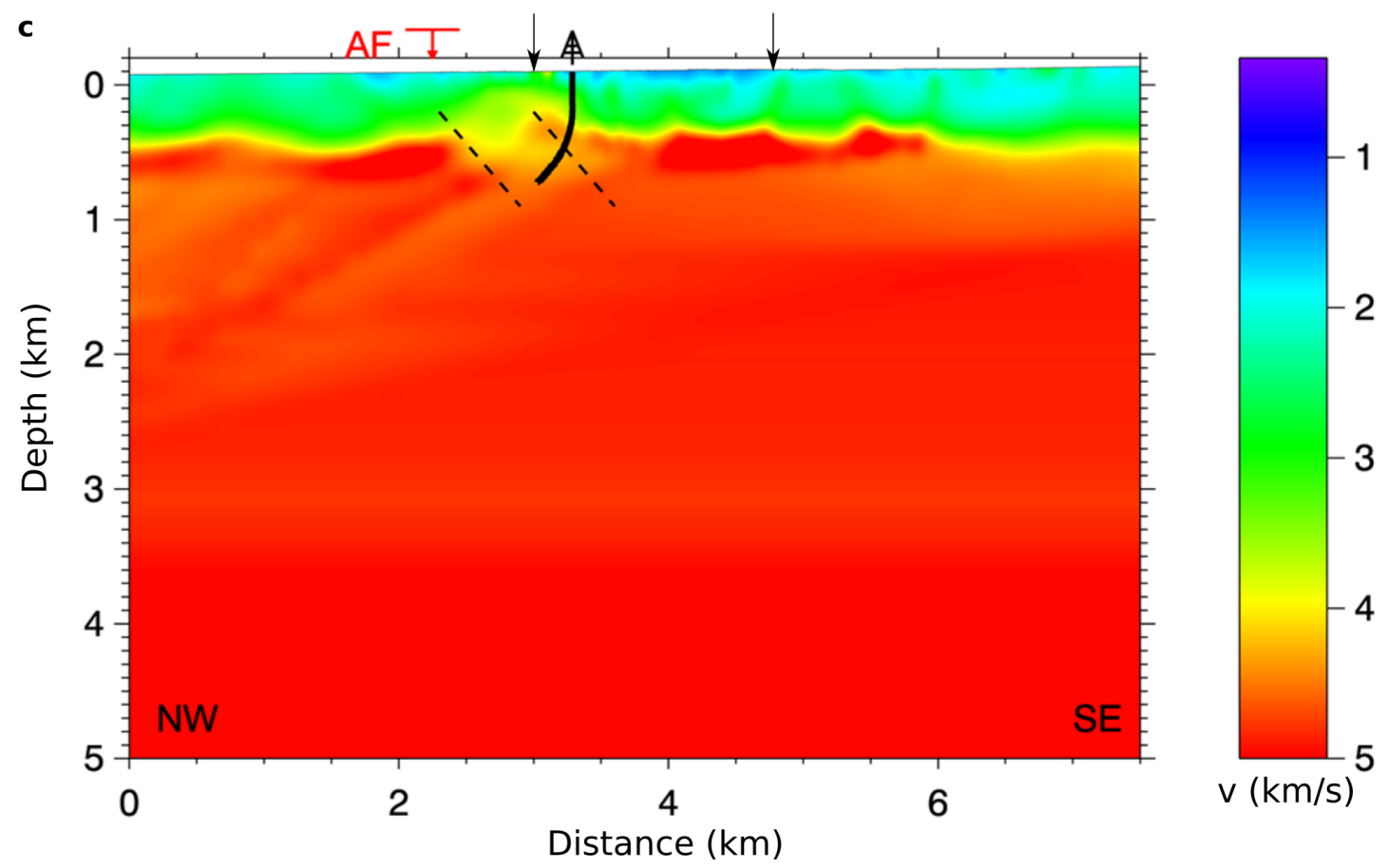

Figure 4.13: Figures from previous studies by Lepine (2016)(a), Jenkins (2017)(b) and Lay et al. (2016)(c). Sub-figure (a) is a seismic reflection and interpretation of line 2 from Lepine (2016), showing the basement (pink), overlain by fluvial (green) and marine (blue) sediments. The profile location is marked on Figure 4.8. Subfigure (b) is a residual Bouguer gravity anomaly of the Whataroa Valley from Jenkins (2017). The residual gravity values are marked on the map. Sub-figure (c) is the final compressional-wave velocity model from Lay et al. (2016). The location of the estimated Alpine Fault surface trace is marked by a AF, the dashed lines mark the Alpine Fault damage zone, and the black line marks the DFDP-2B well trajectory. The black arrows mark the approximate location of our study area. The profile location is marked on Figure 4.8 


\section{Conclusions}

Tomographic analysis of continuous recordings of ambient seismic noise obtained during the 2016 Whataroa Active Source Seismic Experiment (WASSE) allows us to draw the following conclusions:

- It is possible to construct a robust shear-wave velocity model using short (four days) recordings of ambient noise;

- We identify four layers in the shear-wave velocity model. Three corresponding to sedimentary layers and the deepest to a basement layer;

- The basement depth is interpreted from the shear-wave velocity models to be between 400 and $600 \mathrm{~m}$ deep in the centre of the Whataroa Valley.

The use of seismic ambient noise recordings to construct velocity models is typically associated with continental and regional studies. We show it is possible to use several days of continuous ambient noise data, recorded on $4.5 \mathrm{~Hz}$ active-source geophones, to perform similar analysis at a much smaller scale. An important component of the processing flow used to construct the cross-correlation functions was the use of the phase-weighted stack. Higher signal-to-noise ratio are achieved through use of this method compared to the common method of linear stacking. During this study, an alternate cross-correlation method known as phase cross-correlation has been tested. Despite not using phase cross-correlation extensively in this study, we show through comparison to regular cross-correlation that it shows promise, particularly in removing a peak around zero lag-time. Our testing of different methods has highlighted the importance of testing processing techniques for use with short-duration high frequency ambient noise datasets. 
The preferred shear-wave velocity model contains three layers in the Quaternary sedimentary deposits overlying the basement. The first is constrained to the upper $100 \mathrm{~m}$, with a gradual deepening towards the centre of the Whataroa Valley. It has an average velocity of $600 \mathrm{~m} / \mathrm{s}$ and is inferred to correspond to alluvial deposits identified in the DFDP-2B borehole. A second sedimentary layer has a depth profile of $300 \mathrm{~m}$ near the DFDP-2B borehole, deepening to $400 \mathrm{~m}$ in the centre of the valley with an average velocity of $750 \mathrm{~m} / \mathrm{s}$. It is inferred to correspond to fluviolacustrine deposits identified in the DFDP-2B borehole. The third sedimentary layer is laterally isolated to the central part of the valley and has a velocity $1250 \mathrm{~m} / \mathrm{s}$, reaching a maximum depth of $600 \mathrm{~m}$. The basement shows a range of velocities increasing with depth. In the central valley, the basement velocity exceeds $1600 \mathrm{~m} / \mathrm{s}$ while along the valley edge it is between 1300 and $1600 \mathrm{~m} / \mathrm{s}$.

We have constructed interpreted basement isosurfaces based on the lower depth isosurface of the second and third sedimentary layers. We give a maximum depth to basement within the study area a depth range of 400 to $600 \mathrm{~m}$, based on the two isosurfaces. Near the DFDP-2B borehole and western edge of our study area, we have a low degree of confidence in our basement depth estimate of $300 \mathrm{~m}$. We link this to straight ray tomography method and suggest bent-ray tomography may resolve the surface-wave velocity of the area better.

\section{$5.1 \quad$ Future Work}

The dataset used in this thesis could be used for further analysis. We suggest:

- Calculating the orientations of the horizontal components to allow all nine components of the Green's function to be estimated. This would allow Love waves to be included in the analysis, providing further constraints on the shear-wave velocity inversion. It would also impose a stronger constraint on the excitation of higher modes. 
- The cross-correlation functions provide some indication of attenuation across the Alpine Fault trace. To investigate this further, cross-correlation functions could be calculated with distant seismometers outside of the array. This would allow the wave-front to be tracked across the array (including the Alpine Fault) using eikonal tomography.

- To improve cross-correlation functions, Julian day 16 and 20 should be included by shifting the start time of each day by four hours. This would allow four full-days of data to be processed using the MSNoise package at its current capacity. The other option would be to edit MSNoise codes and allow for sub-daily cross-correlation functions to be computed. 


\section{Bibliography}

Aki, K. (1957). Space and time spectra of stationary stochastic waves, with special reference to microtremors. Bulletin of the Earthquake Research Institute, $35: 415-457$.

Altamimi, Z., Métivier, L., and Collilieux, X. (2012). ITRF2008 plate motion model. Journal of Geophysical Research: Solid Earth, 117(B7).

Barmin, M. P., Ritzwoller, M. H., and Levshin, A. L. (2001). A Fast and Reliable Method for Surface Wave Tomography. pure and applied geophysics, 158(8):1351-1375.

Behr, Y. (2011). Imaging New Zealand's Crustal Structure Using Ambient Seismic Noise Recordings from Permanent and Temporary Instruments. PhD thesis.

Behr, Y., Townend, J., Bannister, S., and Savage, M. (2010). Shear velocity structure of the Northland Peninsula, New Zealand, inferred from ambient noise correlations. Journal of Geophysical Research: Solid Earth, 115(B5).

Behr, Y., Townend, J., Bannister, S., and Savage, M. (2011). Crustal shear wave tomography of the Taupo Volcanic Zone, New Zealand, via ambient noise correlation between multiple three-component networks. Geochemistry, Geophysics, Geosystems, 12(3).

Benn, D., Evans, D. J., et al. (2014). Glaciers and glaciation. Routledge.

Bensen, G., Ritzwoller, M., Barmin, M., Levshin, A., Lin, F., Moschetti, M., Shapiro, N., and Yang, Y. (2007). Processing seismic ambient noise data to obtain reliable broad-band surface wave dispersion measurements. Geophysical Journal International, 169(3):1239-1260.

Berryman, K., Beanland, S., Cooper, A., Cutten, H., Norris, R., and Wood, P. (1992). The Alpine Fault, New Zealand: variation in Quaternary structural style and geomorphic expression. In Annales tectonicae, volume 6, pages 126163.

Berryman, K., Cooper, A., Norris, R., Villamor, P., Sutherland, R., Wright, T., Schermer, E., Langridge, R., and Biasi, G. (2012). Late Holocene rupture 
history of the Alpine fault in south Westland, New Zealand. Bulletin of the Seismological Society of America, 102(2):620-638.

Beyreuther, M., Barsch, R., Krischer, L., Megies, T., Behr, Y., and Wassermann, J. (2010). ObsPy: A Python toolbox for seismology. Seismological Research Letters, 81(3):530-533.

Biasi, G. P., Langridge, R. M., Berryman, K. R., Clark, K. J., and Cochran, U. A. (2015). Maximum-Likelihood Recurrence Parameters and Conditional Probability of a Ground-Rupturing Earthquake on the Southern Alpine Fault, South Island, New Zealand. Bulletin of the Seismological Society of America, 105(1):94-106.

Boaga, J., Cassiani, G., Strobbia, C. L., and Vignoli, G. (2013). Mode misidentification in Rayleigh waves: Ellipticity as a cause and a cure. Geophysics, 78(4):EN17-EN28.

Bonnefoy Claudet, S., Cotton, F., and Bard, P.-Y. (2006). The nature of noise wavefield and its applications for site effects studies: A literature review. EarthScience Reviews, 79(3):205-227.

Brenguier, F., Shapiro, N. M., Campillo, M., Nercessian, A., and Ferrazzini, V. (2007). 3-D surface wave tomography of the Piton de la Fournaise volcano using seismic noise correlations. Geophysical research letters, 34(2).

Brikke, N. (2007). Seismic velocity structure of the shallow part of the Alpine fault and gravity study of the basement features in the Whataroa River flood plain, Central Westland, South Island [Post Graduate Diploma]. Technical report.

Burtin, A., Vergne, J., Rivera, L., and Dubernet, P. (2010). Location of riverinduced seismic signal from noise correlation functions. Geophysical Journal International, 182(3):1161-1173.

Campillo, M. and Paul, A. (2003). Long-range correlations in the diffuse seismic coda. Science, 299(5606):547-549.

Chávez García, F. J. and Rodríguez, M. (2007). The correlation of microtremors: empirical limits and relations between results in frequency and time domains. Geophysical Journal International, 171(2):657-664.

Cooper, A. (1980). Retrograde alteration of chromian kyanite in metachert and amphibolite whiteschist from the Southern Alps, New Zealand, with implications for uplift on the Alpine Fault. Contributions to mineralogy and petrology, $75(2): 153-164$. 
Cox, S. C. and Sutherland, R. (2007). Regional Geological Framework of South Island, New Zealand, and its Significance for Understanding the Active Plate Boundary, pages 19-46. American Geophysical Union.

Davey, F. (2010). Crustal seismic reflection profile across the Alpine Fault and coastal plain at Whataroa, South Island. New Zealand Journal of Geology and Geophysics, 53(4):359-368.

Davey, F., Henyey, T., Holbrook, W., Okaya, D., Stern, T., Melhuish, A., Henrys, S., Anderson, H., Eberhart Phillips, D., McEvilly, T., et al. (1998). Preliminary results from a geophysical study across a modern, continent-continent collisional plate boundarythe Southern Alps, New Zealand. Tectonophysics, 288(1):221235.

Davy, R., Stern, T., and Townend, J. (2013). Gravity analysis of glaciotectonic processes, central Alpine Fault, South Island, New Zealand. New Zealand Journal of Geology and Geophysics, 56(2):100-108.

De Ridder, S. and Biondi, B. (2013). Daily reservoir-scale subsurface monitoring using ambient seismic noise. Geophysical Research Letters, 40(12):2969-2974.

DeMets, C., Gordon, R. G., Argus, D. F., and Stein, S. (1994). Effect of recent revisions to the geomagnetic reversal time scale on estimates of current plate motions. Geophysical research letters, 21(20):2191-2194.

Dunkin, J. W. (1965). Computation of modal solutions in layered, elastic media at high frequencies. Bulletin of the Seismological Society of America, 55(2):335358.

Fichtner, A. (2010). Full seismic waveform modelling and inversion. Springer Science \& Business Media.

Gardner, G., Gardner, L., and Gregory, A. (1974). Formation velocity and densityThe diagnostic basics for stratigraphic traps. Geophysics, 39(6):770-780.

Godfrey, H. J., Fry, B., and Savage, M. K. (2017). Shear-wave velocity structure of the Tongariro Volcanic Centre, New Zealand: Fast Rayleigh and slow Love waves indicate strong shallow anisotropy. Journal of Volcanology and Geothermal Research.

Hannemann, K., Papazachos, C., Ohrnberger, M., Savvaidis, A., Anthymidis, M., and Lontsi, A. M. (2014). Three-dimensional shallow structure from highfrequency ambient noise tomography: New results for the Mygdonia basinEuroseistest area, northern Greece. Journal of Geophysical Research: Solid Earth, 119(6):4979-4999. 
Henderson, R. and Thompson, S. (1999). Extreme rainfalls in the Southern Alps of New Zealand. Journal of Hydrology (NZ), 38(2):309-330.

Herman, F. and Braun, J. (2006). Fluvial response to horizontal shortening and glaciations: A study in the Southern Alps of New Zealand. Journal of Geophysical Research: Earth Surface, 111(F1).

Ishii, M., Shearer, P. M., Houston, H., and Vidale, J. E. (2005). Extent, duration and speed of the 2004 Sumatra-Andaman earthquake imaged by the Hi-Net array. Nature, 435(7044):933-936.

Jenkins, S. (2017). A gravity analysis of the Alpine Fault and the DFDP-2 drill site, Whataroa valley, South Westland, South Island, New Zealand. Master's thesis.

Kirkbride, M. P. and Warren, C. R. (1999). Tasman Glacier, New Zealand: 20thcentury thinning and predicted calving retreat. Global and Planetary Change, $22(1): 11-28$.

Langridge, R., Ries, W., Litchfield, N., Villamor, P., Van Dissen, R., Barrell, D., Rattenbury, M., Heron, D., Haubrock, S., Townsend, D., et al. (2016). The New Zealand active faults database. New Zealand Journal of Geology and Geophysics, 59(1):86-96.

Larose, E., Derode, A., Campillo, M., and Fink, M. (2004). Imaging from onebit correlations of wideband diffuse wave fields. Journal of Applied Physics, 95(12):8393-8399.

Lay, V., Buske, S., Lukcs, A., Gorman, A. R., Bannister, S., and Schmitt, D. R. (2016). Advanced seismic imaging techniques characterize the Alpine Fault at Whataroa (New Zealand). Journal of Geophysical Research: Solid Earth, 121(12):8792-8812.

Lecocq, T., Caudron, C., and Brenguier, F. (2014). MSNoise, a python package for monitoring seismic velocity changes using ambient seismic noise. Seismological Research Letters, 85(3):715-726.

Lepine, P. (2016). Shallow Seismic Survey of the Whataroa Glacial Valley in the vicinity of the Alpine Fault, Westland. Master's thesis.

Levshin, A., Pisarenko, V., and Pogrebinsky, G. (1972). Frequency-time analysis of oscillations, volume 28.

Levshin, A., Ratnikova, L., and Berger, J. (1992). Peculiarities of surface-wave propagation across central Eurasia. Bulletin of the Seismological Society of America, 82(6):2464-2493. 
Lin, F.-C., Li, D., Clayton, R. W., and Hollis, D. (2013). High-resolution 3D shallow crustal structure in Long Beach, California: Application of ambient noise tomography on a dense seismic array. Geophysics, 78(4):Q45-Q56.

Lin, F.-C., Moschetti, M. P., and Ritzwoller, M. H. (2008). Surface wave tomography of the western United States from ambient seismic noise: Rayleigh and Love wave phase velocity maps. Geophysical Journal International, 173(1):281-298.

Lin, F.-C., Ritzwoller, M. H., and Shapiro, N. M. (2006). Is ambient noise tomography across ocean basins possible? Geophysical research letters, 33(14).

Lin, F.-C., Ritzwoller, M. H., and Snieder, R. (2009). Eikonal tomography: surface wave tomography by phase front tracking across a regional broad-band seismic array. Geophysical Journal International, 177(3):1091-1110.

Lobkis, O. I. and Weaver, R. L. (2001). On the emergence of the Greens function in the correlations of a diffuse field. The Journal of the Acoustical Society of America, 110(6):3011-3017.

Molnar, P., Anderson, H. J., Audoine, E., Eberhart Phillips, D., Gledhill, K. R., Klosko, E. R., McEvilly, T. V., Okaya, D., Savage, M. K., Stern, T., et al. (1999). Continuous deformation versus faulting through the continental lithosphere of New Zealand. Science, 286(5439):516-519.

Mortimer, N. (2004). New Zealand's geological foundations. Gondwana Research, $7(1): 261-272$.

Nathan, S., Anderson, H. J., Cook, R. A., Herzer, R., Hoskins, R., Raine, J., and Smale, D. (1986). Cretaceous and Cenozoic sedimentary basins of the West Coast region, South Island, New Zealand. Science Information Pub. Centre, DSIR, for the New Zealand Geological Survey.

Norris, R. J. and Cooper, A. F. (1995). Origin of small-scale segmentation and transpressional thrusting along the Alpine fault, New Zealand. Geological Society of America Bulletin, 107(2):231-240.

Norris, R. J. and Cooper, A. F. (2001). Late Quaternary slip rates and slip partitioning on the Alpine Fault, New Zealand. Journal of Structural Geology, 23(2):507-520.

Norris, R. J. and Cooper, A. F. (2007). The Alpine Fault, New Zealand: Surface Geology and Field Relationships, pages 157-175. American Geophysical Union. 
Rawlinson, N., Fichtner, A., Sambridge, M., and Young, M. K. (2014). Seismic Tomography and the Assessment of Uncertainty. Advances in Geophysics, 55:176.

Rawlinson, N. and Sambridge, M. (2003). Seismic traveltime tomography of the crust and lithosphere. Advances in Geophysics, 46:81-199.

Rhie, J. and Romanowicz, B. (2004). Excitation of Earth's continuous free oscillations by atmosphere-ocean-seafloor coupling. Nature, 431(7008):552-556.

Roux, P. (2009). Passive seismic imaging with directive ambient noise: application to surface waves and the San Andreas Fault in Parkfield, CA. Geophysical Journal International, 179(1):367-373.

Sabra, K. G., Gerstoft, P., Roux, P., Kuperman, W., and Fehler, M. C. (2005). Extracting time-domain Green's function estimates from ambient seismic noise. Geophysical Research Letters, 32(3).

Sambridge, M. (1999a). Geophysical inversion with a neighbourhood algorithmI. Searching a parameter space. Geophysical Journal International, 138(2):479494.

Sambridge, M. (1999b). Geophysical inversion with a neighbourhood algorithmII. Appraising the ensemble. Geophysical Journal International, 138(3):727-746.

Schimmel, M. (1999). Phase cross-correlations: Design, comparisons, and applications. Bulletin of the Seismological Society of America, 89(5):1366-1378.

Schimmel, M. and Paulssen, H. (1997). Noise reduction and detection of weak, coherent signals through phase-weighted stacks. Geophysical Journal International, 130(2):497-505.

Schimmel, M., Stutzmann, E., and Gallart, J. (2011). Using instantaneous phase coherence for signal extraction from ambient noise data at a local to a global scale. Geophysical Journal International, 184(1):494-506.

Shapiro, N. M. and Campillo, M. (2004). Emergence of broadband Rayleigh waves from correlations of the ambient seismic noise. Geophysical Research Letters, $31(7)$.

Shapiro, N. M., Campillo, M., Stehly, L., and Ritzwoller, M. H. (2005). Highresolution surface-wave tomography from ambient seismic noise. Science, 307(5715):1615-1618. 
Sibson, R., White, S., and Atkinson, B. (1979). Fault rock distribution and structure within the Alpine Fault Zone: a preliminary account. The Origin of the Southern Alps, 18:55-65.

Snieder, R. (2004). Extracting the Greens function from the correlation of coda waves: A derivation based on stationary phase. Physical Review E, 69(4):046610.

Snieder, R. and Larose, E. (2013). Extracting Earth's elastic wave response from noise measurements. Annual Review of Earth and Planetary Sciences, 41:183206.

Snieder, R. and Wapenaar, K. (2010). Imaging with ambient noise. Physics Today, 63(9):44-49.

Stehly, L., Fry, B., Campillo, M., Shapiro, N., Guilbert, J., Boschi, L., and Giardini, D. (2009). Tomography of the Alpine region from observations of seismic ambient noise. Geophysical Journal International, 178(1):338-350.

Stein, S. and Wysession, M. (2009). An introduction to seismology, earthquakes, and earth structure. John Wiley \& Sons.

Stern, T., Okaya, D., Kleffmann, S., Scherwath, M., Henrys, S., and Davey, F. (2007). Geophysical Exploration and Dynamics of the Alpine Fault Zone, pages 207-233. American Geophysical Union.

Sutherland, R., Berryman, K., and Norris, R. (2006). Quaternary slip rate and geomorphology of the Alpine fault: Implications for kinematics and seismic hazard in South-west New Zealand. Geological Society of America Bulletin, 118(3-4):464-474.

Sutherland, R., Davey, F., and Beavan, J. (2000). Plate boundary deformation in South Island, New Zealand, is related to inherited lithospheric structure. Earth and Planetary Science Letters, 177(3):141-151.

Sutherland, R., Eberhart Phillips, D., Harris, R. A., Stern, T., Beavan, J., Ellis, S., Henrys, S., Cox, S., Norris, R. J., Berryman, K. R., Townend, J., Bannister, S., Pettinga, J., Leitner, B., Wallace, L., Little, T. A., Cooper, A. F., Yetton, M., and Stirling, M. (2007). Do Great Earthquakes Occur on the Alpine Fault in Central South Island, New Zealand?, pages 235-251. American Geophysical Union.

Sutherland, R., Townend, J., Toy, V., Allen, M., Baratin, L., Barth, N., Beacroft, L., Benson, A., Boese, C., Boles, A., Boulton, C., Capova, L., Carpenter, B., 
Celerier, B., Chamberlain, C., Conze, R., Cooper, A., Coussens, J., Coutts, A., Cox, S., Craw, L., Doan, M., Eccles, J., Faulkner, D., Grieve, J., Grochowski, J., Gulley, A., Henry, G., Howarth, J., Jacobs, K., Jeppson, T., Kato, N., Keys, S., Kirilova, M., Kometani, Y., Kovacs, A., Langridge, R., Lin, W., Little, T., Mallyon, D., Mariani, B., Marx, R., Massiot, C., Mathewson, L., Melosh, B., Menzies, C., Moore, J., Morales, L., Morgan, C., Mori, H., Niemeijera, A., Nishikawa, O., Nitsch, O., Paris Cavailhès, J., Pooley, B., Prior, D., Pyne, A., Sauer, K., Savage, M., Schleicher, A., Schmitt, D., Shigematsu, N., Taylor Offord, S., Tobin, H., Upton, P., Valdez, R., Weaver, K., Wiersberg, T., J., W., Yeo, S., and Zimmer, M. (2015). Deep Fault Drilling Project (DFDP), Alpine Fault Boreholes DFDP-2A and DFDP-2B Technical Completion Report. Technical Report 50, Institute of Geological and Nuclear Sciences Limited.

Sutherland, R., Townend, J., Toy, V., Upton, P., Coussens, J., and et.al (2017). Extreme hydrothermal conditions at an active plate-bounding fault. Nature, page In press.

Tape, C., Liu, Q., Maggi, A., and Tromp, J. (2010). Seismic tomography of the southern California crust based on spectral-element and adjoint methods. Geophysical Journal International, 180(1):433-462.

Thurber, C. H., Zeng, X., Thomas, A. M., and Audet, P. (2014). Phase-weighted stacking applied to low-frequency earthquakes. Bulletin of the Seismological Society of America.

Townend, J., Sutherland, R., and Toy, V. (2009). Deep Fault Drilling ProjectAlpine Fault, New Zealand. Scientific drilling, 8:75-82.

Toy, V. G., Boulton, C. J., Sutherland, R., Townend, J., Norris, R. J., Little, T. A., Prior, D. J., Mariani, E., Faulkner, D., Menzies, C. D., et al. (2015). Fault rock lithologies and architecture of the central Alpine fault, New Zealand, revealed by DFDP-1 drilling. Lithosphere, pages L395-1.

Uieda, L., Oliveira Jr, V. C., and Barbosa, V. C. (2013). Modeling the Earth with fatiando a terra.

Van Avendonk, H. J., Holbrook, W. S., Okaya, D., Austin, J. K., Davey, F., and Stern, T. (2004). Continental crust under compression: A seismic refraction study of South Island Geophysical Transect I, South Island, New Zealand. Journal of Geophysical Research: Solid Earth, 109(B6).

Wapenaar, K. (2006). Green's function retrieval by cross-correlation in case of onesided illumination. Geophysical Research Letters, 33(19). 
Wathelet, M. (2008). An improved neighborhood algorithm: parameter conditions and dynamic scaling. Geophysical Research Letters, 35(9).

Wathelet, M., Jongmans, D., and Ohrnberger, M. (2004). Surface-wave inversion using a direct search algorithm and its application to ambient vibration measurements. Near surface geophysics, 2(4):211-221.

Weaver, R. L. and Lobkis, O. I. (2004). Diffuse fields in open systems and the emergence of the Greens function. The Journal of the Acoustical Society of America, 116(5):2731-2734.

Wellman, H. (1953). Data for the study of Recent and late Pleistocene faulting in the South Island of New Zealand. New Zealand journal of science and technology, 34:270-288.

Wellman, H., Grindley, G., and Munden, F. (1952). The Alpine schists and the upper Triassic of Harpers Pass (Sheet S52), South Island, New Zealand. Trans. Roy. Soc. New Zealand, 80(2):213-227.

Wellman, H. and Willett, R. W. (1942). The geology of the west coast from Abut Head to Milford Sound.

Yao, H. and Van Der Hilst, R. D. (2009). Analysis of ambient noise energy distribution and phase velocity bias in ambient noise tomography, with application to SE Tibet. Geophysical Journal International, 179(2):1113-1132.

Yao, H., van Der Hilst, R. D., and Maarten, V. (2006). Surface-wave array tomography in SE Tibet from ambient seismic noise and two-station analysisI. Phase velocity maps. Geophysical Journal International, 166(2):732-744.

Zheng, Y., Shen, W., Zhou, L., Yang, Y., Xie, Z., and Ritzwoller, M. H. (2011). Crust and uppermost mantle beneath the North China Craton, northeastern China, and the Sea of Japan from ambient noise tomography. Journal of Geophysical Research: Solid Earth, 116(B12).

Zhou, Y., Nolet, G., Dahlen, F., and Laske, G. (2006). Global upper-mantle structure from finite-frequency surface-wave tomography. Journal of Geophysical Research: Solid Earth, 111(B4). 
